http://kitaibelia.unideb.hu/

ISSN 2064-4507 (Online) • ISSN 1219-9672 (Print)

(C) 2016, Department of Botany, University of Debrecen, Hungary

22 (1): 147-178.; 2017

DOI: $10.17542 /$ kit.22.147

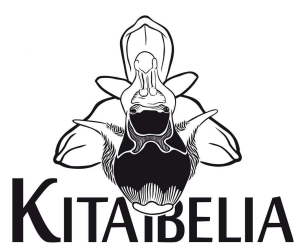

\title{
A Szentendrei-sziget zárt ártéri tölgyesei (Melico nutantis-Quercetum roboris KEVEY 2008)
}

\author{
KEVEY Balázs ${ }^{1}$ \& BőHM Éva Irén ${ }^{2}$
}

(1) Pécsi Tudományegyetem, Ökológiai Tanszék; H-7624 Pécs, Ifjúság u. 6.; keveyb@ttk.pte.hu

(2) H-2016 Leányfalu, Móricz Zs. u. 75.

\section{Dry oak woods on the Szentendre Island}

\begin{abstract}
The phytosociological characteristics of the oak woods on the Szentendre Island were first studied 70 years ago. We conducted a follow-up study to determine the phytosociological relationships of theses woods and assess their possible changes over time. We found that these woods are most similar in their phytosociological characteristics to the closed pedunculate oak forests occurring in the high floodplain in the Szigetköz area (Melico nutantis-Quercetum roboris) along the Danube. Our results also showed a marked increase in the proportion of natural weeds, introduced species and invasive aliens in the studied woods.
\end{abstract}

Keywords: Hungarian Plain, multivariate analyses, nature reserve, Natura 2000 site, phytosociology

Összefoglalás - Jelen tanulmány a Szentendrei-sziget zárt száraz tölgyeseinek társulási viszonyait mutatja be tíz cönológiai felvétel alapján. A felmért állományok az egyéb alföldi tájak erdei közül a Szigetköz zárt ártéri tölgyeseivel (Melico nutantis-Quercetum roboris) mutatják a legközelebbi rokonságot. Az elemzési eredmények szerint ezen erdőkben az elmúlt 70 év alatt megnövekedett a természetes gyomok (W), a meghonosodott idegen fajok (I) és az agresszív tájidegen inváziós fajok (AC) aránya.

Kulcsszavak: növénycönológia, természetvédelmi terület, Natura 2000 terület, Magyar Alföld, clusteranalízis, ordináció

\section{Bevezetés}

A Szentendrei-sziget vegetációjáról ZsoLT (1943) készített először részletes tanulmányt, amelyben - Quercetum roboris convallarietosum néven - 10 felvétellel jellemzi a sziget zárt száraz tölgyeseit. Mintegy 70 év után érdemesnek láttuk e tölgyesek újra felmérését és jellemzését elvégezni.

\section{Anyag és módszer}

Kutatási terület jellemzése

Soó (1960) szerint a Szentendrei-sziget a Duna-Tisza köze flórajárásának (Praematricum) északnyugati peremén van. A természetes vegetációból kevés erdő érte meg a jelenkort. Felméréseinket e még természetszerűnek mondható zárt száraz tölgyesekben végeztük. 


\section{Alkalmazott módszerek}

A cönológiai felvételeket a Zürich-Montpellier növénycönológiai iskola (BECKING 1957, BRAUN-BLANQUET 1964) hagyományos kvadrát-módszerével készítettük. A felvételek táblázatos összeállítását, valamint a karakterfajok csoportrészesedését és csoporttömegét az „NS” számítógépes programcsomag (KEVEY \& HIRMANN 2002) segítségével végeztük. A felvételkészítés és a hagyományos statisztikai számítások módszerét KEVEY (2008) korábban részletesen közölte. Az asszociációk összehasonlításánál - a SYN-TAX 2000 programcsomag (PoDANI 2001) segítségével - bináris cluster-analízist (hasonlósági index: Baroni-Urbani-Buser; fúziós algoritmus: összetett lánc) és ugyancsak bináris ordinációt végeztünk (hasonlósági index: Baroni-Urbani-Buser; fúziós algoritmus: főkoordináta-analízis). A fajok esetében KIRÁLY (2009), a társulásoknál pedig az újabb hazai nómenklatúrát (BoRHIDI \& KEVEY 1996, KEVEY 2008, BORHIDI et al. 2012) követjük. A társulástani és a karakterfaj-statisztikai táblázatok felépítése az újabb eredményekkel (OBERDORFER 1992, MuCinA et al. 1993, KEVEY 2008, BoRHIDI et al. 2012) módosított Soó (1980) féle cönológiai rendszerre épül. A növények cönoszisztematikai besorolásánál is elsősorban Soó $(1964,1966,1968,1970,1973,1980)$ Synopsis-ára támaszkodtunk, de figyelembe vettük az újabb kutatási eredményeket is (vö. BORHIDI 1993, 1995, HoRVÁTH et al. 1995, KEVEY 2008).

\section{Eredmények}

Termőhelyi viszonyok, zonalitás

BoRHIDI (1961) klímazonális térképe szerint a Szentendrei-sziget az erdőssztyep klímazóna északnyugati peremén található. Ezek szerint a zonális vegetációt e tájon a pusztai tölgyes (Festuco rupicolae-Quercetum roboris) képviseli. A sziget déli részén szinte ősidők óta akadnak még természetszerű állapotban levő zárt száraz tölgyesek, amelyekből ZsoLT (1943) közölt 10 felvételt. Mivel e homoki tölgyesek a zárt tölgyes klímazónán kívül fordulnak elő, az erdőssztyep zónán belüli megjelenésük extrazonálisnak tekinthető, amely a talajvíz által kissé befolyásolt, kevésbé száraz mikroklímának köszönhető.

A felvételezett állományok mintegy 105 m tengerszint feletti magasságon találhatók. Síkvidék lévén az égtáji kitettség és a lejtőszög e társulás kialakulásában nem játszik szerepet. Megfigyeléseink szerint az alapkőzetet kavicstakaró képezi, amelyet folyami homok borít. Ennek felső rétege barna erdőtalajhoz hasonlítható termőréteggé fejlődött. E talajok a félszáraz-félüde vízgazdálkodási fokozatba sorolhatók.

\section{Fiziognómia}

A vizsgált tölgyesek felső lombkoronaszintje az állomány korától függően 23-30 m magas, közepesen, vagy jól záródó (60-85\%). Állandó fajai (K: V) a Quercus cerris és a Q. robur. Nagyobb tömegben (A-D: 3-5) a Q. cerris és a Q. robur mellett a Fraxinus excelsior is előfordulhat. Az alsó lombkoronaszint gyengén, vagy közepesen fejlett. Magassága 15-18 m, borítása pedig 10-25\%. Főleg alászorult fák alkotják. Állandó fája (K: IV) csak a F. excelsior. Nagyobb tömeget (A-D: 3-5) e szintben egyetlen fafaj sem ér el.

A cserjeszint általában fejlett, amely erdészeti beavatkozásokkal is kapcsolatos. Magassága 2-3 m, borítása pedig 50-70\%. Állandó elemei (K: IV-V) a következők: Berberis vulgaris, Celtis occidentalis, Cornus sanguinea, Crataegus monogyna, Fraxinus excelsior, Ligustrum vulgare, Prunus spinosa. Nagyobb tömeget (A-D: 3-4) csak a Crataegus monogyna és a Ligustrum vulgare ér el. Az alsó cserjeszint (újulat) borítása mindössze 5-25\%. Állandó fajai (K: IV-V) az alábbiak: Acer campestre, A. tataricum, Berberis vulgaris, Celtis occidentalis, 
Crataegus monogyna, Euonymus europaeus, E. verrucosus, Fraxinus excelsior, Hedera helix, Ligustrum vulgare, Quercus cerris, Q. robur, Rhamnus catharticus, Robinia pseudo-acacia, Rosa canina, Ulmus minor. Nagyobb tömegben (A-D: 3-5) itt egyetlen faj sem fordul elő.

A gyepszint közepesen, vagy erősebben fejlett, borítása 50-80\%. Állandó elemei (K: IV-V) a következők: Brachypodium sylvaticum, Buglossoides purpurocoerulea, Carex michelii, Colchicum autumnale, Convallaria majalis, Fallopia dumetorum, Ornithogalum umbellatum, Polygonatum latifolium, P. odoratum, Solidago gigantea, Vincetoxicum hirundinaria, Viola hirta, V. mirabilis. Fáciest (A-D: 4) csak a Buglossoides purpuro-coerulea és a Polygonatum latifolium képez.

Fajkombináció

$$
\text { Állandósági osztályok }
$$

Az 50 cönológiai felvétel alapján a társulásban 25 konstans és 7 szubkonstans faj szerepel az alábbiak szerint: K V: Acer campestre, A. tataricum, Berberis vulgaris, Brachypodium sylvaticum, Buglossoides purpuro-coerulea, Carex michelii, Celtis occidentalis, Colchicum autumnale, Convallaria majalis, Crataegus monogyna, Euonymus europaeus, Fallopia dumetorum, Fraxinus excelsior, Hedera helix, Ligustrum vulgare, Ornithogalum umbellatum, Polygonatum latifolium, P. odoratum, Prunus spinosa, Quercus cerris, Q. robur, Rhamnus catharticus, Robinia pseudo-acacia, Rosa canina, Viola hirta. - K IV: Cornus sanguinea, Euonymus verrucosus, Solidago gigantea, Ulmus minor, Viburnum lantana, Vincetoxicum hirundinaria, Viola mirabilis. A felvételi anyagban ezen kívül 17 akcesszórikus (K III), 26 szubakcesszórikus (K II) és 61 akcidens (K I) faj is szerepel. Az állandósági osztályok terén tehát a legkisebb fajszám a szubkonstans (K IV) elemeknél van, míg az akcidens (K I) elemek mellett a konstans (K V) fajoknál jelentkezik egy második maximum (vö. 1. ábra A; 1. táblázat).

\section{Karakterfajok aránya}

A Szentendrei-sziget zárt száraz tölgyeseit egyéb alföldi tájak tölgyeseivel is összehasonlítottuk. Ilyen a Szigetköz homokréteggel fedett kavicstakaróján kialakult zárt ártéri tölgyes, valamint a Nyírség, a Duna-Tisza köze, a Dél-Mezőföld és a Bakonyalja homokvidékének zárt tölgyesei (3. táblázat).

A karakterfajok arányával kapcsolatos elemzési eredmények elég nagy változatosságot mutatnak (4. táblázat), közöttük nem könnyü egyértelmű hasonlóságot találni. A Fagetalia elemekben (1. ábra B) a Szentendrei-sziget és a Duna-Tisza közének felvételei a legszegényebbek. Ezzel szemben az Alnion incanae s.l. elemek (1. ábra C) terén a Szentendrei-sziget tölgyesei legjobban a Szigetköz tölgyeseire emlékeztetnek. Ugyanez mondható el a Quercetea pubescentis-petraeae (1. ábra D) és a Prunetalia s.l. (1.ábra E) fajok arányáról is, amelyek szintén a Szentendrei-sziget és a Szigetköz tölgyeseinek hasonlóságát mutatják.

A száraz tölgyesek karakterfajai (Quercetea pubescentis-petraeae, Aceri tatarici-Quercion) kiemelkedő szerepet játszanak a társulás felépítésében: K V: Acer tataricum, Berberis vulgaris, Buglossoides purpuro-coerulea, Carex michelii, Prunus spinosa, Polygonatum odoratum, Quercus cerris, Rosa canina, Viola hirta. - K IV: Euonymus verrucosus, Vincetoxicum hirundinaria. - K III: Clematis recta, Cornus mas, Clinopodium vulgare, Hylotelephium telephium. - K II: Asparagus officinalis, Astragalus glycyphyllos, Hieracium sabaudum, Peucedanum oreoselinum, Pulmonaria mollissima, Thalictrum minus. - K I: Campanula bononiensis, Inula salicina, Lactuca quercina, Lithospermum officinale, Melica altissima, Pyrus pyraster, Silene nutans, Trifolium diffusum stb. 

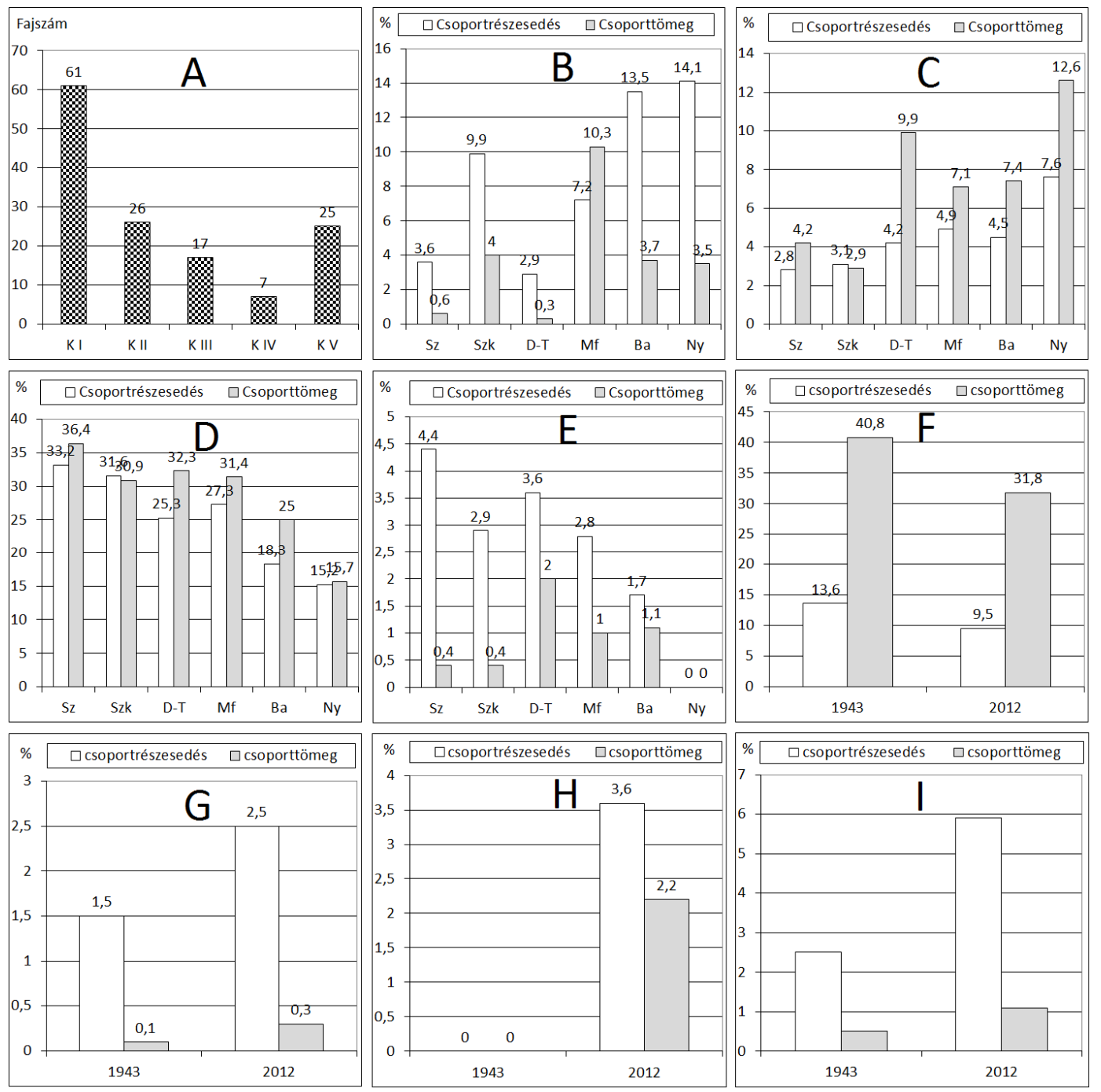

1. ábra. (A) Állandósági osztályok eloszlása, (B) Fagetalia elemek, (C) Alnion incanae s.l. elemek, (D) Quercetea pubescentis-petraeae elemek, (E) Prunetalia spinosae s.l. elemek, (F) kompetítorok, (G) természetes gyomok, $(\mathrm{H})$ meghonosodott idegen fajok és (I) agresszív tájidegen inváziós fajok aránya Fig. 1. (A) Frequency distribution of species in different constancy classes, (B) proportion of species characteristic of Fagetalia, (C) Alnion incanae s.l., (D) Quercetea pubescentis-petraeae, (E) Prunetalia

spinosae s.l., (F) competitors, (G) native weeds, (H) naturalized aliens and (I) invasive species

Sz: Melico nutantis-Quercetum roboris, Szentendrei-sziget (KeveY \& BőHM ined.: 10 felv.)

Szk: Melico nutantis-Quercetum roboris, Szigetköz (Kevey 2008: 25 felv.)

D-T: Polygonato latifolii-Quercetum roboris, Duna-Tisza köze (Kevey \& Lendvai ined.: 10 felv.)

Mf: Polygonato latifolii-Quercetum roboris, Mezőföld (Kevey 2015: 25 felv.)

Ba: Polygonato latifolii-Quercetum roboris, Bakonyalja (Kevey 2013: 10 felv.)

Ny: Convallario-Quercetum roboris, Nyírség (Horánszky 1998: 15 felv.)

1943: Szentendrei-sziget, Zsolt (1943): 10 felv.

2012: Szentendrei-sziget, KEvEY \& BőHm (ined. 2012): 10 felv. 


\section{Szociális magatartási típusok aránya}

Felvételi anyagunkat Zsolt (1943) - mintegy 70 évvel ezelőtt közölt - felvételeivel is összehasonlítottuk. Jelen esetben a BoRHIDI $(1993,1995)$ féle szociális magatartási típusok (5. táblázat) használatát láttuk célszerűnek. Az eredményekből úgy látszik, hogy az elmúlt hét évtized alatt a kompetítorok (C) aránya (1. ábra F) csökkent, ezzel szemben a természetes gyomok (W), a meghonosodott idegen fajok (I) és az agresszív tájidegen inváziós fajok (AC) aránya növekedett (1. ábra G-I).

\section{Sokváltozós elemzések eredményei}

A Szentendrei-sziget és a hasonló síkvidéki zárt száraz tölgyesek felvételeit sokváltozós elemzésekkel is összehasonlítottuk. A bináris cluster-analízissel (2. ábra) és ordinációval (3. ábra) azt az eredményt kaptuk, hogy a Szentendrei-sziget tölgyesei a Szigetköz ártéri tölgyeseivel mutatják a legközelebbi rokonságot. Külön csoportot képeznek a Nyírség tölgyesei is, míg a legnagyobb hasonlóság a Duna-Tisza köze, a Mezőföld és a Bakonyalja tölgyesei között mutatkozik.

\section{Megvitatás}

Az összehasonlításra szánt zárt homoki tölgyesek (3. táblázat) sokváltozós elemzése (2-3. ábra) azt mutatja, hogy a legnagyobb hasonlóság a Szentendrei-sziget és a Szigetköz erdei között mutatkozik. Mindkét földrajzi táj a Duna árterét képezi, s úgy látszik, hogy ezen kavicsos alapkőzetet borító homoktakarón kifejlődött ártéri tölgyesek fajkombinációja némileg eltér a valódi homokvidékek zárt tölgyeseinek faji összetételétől. A hat földrajzi táj zárt száraz tölgyeseinek összehasonlítása alátámasztja azokat a közelmúltban tett megállapításokat, amely szerint az Alföldön három zárt homoki tölgyes társulást különböztethetünk meg. A Melico nutantis-Quercetum roboris KEVEY 2008 a kavicsos alapkőzetet borító vékonyabb homoktakarón figyelhető meg, így a Szigetközben (KEVEY 2008), a Szentendrei-szigeten (KEVEY \& BőHM ined.) és nyomokban a Csepel-szigeten (KEvEY ined.). A Convallario-Quercetum roboris (Soó 1937) Soó 1957 asszociáció a Nyírség homoki erdeje. Végül a Polygonato latifolii-Quercetum roboris BORHIDI in BORHIDI \& KEVEY 1996 erdőtársulás leírása a DunaTisza közének homokvidékéről történt, de ide sorolhatók a Dél-Mezőföld (KEVEY 2015) és a Bakonyalja homokvidékének (KEVEY 2013) zárt tölgyesei is. Ezen összefüggések jól láthatók a dendrogramon (2. ábra) és az ordinációs diagramokon (3. ábra).

ZsolT (1943) tíz felvétele és saját tíz felvételünk összevetéséből kiderült, hogy az elmúlt hét évtized alatt a Szentendrei-sziget erdeinek természetességi állapota romlott. Ezt bizonyítja a természetes gyomok (W), a meghonosodott idegen fajok (I) és az agresszív tájidegen inváziós fajok (AC) megnövekedett aránya (1. ábra G-I) annak ellenére, hogy a terepmunka során a leginkább természetszerűnek tűnő erdőállományokban végeztük a felméréseket. E részleges leromlás oka a tájhasználatban, elsősorban a vízrendezésekben és az erdőgazdálkodásban keresendő (bővebben lásd: BőHM 2009, 2015). Ennek ellenére a felmért állományok - az állandósági osztályok eloszlásával (1. ábra A), a karakterfajok (4. táblázat; 1. ábra B-E) és a szociális magatartási típusok arányával (5. táblázat; 1. ábra F-I) még ma is egy természetközeli erdőtársulás képét mutatják. 


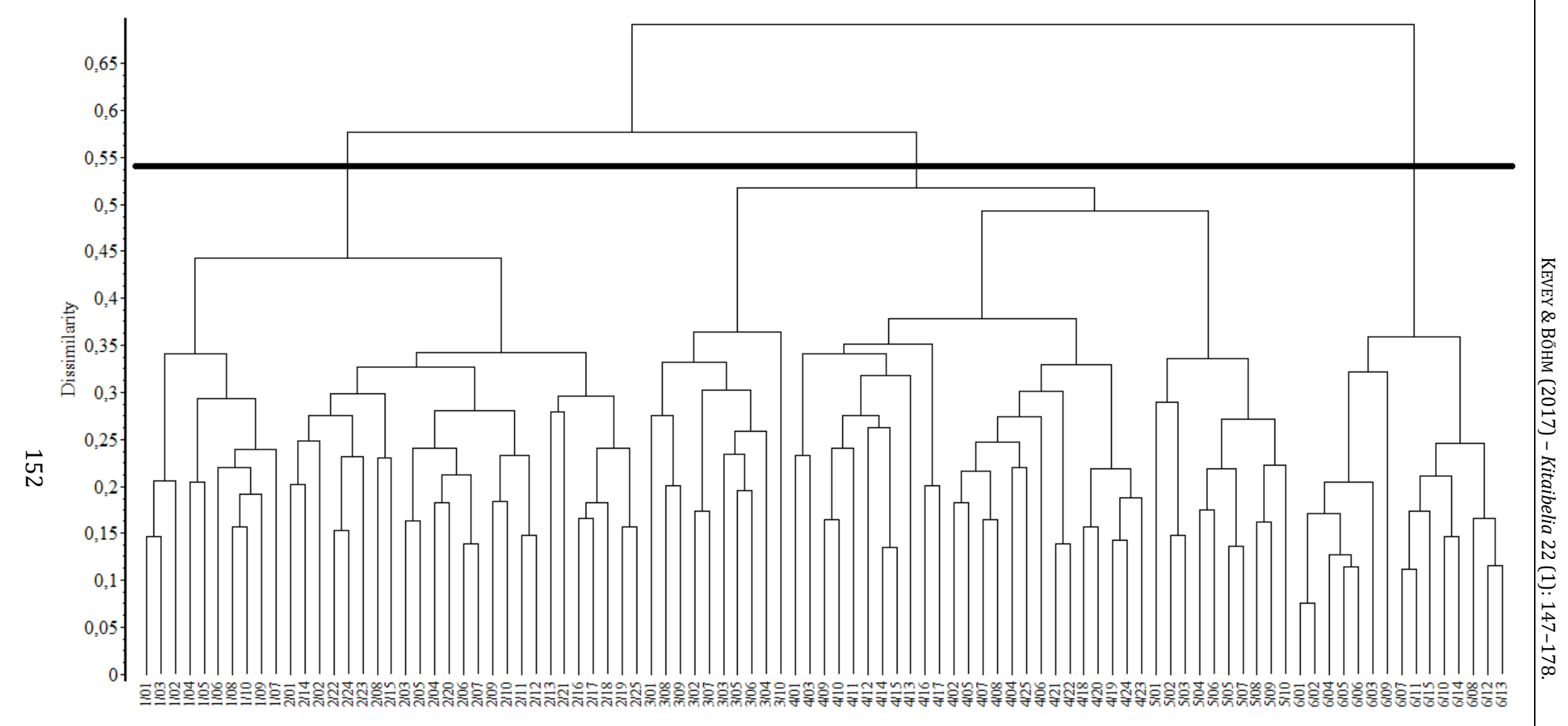

2. ábra. Az Alföld zárt homoki tölgyeseinek bináris dendrogramja

(hasonlósági index: Baroni-Urbani-Buser; fúziós algoritmus: összetett lánc)

Fig. 2. Binary dendrogram of dry oak woods on sand

1/1-10: Melico nutantis-Quercetum roboris, Szentendrei-sziget (KeveY \& BőHM ined.); 2/1-25: Melico nutantis-Quercetum roboris, Szigetköz (Kevey 2008)

3/1-10: Polygonato latifolii-Quercetum roboris, Duna-Tisza köze (KeveY \& LendVAI ined.); 4/1-25: Polygonato latifolii-Quercetum roboris, Mezőföld (KeveY 2015); 5/1-10: Polygonato latifolii-Quercetum roboris, Bakonyalja (KeVEY 2013); 6/1-15: Convallario-Quercetum roboris, Nyírség (HoRÁnsZKY 1998) 

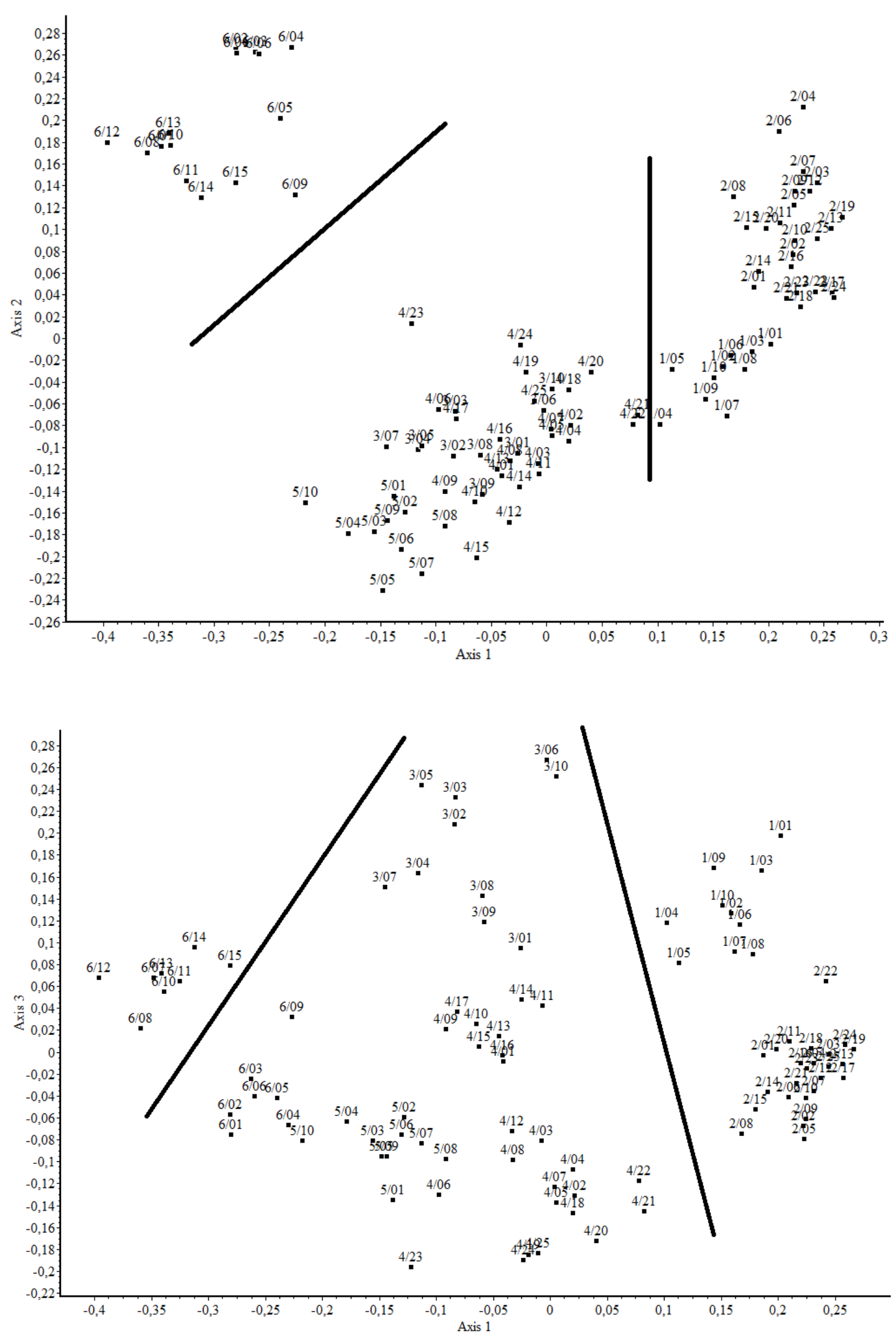
3. ábra. Az Alföld zárt homoki tölgyeseinek bináris ordinációs diagramjai (az előző oldalon) (hasonlósági index: Baroni-Urbani-Buser; fúziós algoritmus: főkoordináta-analízis)

Fig. 3. Binary ordination diagram of dry oak woods (previous page)

1/1-10: Melico nutantis-Quercetum roboris, Szentendrei-sziget (KeveY \& BőHM ined.); 2/1-25: Melico nutantis-Quercetum roboris, Szigetköz (Kevey 2008); 3/1-10: Polygonato latifolii-Quercetum roboris, Duna-Tisza köze (Kevey \& Lendvai ined.); 4/1-25: Polygonato latifolii-Quercetum roboris, Mezőföld (Kevey 2015); 5/1-10: Polygonato latifolii-Quercetum roboris, Bakonyalja (Kevey 2013); 6/1-15: Convallario-Quercetum roboris, Nyírség (Horánszky 1998)

Az asszociáció helye a szüntaxonómiai rendszerben az alábbi módon vázolható:

Divisio: Q U E R C O - F A G E A JAKUCS 1967

Classis: QUERCETEA PUBESCENTIS-PETRAEAE (OBERD. 1948) JAKUCS 1960

Ordo: QUERCETALIA CERRIDIS BORHIDI in BORHIDI et KEVEY 1996

Alliance: Aceri tatarici-Quercion ZóLYOMI et JAKUCS 1957

Suballiance: Polygonato latifolii-Quercenion roboris KEVEY 2008

Associatio: Melico nutantis-Quercetum roboris KEVEY 2008

\section{Természetvédelmi vonatkozások}

A tíz cönológiai felvételből mindössze két védett növényfaj került elő: az Orchis militaris (K II) és a Cephalanthera longifolia (K I). Alföldi viszonylatban egyéb értékesebb fajok a következők: Acer tataricum, Asparagus officinalis, Brachypodium pinnatum, Campanula bononiensis, Cardamine bulbifera, Clematis recta, Cornus mas, Corydalis solida, Hieracium sabaudum, Hylotelephium telephium, Inula salicina, Lonicera xylosteum, Melica altissima, $M$. nutans, Peucedanum oreoselinum, Polygonatum odoratum, Primula veris, Pulmonaria mollissima, Ribes rubrum, R. uva-crispa, Stachys sylvatica, Viola mirabilis. Zsolt (1943) felvételeiben szereplő fontosabb fajok közül viszont nem találtuk a következőket: Anthericum ramosum, Cephalanthera rubra, Dictamnus albus, Melica transsylvanica, Pulmonaria officinalis.

Flóraszennyező hatást fejtenek ki egyes tájidegen növények: K V: Celtis occidentalis, Robinia pseudo-acacia. - K IV: Solidago gigantea. - K III: Ailanthus altissima, Mahona aquifolium, Parthenocissus inserta. - K II: Acer negundo. - K I: Fraxinus pennsylvanica, Gleditsia triacanthos, Juglans regia, Morus alba, Padus serotina, Pinus sylvestris. E fajok terjeszkedése az asszociáció további degradálódását vonhatja maga után.

Az általunk vizsgált két erdő (Szigetmonostor „Makkos-erdő”, „Vízművek-erdeje”) országos jelentőségű természetvédelmi terület, továbbá a Natura 2000 hálózat részét is képezi (BőHM 2015). Maradvány állományaik megőrzése, helyenkénti rekonstrukciója természetvédelmünk fontos feladata.

\section{Köszönetnyilvánítás}

Köszönetünk illeti Lendvai Gábor kollégánkat, aki a Duna-Tisza köze homokvidékének gyöngyvirágos tölgyeseiben készült felvételeket rendelkezésünkre bocsátotta.

\section{Rövidítések}

A1: felső lombkoronaszint; A2: alsó lombkoronaszint; AF: Aremonio-Fagion; Agi: Alnenion glutinosae-incanae; Ai: Alnion incanae; Alo: Alopecurion pratensis; APa: Abieti-Piceea; AQ: Aceri tatarici-Quercion; Ar: Artemisietea; Ara: Arrhenatheretea; Arn: Arrhenatherion elatioris; Ate: Alnetea glutinosae; B1: cserjeszint; B2: újulat; Ber: Berberidion; Bia: Bidentetea; Bra: 
Brometalia erecti; C: gyepszint; Cal: Calystegion sepium; Cau: Caucalidion platycarpos; Ccn: Caricion canescenti-nigrae; CeF: Cephalanthero-Fagenion; Cgr: Caricenion gracilis; Che: Chenopodietea; ChS: Chenopodio-Scleranthea; Cp: Carpinenion betuli; CyF: CynodontoFestucenion; Des: Deschampsion caespitosae; EP: Erico-Pinetea; Epa: Epilobietea angustifolii; Epn: Epilobion angustifolii; EuF: Eu-Fagenion; F : Fagetalia sylvaticae; FB: Festuco-Bromea; FBt: Festuco-Brometea; FiC: Filipendulo-Cirsion oleracei; FPe: Festuco-Puccinellietea; FPi: Festuco-Puccinellietalia; Fru: Festucion rupicolae; Fvg: Festucetea vaginatae; Fvl: Festucetalia valesiacae; GA: Galio-Alliarion; GU: Galio-Urticetea; ined.: ineditum (kiadatlan közlés); Mag: Magnocaricetalia; Moa: Molinietalia coeruleae; MoA: Molinio-Arrhenatherea; MoJ: MolinioJuncetea; Mon: Molinion coeruleae; NC: Nardo-Callunetea; Nc: Nanocyperion flavescentis; OCn: Orno-Cotinion; Onn: Onopordion acanthii; Pla: Plantaginetea; Pna: Populenion nigro-albae; PP: Pulsatillo-Pinetea; PQ: Pino-Quercetalia; Prf: Prunion fruticosae; Pru: Prunetalia spinosae; Pte: Phragmitetea; Qc: Quercetalia cerridis; Qfa: Quercion farnetto; QFt: Querco-Fagetea; Qp: Quercion petraeae; Qpp: Quercetea pubescentis-petraeae; Qr: Quercetalia roboris; Qrp: Quercion robori-petraeae; S: summa (összeg); Sal: Salicion albae; Sea: Secalietea; s.l.: sensu lato (tágabb értelemben); Spu: Salicetea purpureae; TA: Tilio platyphyllae-Acerenion pseudoplatani; Ulm: Ulmenion; US: Urtico-Sambucetea; VP: Vaccinio-Piceetea.

\section{Irodalom}

BECKING R. W. (1957): The Zürich-Montpellier Schol of phytosociology. - Botanical Review 23: 411-488.

Borhidi A. (1961): Klimadiagramme und klimazonale Karte Ungarns. - Annales Universitatis Scientiarum Budapestinensis, Sectio Biologica 4: 21-250.

Borhidi A. (1993): A magyar flóra szociális magatartás típusai, természetességi és relatív ökológiai értékszámai. - Janus Pannonius Tudományegyetem, Pécs, 95 pp.

Borhid A. (1995): Social behaviour types, the naturalness and relative ecological indicator values of the higher plants 155nt he hungarian flora. - Acta Botanica Academiae Scientiarum Hungaricae 39: 97181.

BoRHIDI A. \& Kevey B. (1996): An annotated checklist of the hungarian plant communities II. - In: BoRHIDI A. (szerk.), Critical revision of the hungarian plant communities. Janus Pannonius University, Pécs, pp. 95-138.

Borhidi A., Kevey B. \& Lendvai G. (2012): Plant communities of Hungary. - Akadémiai Kiadó, Budapest, $544 \mathrm{pp}$.

Braun-Blanquet J. (1964): Pflanzensoziologie (ed. 3.). - Springer Verlag, Wien-New York, 865 pp.

BőHM É. I. (2009): Zsolt János nyomában a Szentendrei-szigeten. - Magyar Biológiai Társaság VI. Kárpátmedencei Biológiai Szimpózium. 2009. november 12-13. Előadáskötet. Fővárosi Állat- és Növénykert, Budapest, pp. 155.

BőHM É. I. (2015): A Szentendrei-sziget tájtörténete. - Szigetmonostor Község Önkormányzata, Szigetmonostor, $104 \mathrm{pp}$.

HorvÁth F., DobolyI Z. K., MORSCHHAUSER T., LőKÖS L., KARAS L. \& SZERDAHElYI T. (1995): Flóra adatbázis 1.2. - MTA Ökológiai és Botanikai Kutatóintézete, Vácrátót, 267 pp.

JaKucs P. (1960): Nouveau classement cénologique des bois de chęnes xérothermes (Quercetea pubescenti-petraeae Cl. nova) de l'Europe. - Acta Botanica Academiae Scientiarum Hungaricae 6: 267-303.

JAKUCS P. (1967): Gedanken zur höheren Systematik der europäischen Laubwälder. - Contribuţii Botanice, Cluj 1967: 159-166.

KeveY B. (2008): Magyarország erdôtársulásai [Forest associations of Hungary]. - Tilia 14: 488 pp. + CDmelléklet (230 táblázat + 244 ábra).

Kevey B. \& HiRmanN A. (2002): „NS” számítógépes cönológiai programcsomag. - In: HoRvÁtH A. (szerk.), Aktuális flóra- és vegetációkutatások a Kárpát-medencében V., Pécs, 2002. március 8-10. (Összefoglalók), Pécsi Tudományegyetem Növénytani Tanszék, Duna-Dráva Nemzeti Park Igazgatósága, Baranya Megyei Múzeumok Igazgatósága, Kosbor Természetvédelmi Egyesület, Pécs, p. 74.

KIRÁLY G. (szerk.) (2009): Új magyar füvészkönyv. Magyarország hajtásos növényei. Határozókulcsok. Aggteleki Nemzeti Park Igazgatóság, Jósvafő, 616 pp. 
Mucina L., GrabherR G. \& WALlNÖFER S. (1993): Die Pflanzengesellschaften Österreichs III. Wälder und Gebüsche. - Gustav Fischer, Jena-Stuttgart-New York, 353 pp.

OBERDORFER E. (1948): Gliederung und Umgrenzung der Mittelmeervegetation auf der Balkanhalbinsel. - Bericht über das Geobotanische Forschungsinstitut Rübel in Zürich 3 (1947): 84-111.

OBerdorfer E. (1992): Süddeutsche Pflanzengesellschaften IV. A. Textband. - Gustav Fischer Verlag, JenaStuttgart-New York, $282 \mathrm{pp}$.

PodAni J. (2001): SYN-TAX 2000 Computer Programs for Data Analysis in Ecologi and Systematics. Scientia, Budapest, $53 \mathrm{pp}$.

Soó R. (1937): A Nyírség erdői és erdőtípusai. - Erdészeti Kisérletek 39: 337-380.

Soó R. (1957): Provisorische Einteilung der pannonischen und der angrenzenden Waldgesellschaften (Diskussionsvorlage). - ELTE, Budapest, 11 pp. (multipl.).

Soó R. (1960): Magyarország új florisztikai-növényföldrajzi felosztása. - Magyar Tudományos Akadémia Biológiai Csoportjának Közleményei 4: 43-70.

Soó R. (1964, 1966, 1968, 1970, 1973, 1980): A magyar flóra és vegetáció rendszertani-növényföldrajzi kézikönyve I-VI. - Akadémiai kiadó, Budapest.

ZólYomi B. \& JAKUCS P. (1957): Neue Einteilung der Assoziationen der Quercetalia pubescentis-petraeaeOrdnung im pannonischen Eichenwaldgebiet. - Annales Historico-Naturales Musei Nationalis Hungarici 8: 227-229.

Zsolt J. (1943): A Szent-Endrei sziget növénytakarója. - Index Horti Botanici Universitatis Budapestinensis 6 (1942-1943): 3-19+ 7 tab.

Beérkezett: 2016.11.21. • Elfogadva: 2017.01. 09. 
1. táblázat. Melico nutantis-Quercetum roboris (Szentendrei-sziget) Table 1. Melico nutantis-Quercetum roboris (Szentendre Island)

\begin{tabular}{|c|c|c|c|c|c|c|c|c|c|c|c|c|c|c|}
\hline & & 1 & 2 & 3 & 4 & 5 & 6 & 7 & 8 & 9 & 10 & A-D & $\mathbf{K}$ & $\%$ \\
\hline \multicolumn{15}{|l|}{$\begin{array}{l}\text { 1. Querco-Fagea } \\
\text { 1.1. Salicetea purpureae } \\
\text { 1.1.1. Salicetalia purpureae } \\
\text { 1.1.1.1. Salicion albae }\end{array}$} \\
\hline Humulus lupulus (Cal,Ate,Ai) & $\mathrm{C}$ & - & - & - & + & - & - & + & - & + & + & + & II & 40,0 \\
\hline $\begin{array}{l}\text { Cucubalus baccifer (Cal,Ulm) } \\
\text { 1.2. Querco-Fagetea }\end{array}$ & \multicolumn{13}{|c|}{ 1.2. Querco-Fagetea } & 10,0 \\
\hline Brachypodium sylvaticum (Qpp) & $\mathrm{C}$ & 2 & + & + & 2 & + & 1 & 1 & + & 1 & + & +-2 & $\mathrm{~V}$ & 100,0 \\
\hline Convallaria majalis (Qpp) & $\mathrm{C}$ & 1 & 1 & 1 & + & + & 1 & 2 & 2 & 2 & 2 & +-2 & $\mathrm{~V}$ & 100,0 \\
\hline \multirow[t]{4}{*}{ Crataegus monogyna (Qpp) } & $\mathrm{A} 2$ & - & - & - & - & - & + & - & - & + & + & + & II & 30,0 \\
\hline & B1 & 2 & 2 & 3 & 1 & 1 & 3 & 3 & 4 & 3 & 4 & $1-4$ & V & 100,0 \\
\hline & $\mathrm{B} 2$ & - & 1 & 1 & + & + & 1 & + & + & 1 & 1 & +-1 & $\mathrm{~V}$ & 90,0 \\
\hline & $\mathrm{S}$ & 2 & 2 & 3 & 1 & 1 & 3 & 3 & 4 & 3 & 4 & $1-4$ & $\mathrm{~V}$ & 100,0 \\
\hline Euonymus europaeus (Qpp) & $\mathrm{B} 2$ & + & + & + & + & + & + & + & + & + & + & + & $\mathrm{V}$ & 100,0 \\
\hline \multirow[t]{3}{*}{ Fallopia dumetorum (Qpp,GA) } & B1 & - & - & - & - & + & - & - & - & - & - & + & I & 10,0 \\
\hline & $\mathrm{C}$ & + & + & + & + & + & + & + & + & + & + & + & $\mathrm{V}$ & 100,0 \\
\hline & $\mathrm{S}$ & + & + & + & + & + & + & + & + & + & + & + & V & 100,0 \\
\hline \multirow[t]{5}{*}{ Fraxinus excelsior (Qpp,TA) } & $\mathrm{A} 1$ & 3 & 3 & 3 & 2 & - & - & 1 & - & - & - & $1-3$ & III & 50,0 \\
\hline & $\mathrm{A} 2$ & 2 & 2 & 2 & 2 & + & - & + & 1 & - & - & +-2 & IV & 70,0 \\
\hline & B1 & - & 1 & + & 2 & + & - & + & + & + & - & +-2 & IV & 70,0 \\
\hline & B2 & + & + & 1 & - & + & + & - & + & + & + & +-1 & IV & 80,0 \\
\hline & $S$ & 4 & 4 & 4 & 3 & 1 & + & 1 & 1 & + & + & +-4 & $\mathrm{~V}$ & 100,0 \\
\hline \multirow[t]{3}{*}{ Ligustrum vulgare (Cp,Qpp) } & B1 & 3 & 3 & 2 & 3 & 3 & + & 1 & + & 2 & 1 & +-3 & V & 100,0 \\
\hline & B2 & 2 & 2 & 2 & 2 & 2 & 1 & 1 & 1 & 2 & 1 & $1-2$ & V & 100,0 \\
\hline & $\mathrm{S}$ & 4 & 4 & 3 & 4 & 4 & 1 & 2 & 1 & 3 & 2 & $1-4$ & V & 100,0 \\
\hline Polygonatum latifolium (Qpp) & $\mathrm{C}$ & 2 & 2 & 2 & 2 & 2 & 3 & 4 & 4 & 4 & 3 & $2-4$ & $\mathrm{~V}$ & 100,0 \\
\hline \multirow[t]{4}{*}{ Quercus robur (Ai,Cp,Qpp) } & $\mathrm{A} 1$ & 2 & 2 & 3 & 3 & 2 & 5 & 4 & 2 & 4 & 4 & $2-5$ & $\mathrm{~V}$ & 100,0 \\
\hline & A2 & 1 & - & 1 & - & - & - & - & + & 1 & 1 & +-1 & III & 50,0 \\
\hline & B2 & - & - & + & + & + & + & + & + & + & + & + & IV & 80,0 \\
\hline & S & 2 & 2 & 3 & 3 & 2 & 5 & 4 & 2 & 4 & 4 & $2-5$ & V & 100,0 \\
\hline \multirow[t]{4}{*}{ Rhamnus catharticus (Qpp,Pru) } & $\mathrm{A} 2$ & + & - & - & - & - & - & - & - & - & - & + & I & 10,0 \\
\hline & B1 & - & - & + & + & + & - & - & - & - & + & + & II & 40,0 \\
\hline & $\mathrm{B} 2$ & + & + & + & + & + & + & + & + & + & + & + & $\mathrm{V}$ & 100,0 \\
\hline & $\mathrm{S}$ & + & + & + & + & + & + & + & + & + & + & + & $\mathrm{V}$ & 100,0 \\
\hline
\end{tabular}


KEVEY \& BőHM (2017) - Kitaibelia 22 (1): 147-178.

\begin{tabular}{|c|c|c|c|c|c|c|c|c|c|c|c|c|c|c|}
\hline & & 1 & 2 & 3 & 4 & 5 & 6 & 7 & 8 & 9 & 10 & A-D & $\mathbf{K}$ & $\%$ \\
\hline \multirow[t]{4}{*}{ Acer campestre (Qpp) } & A2 & - & - & - & - & - & 2 & - & - & - & - & 2 & I & 10,0 \\
\hline & B1 & - & - & - & + & 2 & 2 & 1 & 1 & - & - & +-2 & III & 50,0 \\
\hline & B2 & - & + & + & + & 1 & + & + & + & + & + & +-1 & $\mathrm{~V}$ & 90,0 \\
\hline & $S$ & - & + & + & + & 2 & 3 & 1 & 1 & + & + & +-3 & $\mathrm{~V}$ & 90,0 \\
\hline \multirow[t]{3}{*}{ Cornus sanguinea (Qpp) } & B1 & + & + & 1 & - & - & - & 2 & 1 & 2 & + & +-2 & IV & 70,0 \\
\hline & B2 & - & 1 & - & - & - & 1 & + & + & + & - & +-1 & III & 50,0 \\
\hline & $S$ & + & 1 & 1 & - & - & 1 & 2 & 1 & 2 & + & +-2 & IV & 80,0 \\
\hline \multirow[t]{4}{*}{ Ulmus minor (Ai,Ulm,Qpp) } & A2 & - & - & - & - & 1 & - & + & - & - & - & +-1 & I & 20,0 \\
\hline & B1 & - & + & - & + & + & - & + & - & - & - & + & II & 40,0 \\
\hline & B2 & - & + & + & + & + & + & + & - & + & + & + & IV & 80,0 \\
\hline & $S$ & - & + & + & + & 1 & + & 1 & - & + & + & +-1 & IV & 80,0 \\
\hline Viola mirabilis $(\mathrm{F}, \mathrm{Qpp})$ & $\mathrm{C}$ & 1 & 1 & + & - & - & + & + & + & + & 1 & +-1 & IV & 80,0 \\
\hline Geum urbanum (Еpa,Cp,Qpp) & $\mathrm{C}$ & - & + & - & + & + & - & - & + & + & + & + & III & 60,0 \\
\hline Viola suavis s.l. (Qpp) & $\mathrm{C}$ & - & + & + & - & + & - & - & + & + & + & + & III & 60,0 \\
\hline \multirow[t]{3}{*}{ Clematis vitalba (Qpp) } & B1 & + & - & - & - & - & - & - & - & - & - & + & I & 10,0 \\
\hline & B2 & + & + & + & + & - & - & + & - & - & - & + & III & 50,0 \\
\hline & $S$ & + & + & + & + & - & - & + & - & - & - & + & III & 50,0 \\
\hline Melica nutans (Qpp) & $\mathrm{C}$ & - & - & - & - & - & + & + & + & - & + & + & II & 40,0 \\
\hline Dactylis polygama (Qpp,Cp) & $\mathrm{C}$ & - & - & - & + & + & - & - & + & - & - & + & II & 30,0 \\
\hline Galeopsis pubescens (Qpp,Epa) & $\mathrm{C}$ & - & - & - & + & + & - & - & - & - & + & + & II & 30,0 \\
\hline Geranium robertianum (Epa) & $\mathrm{C}$ & - & - & - & + & + & - & - & - & - & + & + & II & 30,0 \\
\hline \multirow[t]{3}{*}{ Corylus avellana (Qpp) } & B1 & - & - & - & - & - & - & - & - & - & + & + & I & 10,0 \\
\hline & B2 & - & + & - & - & - & - & - & - & - & - & + & I & 10,0 \\
\hline & S & - & + & - & - & - & - & - & - & - & + & + & I & 20,0 \\
\hline Fragaria vesca (Qpp,Epa) & $\mathrm{C}$ & + & + & - & - & - & - & - & - & - & - & + & I & 20,0 \\
\hline Mycelis muralis & $\mathrm{C}$ & - & - & - & + & - & - & - & - & + & - & + & I & 20,0 \\
\hline Cephalanthera longifolia & $\mathrm{C}$ & + & - & - & - & - & - & - & - & - & - & + & I & 10,0 \\
\hline Heracleum sphondylium (Qpp,MoA) & $\mathrm{C}$ & - & - & - & - & - & - & - & + & - & - & + & I & 10,0 \\
\hline Lonicera xylosteum (Qpp) & B1 & - & - & - & - & - & - & - & - & - & + & + & I & 10,0 \\
\hline Poa nemoralis (Qpp) & $\mathrm{C}$ & - & - & - & - & + & - & - & - & - & - & + & I & 10,0 \\
\hline Primula veris (Qpp,Ara) & $\mathrm{C}$ & - & - & - & + & - & - & - & - & - & - & + & I & 10,0 \\
\hline \multirow[t]{3}{*}{ Tilia cordata (Cp,Qpp) } & B1 & - & + & - & - & - & - & - & - & - & - & + & I & 10,0 \\
\hline & B2 & - & + & - & - & - & - & - & - & - & - & + & I & 10,0 \\
\hline & S & - & + & - & - & - & - & - & - & - & - & + & I & 10,0 \\
\hline Veronica sublobata & $\mathrm{C}$ & - & - & - & - & + & - & - & - & - & - & + & I & 10,0 \\
\hline \multicolumn{15}{|l|}{ 1.2.1. Fagetalia sylvaticae } \\
\hline \multirow[t]{4}{*}{ Hedera helix } & $\mathrm{A} 2$ & - & - & - & - & - & - & - & - & + & + & + & I & 20,0 \\
\hline & B1 & - & - & - & - & - & - & - & - & + & - & + & I & 10,0 \\
\hline & B2 & + & + & + & + & + & - & + & + & + & + & + & V & 90,0 \\
\hline & $\mathrm{S}$ & + & + & + & + & + & - & + & + & 1 & + & +-1 & $\mathrm{~V}$ & 90,0 \\
\hline
\end{tabular}


KEVEY \& BőHM (2017) - Kitaibelia 22 (1): 147-178.

\begin{tabular}{|c|c|c|c|c|c|c|c|c|c|c|c|c|c|c|}
\hline & & 1 & 2 & 3 & 4 & 5 & 6 & 7 & 8 & 9 & 10 & A-D & $\mathbf{K}$ & $\%$ \\
\hline Acer platanoides (TA) & B2 & + & + & + & - & - & - & - & - & + & - & + & II & 40,0 \\
\hline Stachys sylvatica (Epa) & $\mathrm{C}$ & - & - & - & - & - & + & + & - & + & - & + & II & 30,0 \\
\hline Cerasus avium (Cp) & B2 & - & + & - & - & - & + & - & - & - & - & + & I & 20,0 \\
\hline Acer pseudo-platanus (TA) & B2 & - & - & - & - & - & + & - & - & - & - & + & I & 10,0 \\
\hline Cardamine bulbifera & $\mathrm{C}$ & - & - & - & - & + & - & - & - & - & - & + & I & 10,0 \\
\hline Carpinus betulus (Cp) & B2 & - & - & - & + & - & - & - & - & - & - & + & I & 10,0 \\
\hline Corydalis solida & $\mathrm{C}$ & - & - & - & - & + & - & - & - & - & - & + & I & 10,0 \\
\hline Ribes uva-crispa (Ai,TA,Pru) & B2 & - & - & - & - & - & - & - & - & - & + & + & I & 10,0 \\
\hline \multicolumn{15}{|l|}{ 1.2.1.1. Alnion incanae } \\
\hline \multirow[t]{3}{*}{ Populus $\times$ canescens $(\mathrm{Sal}, \mathrm{AQ})$} & $\mathrm{A} 1$ & - & - & - & - & - & - & - & - & - & 1 & 1 & I & 10,0 \\
\hline & B1 & - & + & - & - & - & - & + & - & - & - & + & I & 20,0 \\
\hline & S & - & + & - & - & - & - & + & - & - & 1 & +-1 & II & 30,0 \\
\hline \multirow[t]{3}{*}{ Populus alba (Sal,AQ) } & A1 & - & - & - & - & - & - & - & - & 1 & - & 1 & I & 10,0 \\
\hline & B1 & - & + & - & - & - & - & - & - & - & - & + & I & 10,0 \\
\hline & $S$ & - & + & - & - & - & - & - & - & 1 & - & +-1 & I & 20,0 \\
\hline \multirow[t]{3}{*}{ Viburnum opulus (Ate) } & B1 & - & - & - & - & - & - & + & - & - & - & + & I & 10,0 \\
\hline & B2 & - & - & - & - & - & - & - & - & + & - & + & I & 10,0 \\
\hline & S & - & - & - & - & - & - & + & - & + & - & + & I & 20,0 \\
\hline Elymus caninus (Pna,Qpp) & C & - & - & - & - & - & - & - & - & + & - & + & I & 10,0 \\
\hline Frangula alnus (Ate,Qr,PQ) & B2 & - & - & - & - & - & - & + & - & - & - & + & I & 10,0 \\
\hline Malus sylvestris (Qpp) & $\mathrm{A} 2$ & - & - & - & - & - & - & + & - & - & - & + & I & 10,0 \\
\hline Ribes rubrum & B2 & - & - & - & - & - & - & - & - & - & + & + & I & 10,0 \\
\hline \multicolumn{15}{|l|}{$\begin{array}{l}\text { 1.2.1.2. Fagion sylvaticae } \\
\text { 1.2.1.2.1. Tilio platyphyllae-Acerenion } \\
\text { pseudoplatani }\end{array}$} \\
\hline \multirow[t]{4}{*}{ Tilia platyphyllos (F) } & A2 & - & - & - & - & - & 1 & - & - & - & - & 1 & I & 10,0 \\
\hline & B1 & - & - & + & - & - & - & - & - & - & - & + & I & 10,0 \\
\hline & B2 & - & - & + & - & - & - & - & - & - & - & + & I & 10,0 \\
\hline & $S$ & - & - & + & - & - & 1 & - & - & - & - & +-1 & I & 20,0 \\
\hline \multicolumn{15}{|l|}{ 1.3. Quercetea pubescentis-petraeae } \\
\hline \multirow[t]{3}{*}{ Berberis vulgaris (Pru) } & B1 & + & + & + & + & + & + & + & - & + & + & + & $\mathrm{V}$ & 90,0 \\
\hline & B2 & + & + & - & + & + & + & + & + & + & + & + & $\mathrm{V}$ & 90,0 \\
\hline & S & + & + & + & + & + & + & + & + & + & + & + & $\mathrm{V}$ & 100,0 \\
\hline Buglossoides purpurocoerulea $(\mathrm{OCn}, \mathrm{AQ})$ & $\mathrm{C}$ & 3 & 3 & 4 & 3 & 2 & 1 & 1 & 1 & 1 & 1 & $1-4$ & $\mathrm{~V}$ & 100,0 \\
\hline Carex michelii & $\mathrm{C}$ & + & + & 1 & + & + & + & + & + & 1 & + & +-1 & $\mathrm{~V}$ & 100,0 \\
\hline \multirow[t]{3}{*}{ Prunus spinosa (Pru,Prf) } & B1 & + & + & + & + & + & + & + & - & - & + & + & IV & 80,0 \\
\hline & B2 & - & - & - & - & + & + & + & + & + & + & + & III & 60,0 \\
\hline & $S$ & + & + & + & + & + & + & + & + & + & + & + & $\mathrm{V}$ & 100,0 \\
\hline
\end{tabular}


KEVEY \& BőHM (2017) - Kitaibelia 22 (1): 147-178.

\begin{tabular}{|c|c|c|c|c|c|c|c|c|c|c|c|c|c|c|}
\hline & & 1 & 2 & 3 & 4 & 5 & 6 & 7 & 8 & 9 & 10 & A-D & $\mathbf{K}$ & $\%$ \\
\hline \multirow[t]{5}{*}{ Quercus cerris $(\mathrm{Qr}, \mathrm{PQ})$} & $\mathrm{A} 1$ & 1 & 2 & 1 & 2 & 4 & 1 & + & 4 & 1 & 2 & +-4 & $\mathrm{~V}$ & 100,0 \\
\hline & A2 & - & + & - & + & - & - & - & 1 & - & - & +-1 & II & 30,0 \\
\hline & B1 & - & + & + & - & - & - & - & - & - & - & + & I & 20,0 \\
\hline & B2 & + & + & + & + & + & - & + & + & + & + & + & $\mathrm{V}$ & 90,0 \\
\hline & S & 1 & 2 & 1 & 2 & 4 & 1 & + & 4 & 1 & 2 & +-4 & $\mathrm{~V}$ & 100,0 \\
\hline Polygonatum odoratum (Fvl) & $\mathrm{C}$ & + & + & + & + & - & + & + & + & + & 1 & +-1 & $\mathrm{~V}$ & 90,0 \\
\hline \multirow[t]{3}{*}{ Rosa canina agg. (Pru,Prf) } & B1 & - & + & + & + & + & - & - & - & - & - & + & II & 40,0 \\
\hline & B2 & - & - & + & + & - & + & + & + & + & + & + & IV & 70,0 \\
\hline & S & - & + & + & + & + & + & + & + & + & + & + & $\mathrm{V}$ & 90,0 \\
\hline Viola hirta & $\mathrm{C}$ & + & + & 1 & + & + & + & - & + & + & + & +-1 & $\mathrm{~V}$ & 90,0 \\
\hline Vincetoxicum hirundinaria (Fvl) & $\mathrm{C}$ & + & + & + & - & - & + & + & + & + & + & + & IV & 80,0 \\
\hline \multirow[t]{3}{*}{ Euonymus verrucosus (Pru) } & B1 & - & - & - & - & - & + & + & + & - & + & + & II & 40,0 \\
\hline & B2 & - & - & - & + & + & + & + & + & + & + & + & IV & 70,0 \\
\hline & S & - & - & - & + & + & + & + & + & + & + & + & IV & 70,0 \\
\hline \multirow[t]{3}{*}{ Viburnum lantana $(\mathrm{QFt})$} & B1 & - & - & - & - & + & + & + & + & - & - & + & II & 40,0 \\
\hline & B2 & + & - & - & - & - & 1 & + & + & + & + & +-1 & III & 60,0 \\
\hline & $S$ & + & - & - & - & + & 1 & + & + & + & + & +-1 & IV & 70,0 \\
\hline Clematis recta & $\mathrm{C}$ & - & - & - & - & + & + & 1 & + & + & + & +-1 & III & 60,0 \\
\hline \multirow[t]{3}{*}{ Cornus mas $(\mathrm{OCn}, \mathrm{Qc})$} & B1 & - & - & - & - & + & 2 & - & + & + & + & +-2 & III & 50,0 \\
\hline & B2 & - & - & - & - & - & - & + & + & - & - & + & I & 20,0 \\
\hline & $S$ & - & - & - & - & + & 2 & + & + & + & + & +-2 & III & 60,0 \\
\hline Clinopodium vulgare & $\mathrm{C}$ & + & + & + & - & - & + & + & - & - & - & + & III & 50,0 \\
\hline Hylotelephium telephium ssp. maximum & $\mathrm{C}$ & - & - & - & + & + & + & + & - & - & + & + & III & 50,0 \\
\hline Allium oleraceum (Fru) & $\mathrm{C}$ & - & - & - & - & - & - & + & + & + & + & + & II & 40,0 \\
\hline Hieracium sabaudum agg. (Qr) & $\mathrm{C}$ & + & + & + & - & - & + & - & - & - & - & + & II & 40,0 \\
\hline Peucedanum oreoselinum & $\mathrm{C}$ & - & - & - & - & - & + & + & + & - & + & + & II & 40,0 \\
\hline Physalis alkekengi (Ulm) & $\mathrm{C}$ & + & - & - & - & + & - & + & - & + & - & + & II & 40,0 \\
\hline Asparagus officinalis (FBt) & $\mathrm{C}$ & - & - & + & - & + & + & - & - & - & - & + & II & 30,0 \\
\hline Astragalus glycyphyllos & $\mathrm{C}$ & - & + & - & + & + & - & - & - & - & - & + & II & 30,0 \\
\hline Pulmonaria mollissima & $\mathrm{C}$ & - & - & - & - & + & - & + & - & + & - & + & II & 30,0 \\
\hline Thalictrum minus (Fvl) & $\mathrm{C}$ & + & - & - & - & - & - & + & - & - & + & + & II & 30,0 \\
\hline Lactuca quercina ssp. quercina & $\mathrm{C}$ & - & - & - & + & + & - & - & - & - & - & + & I & 20,0 \\
\hline \multirow[t]{3}{*}{ Pyrus pyraster (Cp) } & B1 & - & - & - & - & - & + & - & - & + & - & + & I & 20,0 \\
\hline & B2 & - & - & - & - & - & + & - & - & - & - & + & I & 10,0 \\
\hline & S & - & - & - & - & - & + & - & - & + & - & + & $\mathrm{I}$ & 20,0 \\
\hline Silene nutans & $\mathrm{C}$ & - & - & - & + & - & - & + & - & - & - & + & I & 20,0 \\
\hline Campanula bononiensis (Fvl) & $\mathrm{C}$ & - & - & - & + & - & - & - & - & - & - & + & I & 10,0 \\
\hline Inula salicina (MoA,Fvg) & $\mathrm{C}$ & - & + & - & - & - & - & - & - & - & - & + & I & 10,0 \\
\hline Lithospermum officinale & $\mathrm{C}$ & - & - & - & + & - & - & - & - & - & - & + & $\mathrm{I}$ & 10,0 \\
\hline
\end{tabular}


KEVEY \& BőHM (2017) - Kitaibelia 22 (1): 147-178.

\begin{tabular}{|c|c|c|c|c|c|c|c|c|c|c|c|c|c|c|}
\hline & & 1 & 2 & 3 & 4 & 5 & 6 & 7 & 8 & 9 & 10 & A-D & $\mathbf{K}$ & $\%$ \\
\hline \multicolumn{15}{|l|}{$\begin{array}{l}\text { 1.3.1. Quercetalis cerridis } \\
\text { 1.3.1.1. Aceri tatarici-Quercion }\end{array}$} \\
\hline \multirow[t]{4}{*}{ Acer tataricum (Qpp) } & A2 & - & - & - & - & - & 1 & 1 & - & - & - & 1 & $\mathrm{I}$ & 20,0 \\
\hline & B1 & - & - & - & + & - & - & - & + & - & + & + & II & 30,0 \\
\hline & B2 & + & + & + & + & - & 1 & 1 & + & + & - & +-1 & IV & 80,0 \\
\hline & $\mathrm{S}$ & + & + & + & + & - & 2 & 2 & + & + & + & +-2 & V & 90,0 \\
\hline Melica altissima & $\mathrm{C}$ & - & - & - & - & - & - & + & - & - & - & + & $\mathrm{I}$ & 10,0 \\
\hline Trifolium diffusum (Fru) & $\mathrm{C}$ & - & - & - & - & + & - & - & - & - & - & + & $\mathrm{I}$ & 10,0 \\
\hline \multicolumn{15}{|l|}{ 2. Molinio-Arrhenatherea } \\
\hline Colchicum autumnale (Moa) & $\mathrm{C}$ & 2 & 1 & 1 & + & 2 & + & + & + & + & + & +-2 & $\mathrm{~V}$ & 100,0 \\
\hline Carex tomentosa (Qpp) & $\mathrm{C}$ & - & + & + & - & - & - & - & - & - & - & + & $\mathrm{I}$ & 20,0 \\
\hline \multicolumn{15}{|l|}{ 2.1. Molinio-Juncetea } \\
\hline Allium angulosum & $\mathrm{C}$ & - & + & - & - & - & - & - & - & - & - & + & $\mathrm{I}$ & 10,0 \\
\hline \multicolumn{15}{|l|}{ 2.1.1. Molinietalia coeruleae } \\
\hline Orchis militaris (FBt,Qpp) & $\mathrm{C}$ & + & + & + & - & - & - & - & - & - & - & + & II & 30,0 \\
\hline Thalictrum lucidum (Mag,FiC,Spu,Ate,Ai) & $\mathrm{C}$ & - & + & - & - & - & - & - & - & - & - & + & $\mathrm{I}$ & 10,0 \\
\hline \multicolumn{15}{|l|}{ 2.1.1.1. Deschampsion caespitosae } \\
\hline Galium rubioides (Alo,Qpp) & $\mathrm{C}$ & - & - & - & - & - & - & + & - & - & - & + & I & 10,0 \\
\hline \multirow{2}{*}{\multicolumn{15}{|c|}{$\begin{array}{l}\text { 3. Festuco-Bromea } \\
\text { 3.1. Festuco-Brometea }\end{array}$}} \\
\hline & & & & & & & & & & & & & & \\
\hline Muscari racemosum (Qpp) & $\mathrm{C}$ & + & + & + & + & + & - & - & - & + & - & + & III & 60,0 \\
\hline Verbascum lychnitis (Qpp) & $\mathrm{C}$ & - & + & - & + & + & + & + & - & - & - & + & III & 50,0 \\
\hline Brachypodium pinnatum (Bra,Qpp) & $\mathrm{C}$ & - & + & - & + & - & - & - & - & + & - & + & II & 30,0 \\
\hline Potentilla heptaphylla (NC,Arn,Qpp) & $\mathrm{C}$ & + & - & - & - & - & - & - & - & + & - & + & $\mathrm{I}$ & 20,0 \\
\hline \multicolumn{15}{|l|}{ 3.1.1. Festucetalia valesiacae } \\
\hline Seseli hippomarathrum & $\mathrm{C}$ & - & - & - & + & - & - & - & - & - & - & + & I & 10,0 \\
\hline \multicolumn{15}{|l|}{ 3.1.1.1. Festucion rupicolae } \\
\hline Astragalus cicer (Qpp) & $\mathrm{C}$ & - & + & + & + & - & - & + & - & - & - & + & II & 40,0 \\
\hline \multicolumn{15}{|l|}{ 4. Chenopodio-Scleranthea } \\
\hline Cannabis sativa & $\mathrm{C}$ & - & - & - & + & - & - & + & + & + & + & + & III & 50,0 \\
\hline \multicolumn{15}{|l|}{ 4.1. Secalietea } \\
\hline Muscari comosum (FBt) & $\mathrm{C}$ & - & - & - & + & + & - & - & + & + & + & + & III & 50,0 \\
\hline Silene alba $(\mathrm{Cau}, \mathrm{GA})$ & $\mathrm{C}$ & - & - & - & + & + & + & - & - & - & - & + & II & 30,0 \\
\hline \multicolumn{15}{|l|}{ 4.2. Chenopodietea } \\
\hline Ballota nigra (Ar) & $\mathrm{C}$ & + & - & - & - & + & - & - & - & - & - & + & I & 20,0 \\
\hline Arctium minus (Ar,Bia,Pla) & $\mathrm{C}$ & - & - & - & - & - & - & + & - & - & - & + & I & 10,0 \\
\hline Marrubium vulgare (Onn) & $\mathrm{C}$ & - & - & - & - & + & - & - & - & - & - & + & I & 10,0 \\
\hline \multicolumn{15}{|l|}{ 4.3. Galio-Urticetea } \\
\hline \multicolumn{15}{|l|}{ 4.3.1. Calystegietalia sepium } \\
\hline \multicolumn{15}{|l|}{ 4.3.1.1. Galio-Alliarion } \\
\hline Alliaria petiolata (Epa) & $\mathrm{C}$ & - & - & - & + & + & + & - & + & + & + & + & III & 60,0 \\
\hline
\end{tabular}


KEvEY \& BőHM (2017) - Kitaibelia 22 (1): 147-178.

\begin{tabular}{|c|c|c|c|c|c|c|c|c|c|c|c|c|c|c|}
\hline & & 1 & 2 & 3 & 4 & 5 & 6 & 7 & 8 & 9 & 10 & A-D & $\mathbf{K}$ & $\%$ \\
\hline \multicolumn{15}{|l|}{ 4.3.1.2. Calystegion sepium } \\
\hline Aristolochia clematitis (Sea,Sal) & $\mathrm{C}$ & - & - & - & - & - & + & + & + & - & - & + & II & 30,0 \\
\hline Sisymbrium strictissimum (Ar,Sal) & $\mathrm{C}$ & - & - & - & - & + & - & - & - & - & - & + & $\mathrm{I}$ & 10,0 \\
\hline \multicolumn{15}{|l|}{ 5. Indifferens } \\
\hline Ornithogalum umbellatum (Ara,FBt,Sea) & $\mathrm{C}$ & + & + & + & + & + & - & + & + & + & + & + & $\mathrm{V}$ & 90,0 \\
\hline Rubus caesius (Spu) & B2 & - & + & + & + & - & - & + & + & + & - & + & III & 60,0 \\
\hline Taraxacum officinale agg. (MoA,ChS) & $\mathrm{C}$ & + & + & + & + & - & + & - & - & + & - & + & III & 60,0 \\
\hline Euphorbia cyparissias (FB,ChS,Epa,Qpp) & $\mathrm{C}$ & + & + & + & + & - & - & - & - & - & - & + & II & 40,0 \\
\hline Securigea varia (Ara,FBt,Qpp) & $\mathrm{C}$ & + & + & + & + & - & - & - & - & - & - & + & II & 40,0 \\
\hline Torilis japonica (Ar,GA,Epa,QFt) & $\mathrm{C}$ & - & - & - & + & + & + & - & + & - & - & + & II & 40,0 \\
\hline Hypericum perforatum (NC,FB,Qpp,PP) & $\mathrm{C}$ & - & + & + & - & + & - & - & - & - & - & + & II & 30,0 \\
\hline Galium aparine (Sea,Epa,QFt) & $\mathrm{C}$ & - & - & - & - & - & - & + & - & + & - & + & $\mathrm{I}$ & 20,0 \\
\hline Galium mollugo (MoA,FBt,Qrp,Qpp) & $\mathrm{C}$ & + & - & - & - & - & - & - & - & - & + & + & I & 20,0 \\
\hline Glechoma hederacea (MoA,QFt,Sal,Ai) & $\mathrm{C}$ & - & - & - & - & + & - & + & - & - & - & + & I & 20,0 \\
\hline Pimpinella saxifraga (MoA,FB,Qpp) & $\mathrm{C}$ & + & - & + & - & - & - & - & - & - & - & + & I & 20,0 \\
\hline Poa angustifolia (Ara,FPi,FBt,ChS,Qpp) & $\mathrm{C}$ & - & - & - & + & + & - & - & - & - & - & + & I & 20,0 \\
\hline Sambucus nigra (Epa,US,QFt) & B2 & - & - & - & + & + & - & - & - & - & - & + & I & 20,0 \\
\hline $\begin{array}{l}\text { Centaurea jacea ssp. angustifolia } \\
\text { (MoA,FPe,Fvl,PQ,Qpp) }\end{array}$ & $\mathrm{C}$ & - & - & + & - & - & - & - & - & - & - & + & I & 10,0 \\
\hline Chelidonium majus (Che,Ar,GA,Epa) & $\mathrm{C}$ & - & - & - & - & + & - & - & - & - & - & + & $\mathrm{I}$ & 10,0 \\
\hline Picris hieracioides (Ara,FB,ChS) & $\mathrm{C}$ & - & - & - & - & + & - & - & - & - & - & + & I & 10,0 \\
\hline Plantago lanceolata (MoA,ChS) & $\mathrm{C}$ & - & + & - & - & - & - & - & - & - & - & + & I & 10,0 \\
\hline Potentilla reptans (Mag,MoA,FPi,Bia,Pla) & $\mathrm{C}$ & - & - & - & - & - & - & - & - & + & - & + & $\mathrm{I}$ & 10,0 \\
\hline Silene vulgaris (Ara,Fvl,Qpp) & $\mathrm{C}$ & - & - & - & + & - & - & - & - & - & - & + & I & 10,0 \\
\hline Urtica dioica (Ar,GA,Epa,Spu) & $\mathrm{C}$ & - & - & - & - & - & - & + & - & - & - & + & I & 10,0 \\
\hline \multicolumn{15}{|l|}{ 6. Adventiva } \\
\hline \multirow[t]{4}{*}{ Celtis occidentalis } & $\mathrm{A} 2$ & + & - & - & - & 1 & - & + & - & 1 & - & +-1 & II & 40,0 \\
\hline & B1 & - & - & - & 1 & 1 & + & + & + & 1 & + & +-1 & IV & 70,0 \\
\hline & B2 & + & + & + & 1 & + & + & + & + & + & + & +-1 & $\mathrm{~V}$ & 100,0 \\
\hline & $\mathrm{S}$ & + & + & + & 2 & 2 & + & 1 & + & 2 & + & +-2 & $\mathrm{~V}$ & 100,0 \\
\hline \multirow[t]{5}{*}{ Robinia pseudo-acacia } & A1 & + & - & - & - & - & - & - & + & + & - & + & II & 30,0 \\
\hline & $\mathrm{A} 2$ & 1 & + & - & - & - & + & 1 & - & - & 1 & +-1 & III & 50,0 \\
\hline & B1 & + & + & + & 1 & - & - & - & - & - & - & +-1 & II & 40,0 \\
\hline & B2 & + & + & + & + & + & + & + & - & + & - & + & IV & 80,0 \\
\hline & $S$ & 1 & 1 & + & 1 & + & + & 1 & + & + & 1 & +-1 & $\mathrm{~V}$ & 100,0 \\
\hline Solidago gigantea & $\mathrm{C}$ & + & + & + & + & - & + & + & + & + & - & + & IV & 80,0 \\
\hline Ailanthus altissima & B2 & + & + & + & - & - & + & + & - & + & - & + & III & 60,0 \\
\hline Mahonia aquifolium & $\mathrm{B} 2$ & + & + & + & + & - & + & - & - & - & - & + & III & 50,0 \\
\hline Parthenocissus inserta & B2 & - & + & - & + & - & + & + & - & + & - & + & III & 50,0 \\
\hline Acer negundo & B2 & - & - & - & - & - & + & - & - & + & + & + & II & 30,0 \\
\hline Fraxinus pennsylvanica & B2 & - & + & - & - & - & - & - & - & - & - & + & $\mathrm{I}$ & 10,0 \\
\hline Gleditsia triacanthos & B2 & - & - & - & - & - & - & - & - & + & - & + & I & 10,0 \\
\hline Juglans regia & B1 & - & + & - & - & - & - & - & - & - & - & + & I & 10,0 \\
\hline Morus alba & B2 & - & - & - & - & - & - & + & - & - & - & + & I & 10,0 \\
\hline Padus serotina & B2 & - & + & - & - & - & - & - & - & - & - & + & I & 10,0 \\
\hline Pinus sylvestris & A1 & - & - & - & - & - & 1 & - & - & - & - & 1 & $\mathrm{I}$ & 10,0 \\
\hline
\end{tabular}


2. táblázat. Felvételi adatok az 1. táblázathoz / Table 2. Data of the relevés

\begin{tabular}{|c|c|c|c|c|c|c|c|c|c|c|}
\hline & 1 & 2 & 3 & 4 & 5 & 6 & 7 & 8 & 9 & 10 \\
\hline Minta felvételi sorszáma & 16336 & 16337 & 16338 & 16339 & 16340 & 16341 & 16342 & 16343 & 16344 & 16345 \\
\hline Felvételi évszám 1. & 2012 & 2012 & 2012 & 2012 & 2012 & 2012 & 2012 & 2012 & 2012 & 2012 \\
\hline Felvételi időpont 1. & 04.24 & 04.24 & 04.24 & 04.24 & 04.24 & 04.25 & 04.25 & 04.25 & 04.25 & 04.25 \\
\hline Felvételi évszám 2. & 2012 & 2012 & 2012 & 2012 & 2012 & 2012 & 2012 & 2012 & 2012 & 2012 \\
\hline Felvételi időpont 2. & 06.30 & 06.30 & 06.30 & 06.30 & 06.30 & 06.30 & 06.30 & 06.30 & 06.30 & 06.30 \\
\hline Tengerszint feletti magasság (m) & 105 & 105 & 105 & 105 & 105 & 105 & 105 & 105 & 105 & 105 \\
\hline Lejtőszög (fok) & 0 & 0 & 0 & 0 & 0 & 0 & 0 & 0 & 0 & 0 \\
\hline Felső lombkoronaszint borítása (\%) & 60 & 70 & 70 & 70 & 75 & 85 & 75 & 75 & 80 & 80 \\
\hline Alsó lombkoronaszint borítása (\%) & 25 & 20 & 20 & 20 & 10 & 25 & 10 & 10 & 10 & 10 \\
\hline Cserjeszint borítása (\%) & 60 & 50 & 50 & 50 & 60 & 60 & 60 & 70 & 70 & 70 \\
\hline Újulat borítása (\%) & 20 & 25 & 25 & 25 & 25 & 20 & 15 & 5 & 20 & 5 \\
\hline Gyepszint borítása (\%) & 80 & 70 & 80 & 70 & 60 & 50 & 80 & 80 & 80 & 60 \\
\hline Felső lombkoronaszint magassága (m) & 25 & 25 & 25 & 23 & 25 & 28 & 30 & 28 & 30 & 30 \\
\hline Alsó lombkoronaszint magassága (m) & 18 & 18 & 15 & 15 & 15 & 15 & 17 & 15 & 18 & 15 \\
\hline Cserjeszint magassága $(\mathrm{cm})$ & 2,5 & 2 & 2,5 & 2 & 2,5 & 2,5 & 2,5 & 3 & 3 & 3 \\
\hline Átlagos törzsátmérő (cm) & 45 & 45 & 45 & 45 & 50 & 50 & 60 & 50 & 60 & 60 \\
\hline Felvételi terület nagysága $\left(\mathrm{m}^{2}\right)$ & 1600 & 1600 & 1600 & 1600 & 1600 & 1600 & 1600 & 1600 & 1600 & 1600 \\
\hline
\end{tabular}


KEVEY \& BőHM (2017) - Kitaibelia 22 (1): 147-178.

3. táblázat. Az Alföld zárt homoki tölgyesei / Table 3. Closed dry oak woods on sand in the Alföld

\begin{tabular}{|c|c|c|c|c|c|c|c|c|c|c|c|c|c|}
\hline & \multicolumn{2}{|c|}{ Sztendrei-sz. } & \multicolumn{2}{|c|}{ Szigetköz } & \multicolumn{2}{|c|}{ D-T köze } & \multicolumn{2}{|c|}{ Mezőföld } & \multicolumn{2}{|c|}{ Bakonyalja } & \multicolumn{2}{|c|}{ Nyírség } \\
\hline & & $\mathbf{K}$ & $\%$ & $\mathbf{K}$ & $\%$ & $\mathbf{K}$ & $\%$ & $\mathbf{K}$ & $\%$ & $\mathbf{K}$ & $\%$ & $\mathbf{K}$ & $\%$ \\
\hline \multicolumn{14}{|l|}{$\begin{array}{l}\text { 1. Querco-Fagea } \\
\text { 1.1. Salicetea purpureae } \\
\text { 1.1.1. Salicetalia purpureae } \\
\text { 1.1.1.1. Salicion albae }\end{array}$} \\
\hline Carduus crispus (Cal) & $\mathrm{C}$ & - & - & I & 16 & - & - & - & - & - & - & - & - \\
\hline Cucubalus baccifer (Cal,Ulm) & $\mathrm{C}$ & I & 10 & - & - & IV & 70 & III & 52 & IV & 70 & - & - \\
\hline \multirow[t]{3}{*}{ Humulus lupulus (Cal,Ate,Ai) } & B1 & - & - & - & - & I & 10 & $\mathrm{I}$ & 4 & I & 10 & - & - \\
\hline & $\mathrm{C}$ & II & 40 & I & 4 & II & 40 & II & 24 & III & 50 & - & - \\
\hline & $\mathrm{S}$ & II & 40 & I & 4 & II & 40 & II & 24 & III & 50 & - & - \\
\hline \multicolumn{14}{|l|}{$\begin{array}{l}\text { 1.2. Alnetea glutinosae } \\
\text { 1.2.1. Alnetalia glutinosae }\end{array}$} \\
\hline \multicolumn{14}{|l|}{ 1.3. Querco-Fagetea } \\
\hline \multirow[t]{5}{*}{ Acer campestre (Qpp) } & $\mathrm{A} 1$ & - & - & I & 4 & - & - & I & 8 & I & 10 & III & 46,7 \\
\hline & A2 & I & 10 & III & 52 & - & - & IV & 68 & III & 60 & - & - \\
\hline & B1 & III & 50 & III & 48 & I & 10 & IV & 72 & IV & 80 & III & 46,7 \\
\hline & $\mathrm{B} 2$ & $\mathrm{~V}$ & 90 & $\mathrm{~V}$ & 92 & - & - & IV & 64 & IV & 80 & II & 40 \\
\hline & $\mathrm{S}$ & $\mathrm{V}$ & 90 & $\mathrm{~V}$ & 92 & I & 10 & IV & 76 & $\mathrm{~V}$ & 100 & III & 46,7 \\
\hline Ajuga reptans $(\mathrm{MoA})$ & $\mathrm{C}$ & - & - & - & - & - & - & - & - & II & 40 & - & - \\
\hline Brachypodium sylvaticum (Qpp) & $\mathrm{C}$ & $\mathrm{V}$ & 100 & $\mathrm{~V}$ & 100 & $\mathrm{~V}$ & 100 & $\mathrm{~V}$ & 96 & $\mathrm{~V}$ & 100 & III & 60 \\
\hline Bromus ramosus agg. (Qpp) & $\mathrm{C}$ & - & - & III & 48 & I & 20 & I & 20 & - & - & I & 6,7 \\
\hline Campanula persicifolia (Qpp) & $\mathrm{C}$ & - & - & - & - & - & - & I & 16 & I & 10 & - & - \\
\hline Campanula trachelium (Epa,Cp) & $\mathrm{C}$ & - & - & $\mathrm{V}$ & 96 & - & - & II & 36 & - & - & - & - \\
\hline Carex divulsa ssp. divulsa & $\mathrm{C}$ & - & - & - & - & I & 10 & II & 40 & III & 50 & - & - \\
\hline Carex pairae (Qpp,Epa) & $\mathrm{C}$ & - & - & I & 12 & - & - & I & 8 & - & - & - & - \\
\hline Carex spicata (Qpp,Epa) & $\mathrm{C}$ & - & - & - & - & I & 10 & - & - & - & - & I & 20 \\
\hline Cephalanthera damasonium (Qpp) & $\mathrm{C}$ & - & - & - & - & - & - & I & 4 & - & - & - & - \\
\hline Cephalanthera longifolia & $\mathrm{C}$ & I & 10 & - & - & - & - & - & - & I & 20 & - & - \\
\hline \multirow[t]{4}{*}{ Clematis vitalba (Qpp) } & A2 & - & - & I & 16 & - & - & I & 8 & I & 10 & - & - \\
\hline & B1 & I & 10 & II & 32 & - & - & III & 44 & I & 10 & - & - \\
\hline & $\mathrm{B} 2$ & III & 50 & III & 48 & I & 10 & III & 60 & I & 20 & - & - \\
\hline & $\mathrm{s}$ & III & 50 & IV & 68 & I & 10 & IV & 72 & II & 30 & - & - \\
\hline Convallaria majalis (Qpp) & $\mathrm{C}$ & $\mathrm{V}$ & 100 & $\mathrm{~V}$ & 96 & $\mathrm{~V}$ & 100 & $\mathrm{~V}$ & 84 & - & - & I & 20 \\
\hline \multirow[t]{3}{*}{ Cornus sanguinea (Qpp) } & B1 & IV & 70 & IV & 68 & IV & 80 & IV & 80 & $\mathrm{~V}$ & 90 & III & 53,3 \\
\hline & $\mathrm{B} 2$ & III & 50 & III & 48 & $\mathrm{~V}$ & 90 & IV & 72 & $\mathrm{~V}$ & 90 & I & 20 \\
\hline & $\mathrm{s}$ & IV & 80 & IV & 68 & $\mathrm{~V}$ & 90 & $\mathrm{~V}$ & 88 & $\mathrm{~V}$ & 90 & III & 53,3 \\
\hline \multirow[t]{4}{*}{ Corylus avellana (Qpp) } & $\mathrm{A} 2$ & - & - & I & 4 & - & - & I & 20 & - & - & - & - \\
\hline & B1 & I & 10 & II & 32 & III & 50 & IV & 76 & III & 60 & II & 40 \\
\hline & $\mathrm{B} 2$ & I & 10 & I & 16 & II & 40 & IV & 72 & III & 60 & I & 13,3 \\
\hline & $\mathrm{S}$ & I & 20 & II & 40 & III & 50 & IV & 80 & $\mathrm{~V}$ & 90 & II & 40 \\
\hline \multirow[t]{4}{*}{ Crataegus monogyna (Qpp) } & $\mathrm{A} 2$ & II & 30 & I & 16 & II & 30 & I & 16 & I & 10 & - & - \\
\hline & B1 & $\mathrm{V}$ & 100 & $\mathrm{~V}$ & 96 & $\mathrm{~V}$ & 100 & $\mathrm{~V}$ & 96 & $\mathrm{~V}$ & 100 & $\mathrm{~V}$ & 86,7 \\
\hline & $\mathrm{B} 2$ & $\mathrm{~V}$ & 90 & $\mathrm{~V}$ & 96 & $\mathrm{~V}$ & 90 & $\mathrm{~V}$ & 84 & $\mathrm{~V}$ & 90 & II & 26,7 \\
\hline & $\mathrm{s}$ & $\mathrm{V}$ & 100 & $\mathrm{~V}$ & 100 & $\mathrm{~V}$ & 100 & $\mathrm{~V}$ & 100 & $\mathrm{~V}$ & 100 & $\mathrm{~V}$ & 100 \\
\hline Cruciata glabra & $\mathrm{C}$ & - & - & - & - & - & - & - & - & - & - & $\mathrm{I}$ & 13,3 \\
\hline Dactylis polygama (Qpp,Cp) & $\mathrm{C}$ & II & 30 & II & 40 & III & 50 & $\mathrm{~V}$ & 100 & III & 60 & III & 53,3 \\
\hline \multirow[t]{3}{*}{ Euonymus europaeus (Qpp) } & B1 & - & - & II & 40 & IV & 70 & III & 48 & III & 50 & - & - \\
\hline & $\mathrm{B} 2$ & $\mathrm{~V}$ & 100 & $\mathrm{~V}$ & 92 & $\mathrm{~V}$ & 100 & $\mathrm{~V}$ & 100 & $\mathrm{~V}$ & 100 & IV & 80 \\
\hline & $\mathrm{s}$ & $\mathrm{V}$ & 100 & $\mathrm{~V}$ & 96 & $\mathrm{~V}$ & 100 & $\mathrm{~V}$ & 100 & $\mathrm{~V}$ & 100 & IV & 80 \\
\hline Fallopia dumetorum (Qpp,GA) & B1 & I & 10 & - & - & II & 40 & I & 4 & III & 60 & - & - \\
\hline & $\mathrm{C}$ & $\mathrm{V}$ & 100 & $\mathrm{~V}$ & 88 & $\mathrm{~V}$ & 100 & IV & 80 & $\mathrm{~V}$ & 100 & III & 60 \\
\hline & $\mathrm{s}$ & $\mathrm{V}$ & 100 & $\mathrm{~V}$ & 88 & $\mathrm{~V}$ & 100 & IV & 80 & $\mathrm{~V}$ & 100 & III & 60 \\
\hline Fragaria vesca (Qpp,Epa) & B1 & - & - & - & - & I & 10 & - & - & - & - & - & - \\
\hline & $\mathrm{C}$ & I & 20 & III & 60 & I & 10 & III & 48 & IV & 70 & I & 13,3 \\
\hline & $\mathrm{S}$ & I & 20 & III & 60 & I & 20 & III & 48 & IV & 70 & I & 13,3 \\
\hline
\end{tabular}


KEVEY \& BőHM (2017) - Kitaibelia 22 (1): 147-178.

\begin{tabular}{|c|c|c|c|c|c|c|c|c|c|c|c|c|c|}
\hline & & \multicolumn{2}{|c|}{ Sztendrei-sz. } & \multicolumn{2}{|c|}{ Szigetköz } & \multicolumn{2}{|c|}{ D-T köze } & \multicolumn{2}{|c|}{ Mezőföld } & \multicolumn{2}{|c|}{ Bakonyalja } & \multicolumn{2}{|c|}{ Nyírség } \\
\hline & & $\mathbf{K}$ & $\%$ & $\mathbf{K}$ & $\%$ & $\mathbf{K}$ & $\%$ & $\mathbf{K}$ & $\%$ & $\mathbf{K}$ & $\%$ & $\mathbf{K}$ & $\%$ \\
\hline \multirow[t]{5}{*}{ Fraxinus excelsior (Qpp,TA) } & $\mathrm{A} 1$ & III & 50 & V & 100 & - & - & III & 48 & - & - & - & - \\
\hline & A2 & IV & 70 & $\mathrm{~V}$ & 100 & - & - & III & 56 & - & - & - & - \\
\hline & B1 & IV & 70 & II & 36 & - & - & IV & 76 & II & 30 & - & - \\
\hline & B2 & IV & 80 & $\mathrm{~V}$ & 100 & - & - & IV & 68 & I & 20 & - & - \\
\hline & $S$ & $\mathrm{~V}$ & 100 & $\mathrm{~V}$ & 100 & - & - & IV & 80 & II & 30 & - & - \\
\hline Galeopsis pubescens (Qpp,Epa) & $\mathrm{C}$ & II & 30 & II & 32 & - & - & IV & 68 & $\mathrm{~V}$ & 100 & II & 33,3 \\
\hline Geranium robertianum (Epa) & $\mathrm{C}$ & II & 30 & I & 4 & $\mathrm{~V}$ & 90 & $\mathrm{~V}$ & 92 & $\mathrm{~V}$ & 100 & $\mathrm{~V}$ & 100 \\
\hline Geum urbanum (Epa,Cp,Qpp) & $\mathrm{C}$ & III & 60 & IV & 68 & $\mathrm{~V}$ & 100 & $\mathrm{~V}$ & 96 & $\mathrm{~V}$ & 100 & IV & 80 \\
\hline Heracleum sphondylium (Qpp,MoA) & $\mathrm{C}$ & $\mathrm{I}$ & 10 & II & 24 & - & - & $\mathrm{V}$ & 100 & III & 60 & I & 13,3 \\
\hline Lapsana communis (Qpp,GA,Epa) & $\mathrm{C}$ & - & - & I & 16 & I & 20 & IV & 76 & $\mathrm{~V}$ & 100 & I & 13,3 \\
\hline \multirow[t]{3}{*}{ Ligustrum vulgare (Cp,Qpp) } & B1 & $\mathrm{V}$ & 100 & $\mathrm{~V}$ & 100 & $\mathrm{~V}$ & 100 & $\mathrm{~V}$ & 88 & $\mathrm{~V}$ & 90 & - & - \\
\hline & B2 & $\mathrm{V}$ & 100 & $\mathrm{~V}$ & 96 & $\mathrm{~V}$ & 100 & $\mathrm{~V}$ & 92 & $\mathrm{~V}$ & 100 & I & 20 \\
\hline & $\mathrm{S}$ & $\mathrm{V}$ & 100 & $\mathrm{~V}$ & 100 & $\mathrm{~V}$ & 100 & $\mathrm{~V}$ & 92 & $\mathrm{~V}$ & 100 & I & 20 \\
\hline \multirow[t]{3}{*}{ Lonicera xylosteum (Qpp) } & B1 & I & 10 & II & 28 & - & - & - & - & - & - & - & - \\
\hline & B2 & - & - & I & 4 & - & - & - & - & - & - & - & - \\
\hline & $\mathrm{S}$ & I & 10 & II & 28 & - & - & - & - & - & - & - & - \\
\hline Loranthus europaeus & $\mathrm{A} 1$ & - & - & I & 4 & - & - & I & 20 & I & 20 & II & 26,7 \\
\hline Melica nutans (Qpp) & $\mathrm{C}$ & II & 40 & V & 100 & - & - & - & - & - & - & - & - \\
\hline Melica uniflora (Cp,Qpp) & $\mathrm{C}$ & - & - & - & - & - & - & - & - & I & 10 & - & - \\
\hline Mycelis muralis & $\mathrm{C}$ & I & 20 & I & 8 & I & 10 & II & 28 & IV & 70 & - & - \\
\hline Neottia nidus-avis (F,Qpp) & $\mathrm{C}$ & - & - & I & 12 & I & 10 & - & - & - & - & - & - \\
\hline Platanthera bifolia (Qpp,PQ,NC,Moa) & $\mathrm{C}$ & - & - & I & 4 & - & - & I & 20 & I & 10 & - & - \\
\hline Poa nemoralis (Qpp) & $\mathrm{C}$ & I & 10 & II & 36 & IV & 70 & IV & 68 & III & 60 & I & 13,3 \\
\hline Polygonatum latifolium (Qpp) & $\mathrm{C}$ & $\mathrm{V}$ & 100 & V & 100 & $\mathrm{~V}$ & 100 & $\mathrm{~V}$ & 100 & II & 40 & II & 40 \\
\hline \multirow[t]{5}{*}{ Populus tremula (Qr,Qc,Ber) } & $\mathrm{A} 1$ & - & - & - & - & I & 10 & II & 28 & I & 10 & - & - \\
\hline & $\mathrm{A} 2$ & - & - & - & - & - & - & I & 8 & - & - & - & - \\
\hline & B1 & - & - & - & - & I & 20 & I & 4 & - & - & - & - \\
\hline & B2 & - & - & - & - & I & 20 & II & 28 & - & - & - & - \\
\hline & $S$ & - & - & - & - & II & 30 & II & 32 & I & 10 & - & - \\
\hline Primula veris (Qpp,Ara) & $\mathrm{C}$ & I & 10 & - & - & - & - & - & - & - & - & - & - \\
\hline \multirow[t]{3}{*}{ Quercus petraea agg. (Qpp) } & A1 & - & - & - & - & - & - & - & - & II & 30 & - & - \\
\hline & $\mathrm{A} 2$ & - & - & - & - & - & - & - & - & I & 20 & - & - \\
\hline & $\mathrm{S}$ & - & - & - & - & - & - & - & - & II & 30 & - & - \\
\hline \multirow[t]{5}{*}{ Quercus robur (Ai,Cp,Qpp) } & $\mathrm{A} 1$ & $\mathrm{~V}$ & 100 & IV & 72 & $\mathrm{~V}$ & 100 & V & 100 & IV & 80 & V & 100 \\
\hline & $\mathrm{A} 2$ & III & 50 & II & 36 & II & 40 & II & 40 & III & 50 & - & - \\
\hline & B1 & - & - & I & 16 & I & 10 & I & 8 & - & - & - & - \\
\hline & B2 & IV & 80 & IV & 72 & $\mathrm{~V}$ & 90 & IV & 80 & III & 60 & II & 33,3 \\
\hline & $S$ & $\mathrm{~V}$ & 100 & $\mathrm{~V}$ & 92 & $\mathrm{~V}$ & 100 & $\mathrm{~V}$ & 100 & IV & 80 & $\mathrm{~V}$ & 100 \\
\hline Ranunculus ficaria & $\mathrm{C}$ & - & - & I & 12 & - & - & IV & 76 & $\mathrm{~V}$ & 100 & - & - \\
\hline \multirow[t]{4}{*}{ Rhamnus catharticus (Qpp,Pru) } & $\mathrm{A} 2$ & I & 10 & - & - & - & - & - & - & I & 10 & - & - \\
\hline & B1 & II & 40 & II & 28 & III & 60 & IV & 76 & I & 20 & - & - \\
\hline & B2 & $\mathrm{V}$ & 100 & $\mathrm{~V}$ & 88 & III & 50 & IV & 80 & III & 60 & - & - \\
\hline & $S$ & $\mathrm{~V}$ & 100 & $\mathrm{~V}$ & 88 & $\mathrm{~V}$ & 90 & $\mathrm{~V}$ & 84 & III & 60 & - & - \\
\hline Scrophularia nodosa (GA,Epa) & $\mathrm{C}$ & - & - & - & - & I & 10 & II & 28 & III & 50 & - & - \\
\hline Smyrnium perfoliatum (GA) & $\mathrm{C}$ & - & - & - & - & - & - & I & 16 & - & - & - & - \\
\hline Symphytum tuberosum (Cp,Qpp) & $\mathrm{C}$ & - & - & - & - & I & 10 & I & 4 & II & 30 & - & - \\
\hline Tilia cordata (Cp,Qpp) & $\mathrm{A} 1$ & - & - & I & 12 & - & - & - & - & - & - & I & 6,7 \\
\hline & $\mathrm{A} 2$ & - & - & I & 16 & - & - & I & 4 & IV & 70 & - & - \\
\hline & B1 & I & 10 & I & 12 & - & - & - & - & $\mathrm{V}$ & 90 & - & - \\
\hline & B2 & I & 10 & II & 28 & - & - & - & - & III & 60 & - & - \\
\hline & $\mathrm{S}$ & I & 10 & II & 40 & - & - & I & 4 & $\mathrm{~V}$ & 100 & I & 6,7 \\
\hline Ulmus minor (Ai,Ulm,Qpp) & $\mathrm{A} 1$ & - & - & I & 8 & - & - & I & 4 & - & - & III & 46,7 \\
\hline & $\mathrm{A} 2$ & I & 20 & III & 60 & I & 10 & IV & 80 & I & 10 & - & - \\
\hline & B1 & II & 40 & IV & 80 & I & 20 & $\mathrm{~V}$ & 100 & I & 20 & III & 53,3 \\
\hline & B2 & IV & 80 & $\mathrm{~V}$ & 100 & II & 30 & $\mathrm{~V}$ & 96 & I & 10 & III & 46,7 \\
\hline & $\mathrm{S}$ & IV & 80 & $\mathrm{~V}$ & 100 & II & 30 & $\mathrm{~V}$ & 100 & I & 20 & $\mathrm{~V}$ & 86,7 \\
\hline Veronica chamaedrys (Qpp,Ara) & $\mathrm{C}$ & - & - & - & - & - & - & II & 32 & IV & 70 & I & 6,7 \\
\hline
\end{tabular}


KEvEY \& BőHM (2017) - Kitaibelia 22 (1): 147-178.

\begin{tabular}{|c|c|c|c|c|c|c|c|c|c|c|c|c|c|}
\hline & & \multicolumn{2}{|c|}{ Sztendrei-sz. } & \multicolumn{2}{|c|}{ Szigetköz } & \multicolumn{2}{|c|}{ D-T köze } & \multicolumn{2}{|c|}{ Mezőföld } & \multicolumn{2}{|c|}{ Bakonyalja } & \multicolumn{2}{|c|}{ Nyírség } \\
\hline & & $\mathbf{K}$ & $\%$ & $\mathbf{K}$ & $\%$ & $\mathbf{K}$ & $\%$ & $\mathbf{K}$ & $\%$ & $\mathbf{K}$ & $\%$ & $\mathbf{K}$ & $\%$ \\
\hline Veronica sublobata & $\mathrm{C}$ & I & 10 & I & 4 & $\mathrm{~V}$ & 90 & III & 60 & IV & 80 & - & - \\
\hline Vicia sepium (Ara,Qpp) & $\mathrm{C}$ & - & - & - & - & - & - & - & - & I & 20 & I & 20 \\
\hline Viola alba (Qpp) & $\mathrm{C}$ & - & - & II & 36 & - & - & - & - & - & - & - & - \\
\hline Viola mirabilis $(\mathrm{F}, \mathrm{Qpp})$ & $\mathrm{C}$ & IV & 80 & $\mathrm{~V}$ & 100 & - & - & - & - & II & 30 & - & - \\
\hline Viola odorata & $\mathrm{C}$ & - & - & II & 32 & - & - & - & - & - & - & II & 33,3 \\
\hline Viola suavis s.l. (Qpp) & $\mathrm{C}$ & III & 60 & $\mathrm{~V}$ & 100 & IV & 80 & III & 56 & I & 10 & II & 40 \\
\hline \multicolumn{13}{|l|}{ 1.3.1. Fagetalia sylvaticae } & - \\
\hline \multirow[t]{5}{*}{ Acer platanoides $(\mathrm{TA})$} & $\mathrm{A} 1$ & - & - & I & 8 & - & - & I & 4 & I & 10 & - & - \\
\hline & $\mathrm{A} 2$ & - & - & I & 8 & - & - & - & - & - & - & - & - \\
\hline & B1 & - & - & - & - & - & - & I & 4 & I & 10 & - & - \\
\hline & B2 & II & 40 & III & 52 & I & 10 & I & 4 & I & 10 & - & - \\
\hline & $\mathrm{S}$ & II & 40 & III & 56 & I & 10 & I & 4 & I & 10 & - & - \\
\hline \multirow[t]{5}{*}{ Acer pseudo-platanus (TA) } & $\mathrm{A} 1$ & - & - & I & 8 & - & - & - & - & - & - & - & - \\
\hline & $\mathrm{A} 2$ & - & - & I & 8 & - & - & I & 4 & - & - & - & - \\
\hline & B1 & - & - & II & 28 & - & - & I & 4 & I & 10 & I & 6,7 \\
\hline & B2 & I & 10 & II & 40 & - & - & I & 8 & I & 10 & I & 6,7 \\
\hline & $\mathrm{S}$ & I & 10 & III & 44 & - & - & I & 8 & I & 10 & I & 13,3 \\
\hline Actaea spicata $(\mathrm{EuF}, \mathrm{TA})$ & $\mathrm{C}$ & - & - & - & - & - & - & - & - & - & - & I & 6,7 \\
\hline Aegopodium podagraria $(\mathrm{Ai}, \mathrm{Cp})$ & $\mathrm{C}$ & - & - & - & - & - & - & - & - & I & 10 & - & - \\
\hline Allium ursinum & $\mathrm{C}$ & - & - & I & 4 & - & - & - & - & - & - & - & - \\
\hline Anemone ranunculoides & $\mathrm{C}$ & - & - & III & 52 & - & - & - & - & - & - & - & - \\
\hline Arum maculatum & $\mathrm{C}$ & - & - & III & 48 & - & - & - & - & - & - & I & 13,3 \\
\hline Arum orientale & $\mathrm{C}$ & - & - & - & - & - & - & IV & 64 & I & 10 & - & - \\
\hline Asarum europaeum & $\mathrm{C}$ & - & - & I & 8 & - & - & - & - & - & - & - & - \\
\hline Athyrium filix-femina $(\mathrm{Qr}, \mathrm{VP})$ & $\mathrm{C}$ & - & - & - & - & - & - & - & - & - & - & II & 26,7 \\
\hline Cardamine bulbifera & $\mathrm{C}$ & I & 10 & - & - & - & - & I & 4 & - & - & - & - \\
\hline Cardamine impatiens & $\mathrm{C}$ & - & - & I & 8 & - & - & - & - & IV & 80 & - & - \\
\hline Carex pilosa $(\mathrm{Cp})$ & $\mathrm{C}$ & - & - & I & 4 & - & - & - & - & - & - & - & - \\
\hline Carex sylvatica & $\mathrm{C}$ & - & - & I & 20 & - & - & III & 44 & III & 50 & I & 6,7 \\
\hline \multirow[t]{4}{*}{ Carpinus betulus (Cp) } & A2 & - & - & - & - & - & - & - & - & II & 30 & - & - \\
\hline & B1 & - & - & I & 8 & - & - & I & 4 & $\mathrm{~V}$ & 90 & - & - \\
\hline & B2 & I & 10 & I & 12 & I & 10 & I & 16 & IV & 80 & - & - \\
\hline & $\mathrm{S}$ & I & 10 & I & 12 & I & 10 & I & 20 & $\mathrm{~V}$ & 100 & - & - \\
\hline \multirow[t]{5}{*}{ Cerasus avium $(\mathrm{Cp})$} & $\mathrm{A} 1$ & - & - & I & 4 & - & - & - & - & I & 10 & V & 86,7 \\
\hline & $\mathrm{A} 2$ & - & - & - & - & - & - & I & 4 & - & - & - & - \\
\hline & B1 & - & - & - & - & - & - & I & 4 & II & 30 & II & 33,3 \\
\hline & B2 & I & 20 & I & 4 & - & - & II & 36 & IV & 70 & II & 40 \\
\hline & $\mathrm{S}$ & I & 20 & I & 8 & - & - & II & 36 & IV & 80 & V & 86,7 \\
\hline Circaea lutetiana (Ai) & $\mathrm{C}$ & - & - & - & - & I & 10 & IV & 68 & $\mathrm{~V}$ & 100 & V & 86,7 \\
\hline Corydalis cava & C & - & - & I & 4 & - & - & III & 44 & - & - & - & - \\
\hline Corydalis intermedia & $\mathrm{C}$ & - & - & - & - & - & - & - & - & I & 10 & - & - \\
\hline Corydalis pumila (Cp,Qpp) & $\mathrm{C}$ & - & - & - & - & - & - & II & 32 & II & 30 & - & - \\
\hline Corydalis solida & $\mathrm{C}$ & I & 10 & - & - & - & - & - & - & - & - & - & - \\
\hline Dryopteris filix-mas & $\mathrm{C}$ & - & - & - & - & - & - & I & 4 & III & 50 & II & 40 \\
\hline Epipactis helleborine agg. & $\mathrm{C}$ & - & - & I & 16 & I & 10 & I & 4 & I & 10 & - & - \\
\hline \multirow[t]{3}{*}{ Fagus sylvatica (EuF) } & $\mathrm{A} 1$ & - & - & - & - & - & - & - & - & I & 10 & - & - \\
\hline & B2 & - & - & - & - & - & - & - & - & I & 20 & - & - \\
\hline & $\mathrm{S}$ & - & - & - & - & - & - & - & - & II & 30 & - & - \\
\hline Galanthus nivalis & $\mathrm{C}$ & - & - & IV & 64 & - & - & - & - & - & - & - & - \\
\hline Galeopsis speciosa (Epn,Ai) & $\mathrm{C}$ & - & - & I & 12 & I & 10 & - & - & I & 10 & II & 33,3 \\
\hline Galium odoratum & $\mathrm{C}$ & - & - & II & 32 & - & - & II & 24 & I & 10 & - & - \\
\hline Galium sylvaticum $(\mathrm{Cp}, \mathrm{Qr}, \mathrm{PQ})$ & $\mathrm{C}$ & - & - & - & - & - & - & - & - & I & 10 & - & - \\
\hline Geranium phaeum & $\mathrm{C}$ & - & - & - & - & - & - & - & - & I & 20 & I & 6,7 \\
\hline Glechoma hirsuta (Cp) & $\mathrm{C}$ & - & - & - & - & - & - & II & 32 & $\mathrm{I}$ & 20 & - & - \\
\hline
\end{tabular}


KEVEY \& BőHM (2017) - Kitaibelia 22 (1): 147-178.

\begin{tabular}{|c|c|c|c|c|c|c|c|c|c|c|c|c|c|}
\hline & & \multicolumn{2}{|c|}{ Sztendrei-sz. } & \multicolumn{2}{|c|}{ Szigetköz } & \multicolumn{2}{|c|}{ D-T köze } & \multicolumn{2}{|c|}{ Mezőföld } & \multicolumn{2}{|c|}{ Bakonyalja } & \multicolumn{2}{|c|}{ Nyírség } \\
\hline & & $\mathbf{K}$ & $\%$ & $\mathbf{K}$ & $\%$ & $\mathbf{K}$ & $\%$ & $\mathbf{K}$ & $\%$ & $\mathbf{K}$ & $\%$ & $\mathbf{K}$ & $\%$ \\
\hline \multirow[t]{5}{*}{ Hedera helix } & $\mathrm{A} 1$ & - & - & I & 4 & - & - & - & - & - & - & - & - \\
\hline & A2 & I & 20 & I & 4 & - & - & I & 8 & I & 20 & - & - \\
\hline & B1 & I & 10 & I & 8 & - & - & I & 8 & I & 10 & - & - \\
\hline & B2 & V & 90 & II & 32 & I & 10 & I & 12 & I & 20 & - & - \\
\hline & $S$ & V & 90 & II & 32 & I & 10 & I & 12 & I & 20 & - & - \\
\hline Knautia drymeia (Cp) & $\mathrm{C}$ & - & - & - & - & - & - & - & - & $\mathrm{V}$ & 100 & - & - \\
\hline Milium effusum & $\mathrm{C}$ & - & - & - & - & - & - & - & - & - & - & IV & 80 \\
\hline Moehringia trinervia & $\mathrm{C}$ & - & - & I & 12 & III & 50 & II & 32 & $\mathrm{~V}$ & 100 & I & 6,7 \\
\hline Myosotis sparsiflora (GA,Cp) & $\mathrm{C}$ & - & - & - & - & - & - & - & - & I & 10 & I & 13,3 \\
\hline Paris quadrifolia (Ate,Ai) & $\mathrm{C}$ & - & - & - & - & - & - & - & - & II & 30 & - & - \\
\hline Pimpinella major (Ara,Ai,Qrp,FiC) & $\mathrm{C}$ & - & - & I & 12 & - & - & - & - & - & - & - & - \\
\hline Polygonatum multiflorum (QFt) & $\mathrm{C}$ & - & - & IV & 72 & - & - & - & - & $\mathrm{V}$ & 100 & - & - \\
\hline Primula vulgaris $(\mathrm{AF})$ & $\mathrm{C}$ & - & - & - & - & - & - & - & - & II & 40 & - & - \\
\hline Pulmonaria officinalis & $\mathrm{C}$ & - & - & II & 32 & - & - & I & 4 & I & 20 & - & - \\
\hline \multirow[t]{3}{*}{ Ribes uva-crispa (Ai,TA,Pru) } & B1 & - & - & - & - & - & - & - & - & I & 10 & - & - \\
\hline & B2 & I & 10 & - & - & - & - & I & 4 & - & - & - & - \\
\hline & $\mathrm{S}$ & I & 10 & - & - & - & - & I & 4 & I & 10 & - & - \\
\hline Salvia glutinosa & $\mathrm{C}$ & - & - & I & 4 & - & - & - & - & II & 30 & $\mathrm{~V}$ & 100 \\
\hline Scilla vindobonensis $(\mathrm{Ai}, \mathrm{Cp})$ & $\mathrm{C}$ & - & - & $\mathrm{V}$ & 96 & - & - & I & 4 & - & - & - & - \\
\hline Stachys sylvatica (Epa) & $\mathrm{C}$ & II & 30 & I & 16 & - & - & V & 84 & V & 100 & V & 93,3 \\
\hline \multirow[t]{4}{*}{ Ulmus glabra (TA) } & $\mathrm{A} 2$ & - & - & I & 4 & - & - & I & 8 & - & - & - & - \\
\hline & B1 & - & - & I & 16 & - & - & I & 4 & II & 30 & - & - \\
\hline & $\mathrm{B} 2$ & - & - & I & 16 & - & - & I & 8 & II & 40 & - & - \\
\hline & $\mathrm{S}$ & - & - & II & 24 & - & - & I & 8 & III & 50 & - & - \\
\hline Vinca minor (Cp) & $\mathrm{C}$ & - & - & - & - & - & - & I & 12 & - & - & - & - \\
\hline Viola reichenbachiana & $\mathrm{C}$ & - & - & I & 8 & II & 40 & II & 40 & IV & 80 & - & - \\
\hline Viola riviniana (Qr,PQ) & $\mathrm{C}$ & - & - & I & 8 & I & 20 & I & 4 & I & 10 & - & - \\
\hline \multicolumn{14}{|l|}{ 1.3.1.1. Alnion incanae } \\
\hline Carex brizoides (Ate) & $\mathrm{C}$ & - & - & - & - & - & - & - & - & I & 10 & - & - \\
\hline Dipsacus pilosus (GA) & $\mathrm{C}$ & - & - & - & - & - & - & - & - & II & 30 & - & - \\
\hline Elymus caninus (Pna,Qpp) & $\mathrm{C}$ & I & 10 & I & 12 & IV & 70 & $\mathrm{~V}$ & 84 & - & - & III & 53,3 \\
\hline Festuca gigantea (Cal,Epa) & $\mathrm{C}$ & - & - & - & - & - & - & I & 12 & $\mathrm{~V}$ & 90 & II & 40 \\
\hline \multirow[t]{3}{*}{ Frangula alnus (Ate,Qr,PQ) } & B1 & - & - & - & - & II & 30 & I & 12 & III & 50 & - & - \\
\hline & B2 & I & 10 & - & - & I & 10 & I & 12 & IV & 70 & - & - \\
\hline & $\mathrm{S}$ & I & 10 & - & - & II & 30 & I & 20 & IV & 70 & - & - \\
\hline \multirow[t]{5}{*}{ Fraxinus angustifolia ssp. danubialis (Ate) } & A1 & - & - & - & - & I & 20 & - & - & - & - & - & - \\
\hline & $\mathrm{A} 2$ & - & - & - & - & I & 20 & - & - & - & - & - & - \\
\hline & B1 & - & - & - & - & I & 20 & - & - & - & - & - & - \\
\hline & B2 & - & - & - & - & II & 40 & - & - & - & - & - & - \\
\hline & $\mathrm{S}$ & - & - & - & - & II & 40 & - & - & - & - & - & - \\
\hline Impatiens noli-tangere (Sal) & $\mathrm{C}$ & - & - & - & - & - & - & - & - & II & 30 & - & - \\
\hline \multirow[t]{4}{*}{ Malus sylvestris (Qpp) } & $\mathrm{A} 2$ & I & 10 & I & 16 & I & 10 & I & 20 & I & 20 & - & - \\
\hline & B1 & - & - & I & 8 & - & - & I & 12 & $\mathrm{I}$ & 20 & I & 6,7 \\
\hline & B2 & - & - & II & 28 & - & - & II & 36 & III & 60 & - & - \\
\hline & $\mathrm{S}$ & I & 10 & II & 40 & I & 10 & III & 44 & III & 60 & I & 6,7 \\
\hline \multirow[t]{3}{*}{ Padus avium } & B1 & - & - & - & - & - & - & I & 12 & - & - & - & - \\
\hline & B2 & - & - & - & - & - & - & I & 8 & - & - & - & - \\
\hline & $\mathrm{S}$ & - & - & - & - & - & - & I & 20 & - & - & - & - \\
\hline Populus alba (Sal,AQ) & $\mathrm{A} 1$ & I & 10 & I & 8 & III & 50 & I & 20 & - & - & - & - \\
\hline & B1 & I & 10 & I & 8 & I & 10 & - & - & - & - & - & - \\
\hline & B2 & - & - & I & 20 & II & 40 & I & 20 & - & - & - & - \\
\hline & $S$ & I & 20 & I & 20 & III & 60 & II & 28 & - & - & - & - \\
\hline Populus $\times$ canescens $(\mathrm{Sal}, \mathrm{AQ})$ & $\mathrm{A} 1$ & I & 10 & - & - & - & - & I & 4 & - & - & I & 13,3 \\
\hline & B1 & I & 20 & - & - & - & - & - & - & - & - & - & - \\
\hline & $\mathrm{S}$ & II & 30 & - & - & - & - & $\mathrm{I}$ & 4 & - & - & I & 13,3 \\
\hline
\end{tabular}


KEVEY \& BőHM (2017) - Kitaibelia 22 (1): 147-178.

\begin{tabular}{|c|c|c|c|c|c|c|c|c|c|c|c|c|c|}
\hline & & \multicolumn{2}{|c|}{ Sztendrei-sz. } & \multicolumn{2}{|c|}{ Szigetköz } & \multicolumn{2}{|c|}{ D-T köze } & \multicolumn{2}{|c|}{ Mezőföld } & \multicolumn{2}{|c|}{ Bakonyalja } & \multicolumn{2}{|c|}{ Nyírség } \\
\hline & & $\mathbf{K}$ & $\%$ & $\mathbf{K}$ & $\%$ & $\mathbf{K}$ & $\%$ & $\mathbf{K}$ & $\%$ & $\mathbf{K}$ & $\%$ & $\mathbf{K}$ & $\%$ \\
\hline \multirow[t]{3}{*}{ Ribes rubrum } & B1 & - & - & - & - & - & - & - & - & $\mathrm{I}$ & 10 & - & - \\
\hline & B2 & I & 10 & - & - & - & - & I & 12 & - & - & - & - \\
\hline & $\mathrm{S}$ & I & 10 & - & - & - & - & I & 12 & I & 10 & - & - \\
\hline Rumex sanguineus (Epa,Pna) & $\mathrm{C}$ & - & - & - & - & - & - & II & 28 & III & 60 & - & - \\
\hline \multirow[t]{5}{*}{ Ulmus laevis (Sal,Ulm) } & A1 & - & - & - & - & - & - & - & - & - & - & II & 26,7 \\
\hline & $\mathrm{A} 2$ & - & - & - & - & I & 10 & - & - & - & - & - & - \\
\hline & B1 & - & - & - & - & I & 10 & - & - & - & - & III & 53,3 \\
\hline & B2 & - & - & - & - & I & 20 & - & - & - & - & - & - \\
\hline & $\mathrm{S}$ & - & - & - & - & I & 20 & - & - & - & - & IV & 66,7 \\
\hline \multirow[t]{3}{*}{ Viburnum opulus (Ate) } & B1 & I & 10 & - & - & - & - & - & - & I & 10 & - & - \\
\hline & B2 & I & 10 & I & 4 & II & 30 & II & 24 & II & 30 & I & 6,7 \\
\hline & $\mathrm{S}$ & I & 20 & I & 4 & II & 30 & II & 24 & II & 30 & I & 6,7 \\
\hline Viola elatior (Moa) & $\mathrm{C}$ & - & - & I & 4 & - & - & - & - & - & - & - & - \\
\hline \multirow[t]{4}{*}{ Vitis sylvestris (Ulm) } & $\mathrm{A} 2$ & - & - & I & 4 & - & - & I & 4 & - & - & - & - \\
\hline & B1 & - & - & - & - & - & - & I & 4 & - & - & - & - \\
\hline & B2 & - & - & I & 4 & I & 10 & I & 8 & - & - & - & - \\
\hline & $S$ & - & - & I & 8 & I & 10 & I & 8 & - & - & - & - \\
\hline \multirow{2}{*}{\multicolumn{14}{|c|}{$\begin{array}{l}\text { 1.3.1.2. Fagion sylvaticae } \\
\text { 1.3.1.2.1. Tilio-Acerenion }\end{array}$}} \\
\hline & & & & & & & & & & & & & \\
\hline Geranium lucidum (GA) & $\mathrm{C}$ & - & - & - & - & - & - & I & 4 & - & - & - & - \\
\hline \multirow[t]{5}{*}{ Tilia platyphyllos $(\mathrm{F})$} & $\mathrm{A} 1$ & - & - & I & 8 & - & - & - & - & - & - & I & 6,7 \\
\hline & A2 & I & 10 & I & 4 & - & - & - & - & I & 10 & - & - \\
\hline & B1 & I & 10 & - & - & - & - & - & - & - & - & - & - \\
\hline & B2 & I & 10 & I & 8 & I & 10 & - & - & I & 10 & - & - \\
\hline & $S$ & I & 20 & I & 8 & I & 10 & - & - & I & 20 & I & 6,7 \\
\hline \multicolumn{14}{|l|}{ 1.3.1.3. Aremonio-Fagion } \\
\hline Tilia tomentosa $(\mathrm{Qfa})$ & $\mathrm{A} 1$ & - & - & - & - & - & - & - & - & - & - & I & 13,3 \\
\hline \multicolumn{14}{|l|}{ 1.3.2. Quercetalia roboris } \\
\hline Hieracium murorum agg. (PQ,QFt,Qpp) & $\mathrm{C}$ & - & - & I & 4 & - & - & - & - & - & - & - & - \\
\hline Pteridium aquilinum (PQ) & $\mathrm{C}$ & - & - & - & - & - & - & - & - & III & 50 & I & 13,3 \\
\hline Veronica officinalis (PQ,NC,PP,Epa) & $\mathrm{C}$ & - & - & - & - & - & - & - & - & I & 10 & - & - \\
\hline 1.3.2.1. Quercion robori-petraeae & & & & & & & & & & & & & \\
\hline Lysimachia punctata (Qp,Epa) & $\mathrm{C}$ & - & - & - & - & - & - & I & 4 & II & 40 & - & - \\
\hline 1.4. Quercetea pubescentis-petraeae & & & & & & & & & & & & & \\
\hline Allium oleraceum (Fru) & $\mathrm{C}$ & II & 40 & III & 44 & I & 20 & III & 56 & II & 30 & - & - \\
\hline Asparagus officinalis (FBt) & $\mathrm{C}$ & II & 30 & - & - & I & 20 & I & 12 & I & 10 & - & - \\
\hline Astragalus glycyphyllos & $\mathrm{C}$ & II & 30 & III & 60 & II & 30 & II & 40 & $\mathrm{~V}$ & 100 & I & 6,7 \\
\hline Berberis vulgaris (Pru) & B1 & $\mathrm{V}$ & 90 & $\mathrm{~V}$ & 84 & IV & 70 & I & 16 & - & - & - & - \\
\hline & B2 & $\mathrm{V}$ & 90 & $\mathrm{~V}$ & 84 & III & 60 & I & 8 & - & - & - & - \\
\hline & $\mathrm{S}$ & $\mathrm{V}$ & 100 & $\mathrm{~V}$ & 100 & IV & 80 & I & 20 & - & - & - & - \\
\hline Betonica officinalis (MoA) & $\mathrm{C}$ & - & - & - & - & - & - & I & 4 & I & 10 & - & - \\
\hline Buglossoides purpuro-coerulea $(\mathrm{OCn}, \mathrm{AQ})$ & $\mathrm{C}$ & $\mathrm{V}$ & 100 & $\mathrm{~V}$ & 92 & I & 20 & $\mathrm{~V}$ & 92 & - & - & - & - \\
\hline Campanula bononiensis (Fvl) & $\mathrm{C}$ & I & 10 & - & - & - & - & I & 8 & - & - & - & - \\
\hline Carex michelii & $\mathrm{C}$ & $\mathrm{V}$ & 100 & III & 44 & II & 30 & I & 20 & I & 10 & - & - \\
\hline Clematis recta & $\mathrm{C}$ & III & 60 & II & 40 & - & - & I & 8 & - & - & - & - \\
\hline Clinopodium vulgare & $\mathrm{C}$ & III & 50 & IV & 68 & IV & 80 & II & 40 & III & 60 & I & 13,3 \\
\hline Cornus mas $(\mathrm{OCn}, \mathrm{Qc})$ & A2 & - & - & I & 4 & - & - & - & - & - & - & - & - \\
\hline & B1 & III & 50 & $\mathrm{~V}$ & 100 & - & - & II & 36 & - & - & I & 6,7 \\
\hline & B2 & I & 20 & IV & 76 & - & - & II & 36 & - & - & - & - \\
\hline & $S$ & III & 60 & $\mathrm{~V}$ & 100 & - & - & II & 40 & - & - & I & 6,7 \\
\hline Dictamnus albus (Fvl) & $\mathrm{C}$ & - & - & - & - & - & - & I & 8 & - & - & - & - \\
\hline Doronicum hungaricum (AQ) & $\mathrm{C}$ & - & - & - & - & - & - & I & 16 & - & - & - & - \\
\hline Euonymus verrucosus (Pru) & B1 & II & 40 & I & 12 & - & - & II & 40 & - & - & - & - \\
\hline & B2 & IV & 70 & I & 16 & - & - & III & 44 & I & 10 & - & - \\
\hline & $\mathrm{S}$ & IV & 70 & $\mathrm{I}$ & 16 & - & - & III & 52 & $\mathrm{I}$ & 10 & - & - \\
\hline
\end{tabular}


KEVEY \& BőHM (2017) - Kitaibelia 22 (1): 147-178.

\begin{tabular}{|c|c|c|c|c|c|c|c|c|c|c|c|c|c|}
\hline & & \multicolumn{2}{|c|}{ Sztendrei-sz. } & \multicolumn{2}{|c|}{ Szigetköz } & \multicolumn{2}{|c|}{ D-T köze } & \multicolumn{2}{|c|}{ Mezőföld } & \multicolumn{2}{|c|}{ Bakonyalja } & \multicolumn{2}{|c|}{ Nyírség } \\
\hline & & $\mathbf{K}$ & $\%$ & $\mathbf{K}$ & $\%$ & $\mathbf{K}$ & $\%$ & $\mathbf{K}$ & $\%$ & $\mathbf{K}$ & $\%$ & $\mathbf{K}$ & $\%$ \\
\hline \multirow[t]{4}{*}{ Fraxinus ornus (OCn) } & A2 & - & - & I & 8 & - & - & I & 4 & I & 10 & - & - \\
\hline & B1 & - & - & I & 8 & - & - & I & 12 & - & - & - & - \\
\hline & B2 & - & - & I & 12 & - & - & I & 16 & I & 10 & - & - \\
\hline & $\mathrm{S}$ & - & - & I & 12 & - & - & I & 20 & I & 10 & - & - \\
\hline Geranium divaricatum (GA) & $\mathrm{C}$ & - & - & - & - & - & - & I & 4 & - & - & - & - \\
\hline Hieracium sabaudum agg. (Qr) & $\mathrm{C}$ & II & 40 & I & 12 & - & - & I & 8 & III & 50 & - & - \\
\hline Hylotelephium telephium ssp. maximum & $\mathrm{C}$ & III & 50 & - & - & III & 50 & II & 24 & I & 20 & - & - \\
\hline Inula conyza & $\mathrm{C}$ & - & - & III & 48 & - & - & - & - & - & - & - & - \\
\hline Inula salicina (MoA,Fvg) & $\mathrm{C}$ & I & 10 & I & 20 & - & - & I & 8 & - & - & - & - \\
\hline Iris variegata $(\mathrm{Fvl})$ & $\mathrm{C}$ & - & - & II & 24 & II & 40 & II & 32 & - & - & - & - \\
\hline Lactuca quercina ssp. quercina & $\mathrm{C}$ & I & 20 & III & 60 & II & 30 & - & - & - & - & - & - \\
\hline Lactuca quercina ssp. sagittata & $\mathrm{C}$ & - & - & - & - & - & - & I & 16 & - & - & - & - \\
\hline Lathyrus niger (Qc) & $\mathrm{C}$ & - & - & - & - & I & 10 & I & 8 & I & 10 & - & - \\
\hline Libanotis pyrenaica & $\mathrm{C}$ & - & - & I & 4 & - & - & - & - & - & - & - & - \\
\hline Lithospermum officinale & $\mathrm{C}$ & I & 10 & I & 12 & I & 10 & I & 4 & - & - & - & - \\
\hline Lychnis coronaria & $\mathrm{C}$ & - & - & - & - & - & - & I & 12 & - & - & - & - \\
\hline Melampyrum cristatum (Fvl) & $\mathrm{C}$ & - & - & I & 4 & - & - & - & - & - & - & - & - \\
\hline Orchis purpurea $(\mathrm{F}, \mathrm{OCn})$ & $\mathrm{C}$ & - & - & III & 60 & - & - & I & 12 & - & - & - & - \\
\hline Origanum vulgare $(\mathrm{Pru})$ & $\mathrm{C}$ & - & - & - & - & - & - & - & - & I & 10 & - & - \\
\hline Ornithogalum sphaerocarpum (Cp,Fru) & $\mathrm{C}$ & - & - & - & - & - & - & II & 28 & - & - & - & - \\
\hline Peucedanum alsaticum (Fvl) & $\mathrm{C}$ & - & - & I & 20 & - & - & - & - & - & - & - & - \\
\hline Peucedanum cervaria (Fvl) & $\mathrm{C}$ & - & - & I & 8 & - & - & I & 4 & - & - & - & - \\
\hline Peucedanum oreoselinum & $\mathrm{C}$ & II & 40 & - & - & - & - & - & - & I & 10 & - & - \\
\hline Physalis alkekengi (Ulm) & $\mathrm{C}$ & II & 40 & II & 36 & - & - & II & 28 & - & - & - & - \\
\hline Piptatherum virescens $(\mathrm{OCn}, \mathrm{AQ})$ & $\mathrm{C}$ & - & - & IV & 80 & I & 20 & III & 44 & - & - & - & - \\
\hline Polygonatum odoratum (Fvl) & $\mathrm{C}$ & $\mathrm{V}$ & 90 & - & - & III & 50 & I & 16 & I & 10 & - & - \\
\hline \multirow[t]{3}{*}{ Prunus spinosa (Pru,Prf) } & B1 & IV & 80 & III & 52 & $\mathrm{~V}$ & 90 & IV & 68 & $\mathrm{~V}$ & 100 & - & - \\
\hline & $\mathrm{B} 2$ & III & 60 & II & 28 & IV & 80 & IV & 68 & $\mathrm{~V}$ & 90 & - & - \\
\hline & $S$ & $\mathrm{~V}$ & 100 & III & 56 & $\mathrm{~V}$ & 100 & IV & 80 & $\mathrm{~V}$ & 100 & - & - \\
\hline Pulmonaria mollissima & $\mathrm{C}$ & II & 30 & - & - & I & 10 & IV & 72 & - & - & - & - \\
\hline \multirow[t]{5}{*}{ Pyrus pyraster $(\mathrm{Cp})$} & $\mathrm{A} 1$ & - & - & - & - & I & 10 & I & 8 & - & - & - & - \\
\hline & A2 & - & - & - & - & II & 40 & I & 20 & III & 50 & - & - \\
\hline & B1 & I & 20 & II & 40 & III & 60 & II & 32 & IV & 80 & I & 13,3 \\
\hline & B2 & I & 10 & I & 20 & III & 60 & I & 8 & II & 40 & - & - \\
\hline & $\mathrm{S}$ & I & 20 & III & 44 & $\mathrm{~V}$ & 90 & III & 48 & $\mathrm{~V}$ & 90 & I & 13,3 \\
\hline \multirow[t]{5}{*}{ Quercus cerris (Qr,PQ) } & $\mathrm{A} 1$ & $\mathrm{~V}$ & 100 & I & 20 & - & - & II & 28 & $\mathrm{~V}$ & 100 & - & - \\
\hline & A2 & II & 30 & I & 4 & - & - & I & 8 & III & 60 & - & - \\
\hline & B1 & I & 20 & I & 8 & - & - & I & 8 & II & 40 & - & - \\
\hline & B2 & $\mathrm{V}$ & 90 & I & 16 & - & - & II & 28 & $\mathrm{~V}$ & 90 & - & - \\
\hline & $\mathrm{S}$ & V & 100 & II & 28 & - & - & II & 40 & $\mathrm{~V}$ & 100 & - & - \\
\hline \multirow[t]{4}{*}{ Quercus pubescens } & $\mathrm{A} 1$ & - & - & - & - & - & - & I & 4 & - & - & - & - \\
\hline & A2 & - & - & - & - & - & - & I & 12 & - & - & - & - \\
\hline & B2 & - & - & - & - & - & - & I & 4 & - & - & - & - \\
\hline & $\mathrm{S}$ & - & - & - & - & - & - & I & 12 & - & - & - & - \\
\hline \multirow[t]{3}{*}{ Rosa canina agg. (Pru,Prf) } & B1 & II & 40 & II & 24 & I & 10 & II & 24 & - & - & - & - \\
\hline & B2 & IV & 70 & III & 48 & II & 40 & III & 48 & II & 30 & - & - \\
\hline & $\mathrm{S}$ & $\mathrm{V}$ & 90 & III & 56 & III & 50 & III & 60 & II & 30 & - & - \\
\hline Rosa gallica (Pru) & B2 & - & - & - & - & - & - & I & 4 & - & - & - & - \\
\hline Silene nutans & $\mathrm{C}$ & I & 20 & - & - & I & 10 & - & - & - & - & - & - \\
\hline Silene viridiflora & $\mathrm{C}$ & - & - & - & - & - & - & - & - & I & 10 & - & - \\
\hline Solidago virga-aurea (NC,Epa,Qrp,PQ) & $\mathrm{C}$ & - & - & - & - & - & - & - & - & I & 10 & I & 6,7 \\
\hline Sorbus torminalis (QFt) & B2 & - & - & - & - & - & - & - & - & I & 20 & - & - \\
\hline Thalictrum aquilegiifolium & $\mathrm{C}$ & - & - & - & - & - & - & I & 8 & - & - & - & - \\
\hline Thalictrum minus (Fvl) & $\mathrm{C}$ & II & 30 & I & 4 & I & 10 & - & - & - & - & I & 6,7 \\
\hline Viburnum lantana $(\mathrm{QFt})$ & B1 & II & 40 & $\mathrm{~V}$ & 92 & I & 20 & III & 60 & - & - & - & - \\
\hline & B2 & III & 60 & $\mathrm{~V}$ & 84 & II & 40 & IV & 72 & - & - & - & - \\
\hline & $\mathrm{S}$ & IV & 70 & $\mathrm{~V}$ & 92 & II & 40 & IV & 80 & - & - & - & - \\
\hline Vincetoxicum hirundinaria (Fvl) & $\mathrm{C}$ & IV & 80 & I & 8 & II & 30 & I & 16 & I & 10 & - & - \\
\hline Viola hirta & $\mathrm{C}$ & $\mathrm{V}$ & 90 & $\mathrm{~V}$ & 92 & II & 30 & IV & 72 & I & 20 & - & - \\
\hline
\end{tabular}


KEvEY \& BőHM (2017) - Kitaibelia 22 (1): 147-178.

\begin{tabular}{|c|c|c|c|c|c|c|c|c|c|c|c|c|c|}
\hline \multirow{2}{*}{ 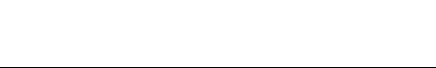 } & & \multicolumn{2}{|c|}{ Sztendrei-sz. } & \multicolumn{2}{|c|}{ Szigetköz } & \multicolumn{2}{|c|}{ D-T köze } & \multicolumn{2}{|c|}{ Mezőföld } & \multicolumn{2}{|c|}{ Bakonyalja } & \multicolumn{2}{|c|}{ Nyírség } \\
\hline & & $\mathbf{K}$ & $\%$ & $\mathbf{K}$ & $\%$ & $\mathbf{K}$ & $\%$ & $\mathbf{K}$ & $\%$ & $\mathbf{K}$ & $\%$ & $\mathbf{K}$ & $\%$ \\
\hline $\begin{array}{l}\text { 1.4.1. Orno-Cotinetalia } \\
\text { 1.4.1.1. Orno-Cotinion }\end{array}$ & & & & & & & & & & & & & \\
\hline $\begin{array}{l}\text { Carex alba }(\mathrm{CeF}) \\
\text { 1.4.2. Quercetalia cerridis }\end{array}$ & $\mathrm{C}$ & - & - & I & 20 & - & - & - & - & - & - & - & - \\
\hline Cerasus mahaleb & B1 & - & - & - & - & I & 10 & - & - & - & - & - & - \\
\hline & B2 & - & - & - & - & I & 10 & - & - & - & - & - & - \\
\hline & $S$ & - & - & - & - & I & 20 & - & - & - & - & - & - \\
\hline Gagea pratensis (Sea) & $\mathrm{C}$ & - & - & - & - & - & - & I & 4 & - & - & - & - \\
\hline 1.4.2.1. Aceri tatarici-Quercion & & & & & & & & & & & & & \\
\hline Acer tataricum (Qpp) & A2 & I & 20 & - & - & II & 30 & III & 60 & - & - & - & - \\
\hline & B1 & II & 30 & - & - & II & 40 & III & 60 & - & - & - & - \\
\hline & B2 & IV & 80 & - & - & II & 40 & IV & 76 & - & - & - & - \\
\hline & $\mathrm{S}$ & V & 90 & - & - & II & 40 & $\mathrm{~V}$ & 88 & - & - & - & - \\
\hline Melica altissima & $\mathrm{C}$ & I & 10 & - & - & I & 20 & - & - & - & - & - & - \\
\hline Trifolium diffusum (Fru) & $\mathrm{C}$ & I & 10 & - & - & - & - & - & - & - & - & - & - \\
\hline 2. Cypero-Phragmitea & & & & & & & & & & & & & \\
\hline 2.1. Phragmitetea & & & & & & & & & & & & & \\
\hline Carex acutiformis (Mag,Cgr,MoJ,Sal,Ate) & $\mathrm{C}$ & - & - & - & - & I & 10 & - & - & - & - & - & - \\
\hline Carex riparia (Mag,Cgr,MoJ,Sal,Ate) & $\mathrm{C}$ & - & - & - & - & I & 10 & - & - & - & - & - & - \\
\hline $\begin{array}{l}\text { Eupatorium cannabinum } \\
\text { (Epa,Sal,Ate,Ai) }\end{array}$ & $\mathrm{C}$ & - & - & - & - & - & - & I & 4 & - & - & - & - \\
\hline Solanum dulcamara (Cal,Bia,Spu) & $\mathrm{C}$ & - & - & - & - & I & 20 & I & 4 & - & - & - & - \\
\hline 3. Molinio-Arrhenatherea & & & & & & & & & & & & & \\
\hline Campanula patula (Arn) & $\mathrm{C}$ & - & - & - & - & - & - & - & - & I & 10 & I & 6,7 \\
\hline Carex tomentosa (Qpp) & $\mathrm{C}$ & I & 20 & I & 4 & - & - & - & - & - & - & - & - \\
\hline Clematis integrifolia $(\mathrm{Qc})$ & $\mathrm{C}$ & - & - & - & - & - & - & I & 4 & - & - & - & - \\
\hline Colchicum autumnale (Moa) & $\mathrm{C}$ & V & 100 & V & 92 & - & - & - & - & - & - & - & - \\
\hline Poa trivialis (Pte,Spu,Ate,Ai) & $\mathrm{C}$ & - & - & - & - & - & - & - & - & I & 10 & - & - \\
\hline 3.1. Molinio-Juncetea & & & & & & & & & & & & & \\
\hline Agrostis canina agg. (Ccn) & $\mathrm{C}$ & - & - & - & - & I & 10 & - & - & - & - & - & - \\
\hline Allium angulosum & $\mathrm{C}$ & I & 10 & - & - & - & - & - & - & - & - & - & - \\
\hline Deschampsia caespitosa (Des,Sal,Ate,Ai) & $\mathrm{C}$ & - & - & - & - & I & 20 & II & 28 & I & 10 & - & - \\
\hline Galium boreale & $\mathrm{C}$ & - & - & - & - & I & 10 & - & - & - & - & - & - \\
\hline Veratrum album (Ate,Ai) & $\mathrm{C}$ & - & - & - & - & - & - & I & 4 & - & - & - & - \\
\hline 3.1.1. Molinietalia coeruleae & & & & & & & & & & & & & \\
\hline Orchis militaris (FBt,Qpp) & $\mathrm{C}$ & II & 30 & II & 24 & - & - & - & - & - & - & - & - \\
\hline Thalictrum lucidum (Mag,FiC,Spu,Ate,Ai) & $\mathrm{C}$ & I & 10 & - & - & - & - & - & - & - & - & - & - \\
\hline Valeriana officinalis (Mag,FiC) & $\mathrm{C}$ & - & - & II & 28 & - & - & I & 8 & I & 10 & - & - \\
\hline 3.1.1.1. Deschampsion caespitosae & & & & & & & & & & & & & \\
\hline Galium rubioides (Alo,Qpp) & $\mathrm{C}$ & I & 10 & II & 28 & - & - & - & - & - & - & - & - \\
\hline 3.2. Arrhenatheretea & & & & & & & & & & & & & \\
\hline 3.2.1. Arrhenatheretalia & & & & & & & & & & & & & \\
\hline Anthriscus sylvestris (Ar,GA,Spu,Ai) & $\mathrm{C}$ & - & - & - & - & - & - & - & - & - & - & I & 6,7 \\
\hline 3.2.1.1. Triseto-Polygonion bistortae & & & & & & & & & & & & & \\
\hline Lilium bulbiferum (Cal,Qpp) & $\mathrm{C}$ & - & - & I & 16 & - & - & - & - & - & - & - & - \\
\hline 3.3. Nardo-Callunetea & & & & & & & & & & & & & \\
\hline 3.3.1. Nardetalia & & & & & & & & & & & & & \\
\hline 3.3.1.1. Nardo-Agrostion tenuis & & & & & & & & & & & & & \\
\hline Carex pallescens (MoA,QFt) & $\mathrm{C}$ & - & - & - & - & - & - & I & 4 & - & - & - & - \\
\hline 3.4. Calluno-Ulicetea & & & & & & & & & & & & & \\
\hline 3.4.1. Vaccinio-Genistetalia & & & & & & & & & & & & & \\
\hline 3.4.1.1. Calluno-Genistion & & & & & & & & & & & & & \\
\hline Betula pendula $(\mathrm{Qr}, \mathrm{APa})$ & A1 & - & - & I & 4 & I & 10 & - & - & - & - & - & - \\
\hline & A2 & - & - & - & - & I & 10 & - & - & I & 10 & - & - \\
\hline & $\mathrm{S}$ & - & - & I & 4 & I & 10 & - & - & I & 10 & - & - \\
\hline 3.4.1.2. Juncion gerardi & & & & & & & & & & & & & \\
\hline Carex divisa (Mon) & $\mathrm{C}$ & - & - & - & - & - & - & - & - & I & 20 & - & - \\
\hline
\end{tabular}


KEvEY \& BőHM (2017) - Kitaibelia 22 (1): 147-178.

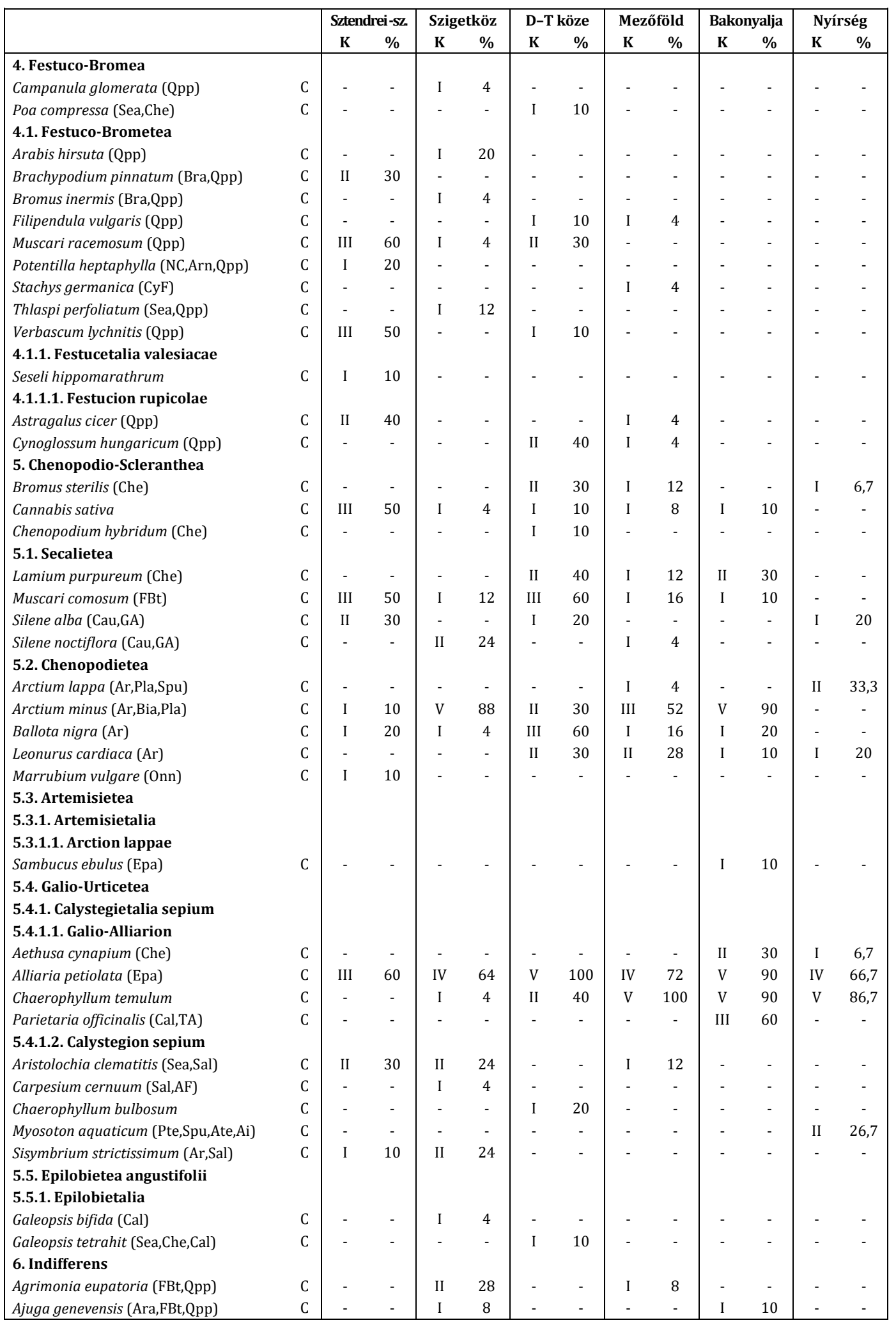


KEvEY \& BőHM (2017) - Kitaibelia 22 (1): 147-178.

\begin{tabular}{|c|c|c|c|c|c|c|c|c|c|c|c|c|c|}
\hline & & \multicolumn{2}{|c|}{ Sztendrei-sz. } & \multicolumn{2}{|c|}{ Szigetköz } & \multicolumn{2}{|c|}{ D-T köze } & \multicolumn{2}{|c|}{ Mezőföld } & \multicolumn{2}{|c|}{ Bakonyalja } & \multicolumn{2}{|c|}{ Nyírség } \\
\hline & & $\mathbf{K}$ & $\%$ & $\mathbf{K}$ & $\%$ & $\mathbf{K}$ & $\%$ & $\mathbf{K}$ & $\%$ & $\mathbf{K}$ & $\%$ & $\mathbf{K}$ & $\%$ \\
\hline Allium scorodoprasum (Qpp,Sea,Che) & $\mathrm{C}$ & - & - & $\mathrm{V}$ & 96 & II & 40 & II & 28 & - & - & - & - \\
\hline Anthriscus cerefolium $(\mathrm{Ar}, \mathrm{GA})$ & $\mathrm{C}$ & - & - & - & - & IV & 70 & II & 32 & IV & 80 & I & 6,7 \\
\hline Calamagrostis epigeios (MoJ,Fvg,Epa) & $\mathrm{C}$ & - & - & I & 4 & I & 10 & - & - & - & - & - & - \\
\hline Carex flacca (Mag,MoJ,Arn,FBt,Qpp) & $\mathrm{C}$ & - & - & - & - & I & 10 & - & - & - & - & - & - \\
\hline $\begin{array}{l}\text { Centaurea jacea ssp. angustifolia } \\
\text { (MoA,FPe,Fvl,PQ,Qpp) }\end{array}$ & $\mathrm{C}$ & I & 10 & - & - & - & - & - & - & - & - & - & - \\
\hline Chelidonium majus (Che,Ar,GA,Epa) & $\mathrm{C}$ & I & 10 & - & - & I & 20 & III & 60 & $\mathrm{~V}$ & 90 & III & 60 \\
\hline Cirsium arvense (Nc,ChS,Epa) & $\mathrm{C}$ & - & - & I & 4 & - & - & - & - & - & - & - & - \\
\hline Cruciata laevipes (Arn,Fru,Ar,GU,Qpp) & $\mathrm{C}$ & - & - & I & 16 & - & - & - & - & I & 10 & I & 6,7 \\
\hline Dactylis glomerata (MoA,FB,Che,Pla,Qpp) & $\mathrm{C}$ & - & - & I & 4 & - & - & - & - & - & - & - & - \\
\hline Equisetum arvense (MoA,Sea,Sal,Ate,Ai) & $\mathrm{C}$ & - & - & - & - & - & - & - & - & - & - & I & 6,7 \\
\hline Euphorbia cyparissias (FB,ChS,Epa,Qpp) & $\mathrm{C}$ & II & 40 & II & 28 & - & - & - & - & - & - & I & 6,7 \\
\hline \multirow[t]{3}{*}{ Galium aparine (Sea,Epa,QFt) } & B1 & - & - & - & - & - & - & - & - & I & 10 & - & - \\
\hline & $\mathrm{C}$ & I & 20 & II & 28 & V & 100 & $\mathrm{~V}$ & 88 & $\mathrm{~V}$ & 100 & $\mathrm{~V}$ & 93,3 \\
\hline & S & I & 20 & II & 28 & $\mathrm{~V}$ & 100 & $\mathrm{~V}$ & 88 & $\mathrm{~V}$ & 100 & $\mathrm{~V}$ & 93,3 \\
\hline Galium mollugo (MoA,FBt,Qrp,Qpp) & $\mathrm{C}$ & I & 20 & $\mathrm{~V}$ & 96 & III & 50 & III & 44 & - & - & - & - \\
\hline Glechoma hederacea $(\mathrm{MoA}, \mathrm{QFt}, \mathrm{Sal}, \mathrm{Ai})$ & $\mathrm{C}$ & I & 20 & I & 16 & II & 40 & II & 40 & II & 30 & II & 40 \\
\hline Hypericum perforatum (NC,FB,Qpp,PP) & $\mathrm{C}$ & II & 30 & I & 20 & - & - & - & - & I & 20 & - & - \\
\hline \multirow[t]{3}{*}{ Juniperus communis (NC,Fvg,Qpp,EP,PP) } & B1 & - & - & - & - & I & 10 & - & - & - & - & - & - \\
\hline & B2 & - & - & - & - & - & - & - & - & I & 10 & - & - \\
\hline & $\mathrm{S}$ & - & - & - & - & I & 10 & - & - & I & 10 & - & - \\
\hline Lysimachia nummularia (Pte,MoJ,Bia) & $\mathrm{C}$ & - & - & - & - & - & - & I & 8 & I & 10 & I & 13,3 \\
\hline Ornithogalum boucheanum (Sea,Ar,Qpp) & $\mathrm{C}$ & - & - & - & - & - & - & I & 8 & II & 40 & - & - \\
\hline Ornithogalum umbellatum (Ara,FBt,Sea) & $\mathrm{C}$ & $\mathrm{V}$ & 90 & I & 16 & III & 60 & I & 20 & IV & 70 & - & - \\
\hline Picris hieracioides (Ara,FB,ChS) & $\mathrm{C}$ & I & 10 & - & - & - & - & - & - & - & - & - & - \\
\hline Pimpinella saxifraga (MoA,FB,Qpp) & $\mathrm{C}$ & I & 20 & I & 4 & - & - & - & - & - & - & - & - \\
\hline Plantago lanceolata (MoA,ChS) & $\mathrm{C}$ & I & 10 & - & - & - & - & - & - & - & - & - & - \\
\hline Poa angustifolia (Ara,FPi,FBt,ChS,Qpp) & $\mathrm{C}$ & I & 20 & - & - & - & - & - & - & - & - & - & - \\
\hline Potentilla reptans $(\mathrm{Mag}, \mathrm{MoA}, \mathrm{FPi}, \mathrm{Bia}, \mathrm{Pla})$ & $\mathrm{C}$ & I & 10 & - & - & - & - & - & - & - & - & - & - \\
\hline Rubus caesius (Spu) & B2 & III & 60 & II & 40 & IV & 80 & III & 48 & $\mathrm{~V}$ & 100 & I & 20 \\
\hline Rubus fruticosus agg. (QFt,Epa,US) & B2 & - & - & - & - & - & - & I & 4 & IV & 70 & - & - \\
\hline \multirow{3}{*}{ Sambucus nigra (Epa,US,QFt) } & B1 & - & - & - & - & III & 60 & IV & 72 & IV & 70 & IV & 66,7 \\
\hline & B2 & I & 20 & I & 4 & $\mathrm{~V}$ & 90 & III & 60 & IV & 80 & IV & 66,7 \\
\hline & $S$ & I & 20 & I & 4 & $\mathrm{~V}$ & 90 & $\mathrm{~V}$ & 88 & $\mathrm{~V}$ & 90 & $\mathrm{~V}$ & 93,3 \\
\hline Securigea varia $(\mathrm{Ara}, \mathrm{FBt}, \mathrm{Qpp})$ & $\mathrm{C}$ & II & 40 & I & 4 & - & - & - & - & I & 10 & - & - \\
\hline $\begin{array}{l}\text { Serratula tinctoria } \\
\text { (MoA,MoJ,Qrp,Qpp,PQ) }\end{array}$ & $\mathrm{C}$ & - & - & - & - & - & - & I & 4 & - & - & - & - \\
\hline Silene vulgaris (Ara,Fvl,Qpp) & $\mathrm{C}$ & I & 10 & II & 24 & - & - & I & 8 & - & - & - & - \\
\hline Stellaria media $(\mathrm{ChS}, \mathrm{QFt}, \mathrm{Spu})$ & $\mathrm{C}$ & - & - & - & - & V & 100 & II & 40 & IV & 80 & III & 53,3 \\
\hline Taraxacum officinale agg. (MoA,ChS) & $\mathrm{C}$ & III & 60 & I & 12 & I & 10 & I & 4 & - & - & - & - \\
\hline Torilis japonica $(\mathrm{Ar}, \mathrm{GA}, \mathrm{Epa}, \mathrm{QFt})$ & $\mathrm{C}$ & II & 40 & III & 44 & II & 30 & I & 12 & IV & 70 & - & - \\
\hline Urtica dioica (Ar,GA,Epa,Spu) & $\mathrm{C}$ & I & 10 & - & - & IV & 80 & IV & 80 & $\mathrm{~V}$ & 90 & V & 93,3 \\
\hline Vicia hirsuta (MoA,FB,Sea,Qpp) & $\mathrm{C}$ & - & - & - & - & - & - & I & 8 & I & 20 & - & - \\
\hline \multicolumn{14}{|l|}{ 7. Adventiva } \\
\hline \multirow[t]{3}{*}{ Acer negundo } & B1 & - & - & - & - & I & 10 & - & - & - & - & - & - \\
\hline & B2 & II & 30 & - & - & I & 10 & - & - & - & - & - & - \\
\hline & $\mathrm{S}$ & II & 30 & - & - & I & 10 & - & - & - & - & - & - \\
\hline \multirow[t]{3}{*}{ Aesculus hippocastanum } & A2 & - & - & - & - & - & - & I & 4 & - & - & - & - \\
\hline & B2 & - & - & I & 4 & - & - & - & - & - & - & - & - \\
\hline & $\mathrm{S}$ & - & - & I & 4 & - & - & I & 4 & - & - & - & - \\
\hline \multirow[t]{4}{*}{ Ailanthus altissima } & A2 & - & - & I & 8 & - & - & - & - & - & - & - & - \\
\hline & B1 & - & - & I & 20 & I & 20 & - & - & - & - & - & - \\
\hline & B2 & III & 60 & III & 44 & II & 30 & I & 8 & - & - & - & - \\
\hline & $\mathrm{S}$ & III & 60 & III & 44 & II & 30 & I & 8 & - & - & - & - \\
\hline Asclepias syriaca & $\mathrm{C}$ & - & - & - & - & $\mathrm{I}$ & 10 & - & - & - & - & - & - \\
\hline
\end{tabular}


KEVEY \& BőHM (2017) - Kitaibelia 22 (1): 147-178.

\begin{tabular}{|c|c|c|c|c|c|c|c|c|c|c|c|c|c|}
\hline & & \multicolumn{2}{|c|}{ Sztendrei-sz. } & \multicolumn{2}{|c|}{ Szigetköz } & \multicolumn{2}{|c|}{ D-T köze } & \multicolumn{2}{|c|}{ Mezőföld } & \multicolumn{2}{|c|}{ Bakonyalja } & \multicolumn{2}{|c|}{ Nyírség } \\
\hline & & $\mathbf{K}$ & $\%$ & $\mathbf{K}$ & $\%$ & $\mathbf{K}$ & $\%$ & $\mathbf{K}$ & $\%$ & $\mathbf{K}$ & $\%$ & $\mathbf{K}$ & $\%$ \\
\hline \multirow[t]{5}{*}{ Celtis occidentalis } & A1 & - & - & - & - & - & - & I & 4 & - & - & - & - \\
\hline & A2 & II & 40 & - & - & I & 20 & I & 4 & - & - & - & - \\
\hline & B1 & IV & 70 & - & - & III & 60 & II & 36 & - & - & - & - \\
\hline & $\mathrm{B} 2$ & $\mathrm{~V}$ & 100 & - & - & III & 50 & III & 56 & - & - & - & - \\
\hline & $\mathrm{S}$ & $\mathrm{V}$ & 100 & - & - & III & 60 & IV & 68 & - & - & - & - \\
\hline \multirow[t]{4}{*}{ Fraxinus pennsylvanica } & $\mathrm{A} 2$ & - & - & - & - & I & 20 & I & 8 & - & - & - & - \\
\hline & B1 & - & - & - & - & I & 10 & I & 4 & - & - & - & - \\
\hline & $\mathrm{B} 2$ & I & 10 & - & - & I & 10 & I & 12 & - & - & I & 13,3 \\
\hline & $\mathrm{S}$ & I & 10 & - & - & I & 20 & I & 12 & - & - & I & 13,3 \\
\hline Gleditsia triacanthos & $\mathrm{B} 2$ & I & 10 & I & 4 & I & 20 & I & 8 & - & - & - & - \\
\hline Impatiens parviflora & $\mathrm{C}$ & - & - & II & 32 & - & - & - & - & - & - & II & 40 \\
\hline \multirow[t]{4}{*}{ Juglans nigra } & $\mathrm{A} 1$ & - & - & I & 4 & - & - & - & - & I & 10 & - & - \\
\hline & $\mathrm{A} 2$ & - & - & - & - & - & - & - & - & I & 10 & - & - \\
\hline & B1 & - & - & - & - & - & - & I & 4 & - & - & - & - \\
\hline & $\mathrm{S}$ & - & - & I & 4 & - & - & I & 4 & I & 10 & - & - \\
\hline \multirow[t]{4}{*}{ Juglans regia } & A2 & - & - & I & 12 & - & - & - & - & - & - & - & - \\
\hline & B1 & I & 10 & I & 8 & - & - & I & 4 & - & - & - & - \\
\hline & $\mathrm{B} 2$ & - & - & I & 20 & - & - & I & 8 & - & - & - & - \\
\hline & $\mathrm{S}$ & I & 10 & II & 28 & - & - & I & 8 & - & - & - & - \\
\hline Mahonia aquifolium & $\mathrm{B} 2$ & III & 50 & - & - & - & - & - & - & - & - & - & - \\
\hline \multirow{3}{*}{ Morus alba } & A2 & - & - & - & - & - & - & I & 8 & - & - & - & - \\
\hline & $\mathrm{B} 2$ & I & 10 & - & - & I & 10 & I & 4 & - & - & - & - \\
\hline & $\mathrm{S}$ & I & 10 & - & - & I & 10 & I & 8 & - & - & - & - \\
\hline \multirow[t]{5}{*}{ Padus serotina } & $\mathrm{A} 2$ & - & - & - & - & II & 30 & - & - & - & - & - & - \\
\hline & B1 & - & - & - & - & III & 50 & I & 4 & - & - & I & 6,7 \\
\hline & $\mathrm{B} 2$ & I & 10 & - & - & III & 60 & I & 16 & - & - & I & 13,3 \\
\hline & $\mathrm{C}$ & - & - & - & - & - & - & I & 4 & - & - & - & - \\
\hline & $\mathrm{S}$ & I & 10 & - & - & IV & 70 & II & 24 & - & - & I & 20 \\
\hline Parthenocissus inserta & $\mathrm{B} 2$ & III & 50 & - & - & - & - & - & - & - & - & - & - \\
\hline Phytolacca americana & $\mathrm{C}$ & - & - & - & - & - & - & I & 16 & - & - & - & - \\
\hline Pinus nigra & $\mathrm{A} 1$ & - & - & I & 8 & - & - & - & - & - & - & - & - \\
\hline Pinus sylvestris & $\mathrm{A} 1$ & I & 10 & - & - & - & - & I & 4 & II & 40 & - & - \\
\hline Quercus rubra & B2 & - & - & - & - & I & 10 & - & - & - & - & - & - \\
\hline \multirow[t]{5}{*}{ Robinia pseudo-acacia } & $\mathrm{A} 1$ & II & 30 & III & 60 & I & 10 & I & 12 & - & - & II & 40 \\
\hline & $\mathrm{A} 2$ & III & 50 & III & 48 & III & 50 & II & 28 & - & - & - & - \\
\hline & B1 & II & 40 & I & 20 & II & 30 & I & 20 & I & 10 & II & 33,3 \\
\hline & $\mathrm{B} 2$ & IV & 80 & III & 56 & III & 50 & II & 36 & II & 30 & II & 26,7 \\
\hline & $\mathrm{S}$ & $\mathrm{V}$ & 100 & $\mathrm{~V}$ & 88 & IV & 80 & IV & 64 & II & 30 & IV & 66,7 \\
\hline Solidago gigantea & $\mathrm{C}$ & IV & 80 & II & 40 & I & 10 & I & 4 & I & 10 & - & - \\
\hline Erigeron annuus & $\mathrm{C}$ & - & - & I & 4 & - & - & - & - & - & - & - & - \\
\hline \multirow[t]{4}{*}{ Tilia tomentosa } & A2 & - & - & I & 4 & - & - & - & - & - & - & - & - \\
\hline & B1 & - & - & I & 4 & - & - & - & - & - & - & - & - \\
\hline & $\mathrm{B} 2$ & - & - & I & 4 & - & - & - & - & - & - & - & - \\
\hline & $\mathrm{S}$ & - & - & I & 4 & - & - & - & - & - & - & - & - \\
\hline
\end{tabular}

Szentendrei-sziget: Melico nutantis-Quercetum roboris (KEVEY \& BőHM ined.: 10 felv.)

Szigetköz: Melico nutantis-Quercetum roboris (Kevey 2008: 25 felv.)

Duna-Tisza köze: Polygonato latifolii-Quercetum roboris (Kevey \& Lendvai ined.: 10 felv.)

Mezőföld: Polygonato latifolii-Quercetum roboris (Kevey 2015: 25 felv.)

Bakonyalja: Polygonato latifolii-Quercetum roboris (Kevey 2013: 10 felv.)

Nyírség: Convallario-Quercetum roboris (Horánszky 1998: 15 felv.) 
KEVEY \& BőHM (2017) - Kitaibelia 22 (1): 147-178.

4. táblázat. Karakterfajok aránya / Table 4. Percentage of characteristic species in various syntaxa

\begin{tabular}{|c|c|c|c|c|c|c|c|c|c|c|c|c|}
\hline & \multicolumn{6}{|c|}{ Csoportrészesedés } & \multicolumn{6}{|c|}{ Csoporttömeg } \\
\hline & Sz & Szk & D-T & Mf & $\mathbf{B a}$ & $\mathrm{Ny}$ & Sz & Szk & D-T & Mf & Ba & $\mathrm{Ny}$ \\
\hline Querco-Fagea & 0,0 & 0,0 & 0,0 & 0,0 & 0,0 & 0,0 & 0,0 & 0,0 & 0,0 & 0,0 & 0,0 & 0,0 \\
\hline Salicetea purpureae & 0,0 & 0,0 & 0,0 & 0,0 & 0,0 & 0,0 & 0,0 & 0,0 & 0,0 & 0,0 & 0,0 & 0,0 \\
\hline Salicetalia purpureae & 0,6 & 0,4 & 1,7 & 0,9 & 1,3 & 1,9 & 0,1 & 0,0 & 0,2 & 0,1 & 0,3 & 5,8 \\
\hline Salicion albae & 0,8 & 0,6 & 1,5 & 0,9 & 0,9 & 1,2 & 0,2 & 0,1 & 0,4 & 0,4 & 0,9 & 0,1 \\
\hline Populenion nigro-albae & 0,1 & 0,1 & 0,5 & 0,6 & 0,3 & 0,6 & 0,0 & 0,0 & 0,1 & 0,1 & 0,0 & 0,1 \\
\hline Salicion albae s.l. & 0,9 & 0,7 & 2,0 & 1,5 & 1,2 & 1,8 & 0,2 & 0,1 & 0,5 & 0,5 & 0,9 & 0,2 \\
\hline Salicetalia purpureae s.l. & 1,5 & 1,1 & 3,7 & 2,4 & 2,5 & 3,7 & 0,3 & 0,1 & 0,7 & 0,6 & 1,2 & 6,0 \\
\hline Salicetea purpureae s.l. & 1,5 & 1,1 & 3,7 & 2,4 & 2,5 & 3,7 & 0,3 & 0,1 & 0,7 & 0,6 & 1,2 & 6,0 \\
\hline Alnetea glutinosae & 0,0 & 0,0 & 0,0 & 0,0 & 0,0 & 0,0 & 0,0 & 0,0 & 0,0 & 0,0 & 0,0 & 0,0 \\
\hline Alnetalia glutinosae & 0,4 & 0,1 & 1,2 & 0,5 & 1,0 & 0,4 & 0,0 & 0,0 & 0,8 & 0,1 & 0,1 & 0,0 \\
\hline Alnetea glutinosae s.l. & 0,4 & 0,1 & 1,2 & 0,5 & 1,0 & 0,4 & 0,0 & 0,0 & 0,8 & 0,1 & 0,1 & 0,0 \\
\hline Querco-Fagetea & 14,3 & 18,7 & 17,6 & 20,5 & 19,7 & 19,7 & 28,6 & 20,2 & 29,2 & 26,7 & 30,2 & 17,4 \\
\hline Fagetalia sylvaticae & 3,6 & 9,9 & 2,9 & 7,2 & 13,5 & 14,1 & 0,6 & 4,0 & 0,3 & 10,3 & 3,7 & 3,5 \\
\hline Alnion incanae & 2,0 & 2,3 & 3,3 & 3,9 & 4,0 & 6,0 & 4,1 & 2,4 & 9,8 & 6,0 & 7,3 & 12,4 \\
\hline Alnenion glutinosae-incanae & 0,0 & 0,0 & 0,0 & 0,0 & 0,1 & 0,1 & 0,0 & 0,0 & 0,0 & 0,0 & 0,0 & 0,0 \\
\hline Ulmenion & 0,8 & 0,8 & 0,9 & 1,0 & 0,4 & 1,5 & 0,1 & 0,5 & 0,1 & 1,1 & 0,1 & 0,2 \\
\hline Alnion incanae s.l. & 2,8 & 3,1 & 4,2 & 4,9 & 4,5 & 7,6 & 4,2 & 2,9 & 9,9 & 7,1 & 7,4 & 12,6 \\
\hline Fagion sylvaticae & 0,0 & 0,0 & 0,0 & 0,0 & 0,0 & 0,0 & 0,0 & 0,0 & 0,0 & 0,0 & 0,0 & 0,0 \\
\hline Eu-Fagenion & 0,0 & 0,0 & 0,0 & 0,0 & 0,2 & 0,1 & 0,0 & 0,0 & 0,0 & 0,0 & 0,0 & 0,0 \\
\hline Carpinenion betuli & 2,0 & 3,5 & 3,1 & 3,7 & 5,3 & 4,2 & 8,5 & 3,1 & 11,5 & 7,1 & 10,5 & 12,1 \\
\hline Tilio-Acerenion & 1,3 & 1,7 & 0,2 & 0,7 & 1,1 & 0,4 & 3,1 & 8,9 & 0,0 & 2,0 & 0,3 & 0,0 \\
\hline Cephalanthero-Fagenion & 0,0 & 0,2 & 0,0 & 0,0 & 0,0 & 0,0 & 0,0 & 0,9 & 0,0 & 0,0 & 0,0 & 0,0 \\
\hline Fagion sylvaticae s.l. & 3,3 & 5,4 & 3,3 & 4,4 & 6,6 & 4,7 & 11,6 & 12,9 & 11,5 & 9,1 & 10,8 & 12,1 \\
\hline Aremonio-Fagion & 0,0 & 0,0 & 0,0 & 0,0 & 0,3 & 0,2 & 0,0 & 0,0 & 0,0 & 0,0 & 0,0 & 0,0 \\
\hline Fagetalia sylvaticae s.l. & 9,7 & 18,4 & 10,4 & 16,5 & 24,9 & 26,6 & 16,4 & 19,8 & 21,7 & 26,5 & 21,9 & 28,2 \\
\hline Quercetalia roboris & 1,0 & 0,4 & 0,5 & 0,5 & 1,7 & 0,6 & 2,3 & 0,5 & 0,3 & 1,0 & 5,8 & 0,3 \\
\hline Quercion robori-petraeae & 0,1 & 0,4 & 0,2 & 0,2 & 0,2 & 0,0 & 0,0 & 0,1 & 0,0 & 0,0 & 0,0 & 0,0 \\
\hline Quercetalia roboris s.l. & 1,1 & 0,8 & 0,7 & 0,7 & 1,9 & 0,6 & 2,3 & 0,6 & 0,3 & 1,0 & 5,8 & 0,3 \\
\hline Querco-Fagetea s.l. & 25,1 & 37,9 & 28,7 & 37,7 & 46,5 & 46,9 & 47,3 & 40,6 & 51,2 & 54,2 & 57,9 & 45,9 \\
\hline Quercetea pubescentis-petraeae & 33,2 & 31,6 & 25,3 & 27,3 & 18,3 & 15,2 & 36,4 & 30,9 & 32,3 & 31,4 & 25,0 & 15,7 \\
\hline Orno-Cotinetalia & 0,0 & 0,0 & 0,0 & 0,0 & 0,0 & 0,0 & 0,0 & 0,0 & 0,0 & 0,0 & 0,0 & 0,0 \\
\hline Orno-Cotinion & 1,0 & 2,2 & 0,3 & 1,2 & 0,1 & 0,1 & 2,8 & 9,5 & 0,6 & 2,6 & 0,0 & 0,0 \\
\hline Orno-Cotinetalia s.l. & 1,0 & 2,2 & 0,3 & 1,2 & 0,1 & 0,1 & 2,8 & 9,5 & 0,6 & 2,6 & 0,0 & 0,0 \\
\hline Quercetalia cerridis & 0,4 & 0,6 & 0,7 & 0,5 & 0,1 & 0,1 & 0,2 & 6,9 & 0,1 & 1,9 & 0,0 & 0,0 \\
\hline Quercion farnetto & 0,0 & 0,0 & 0,0 & 0,0 & 0,0 & 0,2 & 0,0 & 0,0 & 0,0 & 0,0 & 0,0 & 0,0 \\
\hline Quercion petraeae & 0,0 & 0,0 & 0,0 & 0,0 & 0,2 & 0,0 & 0,0 & 0,0 & 0,0 & 0,0 & 0,0 & 0,0 \\
\hline Aceri tatarici-Quercion & 2,0 & 1,1 & 1,5 & 1,8 & 0,0 & 0,1 & 3,3 & 1,4 & 1,9 & 2,5 & 0,0 & 0,0 \\
\hline Quercetalia cerridis s.l. & 2,4 & 1,7 & 2,2 & 2,3 & 0,3 & 0,4 & 3,5 & 8,3 & 2,0 & 4,4 & 0,0 & 0,0 \\
\hline Prunetalia spinosae & 3,3 & 2,2 & 2,4 & 1,9 & 1,1 & 0,0 & 0,3 & 0,3 & 1,3 & 0,4 & 0,6 & 0,0 \\
\hline Berberidion & 0,0 & 0,0 & 0,2 & 0,1 & 0,0 & 0,0 & 0,0 & 0,0 & 0,0 & 0,4 & 0,0 & 0,0 \\
\hline Prunion fruticosae & 1,1 & 0,7 & 1,0 & 0,8 & 0,6 & 0,0 & 0,1 & 0,1 & 0,7 & 0,2 & 0,5 & 0,0 \\
\hline Prunetalia spinosae s.l. & 4,4 & 2,9 & 3,6 & 2,8 & 1,7 & 0,0 & 0,4 & 0,4 & 2,0 & 1,0 & 1,1 & 0,0 \\
\hline Quercetea pubescentis-petraeae s.l. & 41,0 & 38,4 & 31,4 & 33,6 & 20,4 & 15,7 & 43,1 & 49,1 & 36,9 & 39,4 & 26,1 & 15,7 \\
\hline
\end{tabular}


KEVEY \& BőHM (2017) - Kitaibelia 22 (1): 147-178.

\begin{tabular}{|c|c|c|c|c|c|c|c|c|c|c|c|c|}
\hline & \multicolumn{6}{|c|}{ Csoportrészesedés } & \multicolumn{6}{|c|}{ Csoporttömeg } \\
\hline & Sz & Szk & D-T & Mf & Ba & $\mathrm{Ny}$ & Sz & Szk & D-T & Mf & Ba & $\mathrm{Ny}$ \\
\hline Querco-Fagea s.l. & 68,0 & 77,5 & 65,0 & 74,2 & 70,4 & 66,7 & 90,7 & 89,8 & 89,6 & 94,3 & 85,3 & 67,6 \\
\hline Abieti-Piceea & 0,0 & 0,0 & 0,1 & 0,0 & 0,0 & 0,0 & 0,0 & 0,0 & 0,2 & 0,0 & 0,0 & 0,0 \\
\hline Pulsatillo-Pinetea & 0,0 & 0,0 & 0,0 & 0,0 & 0,0 & 0,0 & 0,0 & 0,0 & 0,0 & 0,0 & 0,0 & 0,0 \\
\hline Pulsatillo-Pinetalia & 0,0 & 0,0 & 0,0 & 0,0 & 0,0 & 0,0 & 0,0 & 0,0 & 0,0 & 0,0 & 0,0 & 0,0 \\
\hline Festuco vaginatae-Pinion & 0,1 & 0,1 & 0,0 & 0,0 & 0,1 & 0,0 & 0,0 & 0,0 & 0,0 & 0,0 & 0,0 & 0,0 \\
\hline Pulsatillo-Pinetalia s.l. & 0,1 & 0,1 & 0,0 & 0,0 & 0,1 & 0,0 & 0,0 & 0,0 & 0,0 & 0,0 & 0,0 & 0,0 \\
\hline Pulsatillo-Pinetea s.l. & 0,1 & 0,1 & 0,0 & 0,0 & 0,1 & 0,0 & 0,0 & 0,0 & 0,0 & 0,0 & 0,0 & 0,0 \\
\hline Vaccinio-Piceetea & 0,0 & 0,0 & 0,0 & 0,0 & 0,1 & 0,4 & 0,0 & 0,0 & 0,0 & 0,0 & 0,0 & 0,0 \\
\hline Pino-Quercetalia & 0,0 & 0,0 & 0,0 & 0,0 & 0,0 & 0,0 & 0,0 & 0,0 & 0,0 & 0,0 & 0,0 & 0,0 \\
\hline Pino-Quercion & 0,7 & 0,2 & 0,3 & 0,4 & 1,3 & 0,3 & 2,3 & 0,5 & 0,0 & 0,6 & 5,7 & 0,3 \\
\hline Pino-Quercetalia s.l. & 0,7 & 0,2 & 0,3 & 0,4 & 1,3 & 0,3 & 2,3 & 0,5 & 0,0 & 0,6 & 5,7 & 0,3 \\
\hline Vaccinio-Piceetea s.l. & 0,7 & 0,2 & 0,3 & 0,4 & 1,4 & 0,7 & 2,3 & 0,5 & 0,0 & 0,6 & 5,7 & 0,3 \\
\hline Abieti-Piceea s.l. & 0,8 & 0,3 & 0,4 & 0,4 & 1,5 & 0,7 & 2,3 & 0,5 & 0,2 & 0,6 & 5,7 & 0,3 \\
\hline Cypero-Phragmitea & 0,0 & 0,0 & 0,0 & 0,0 & 0,0 & 0,0 & 0,0 & 0,0 & 0,0 & 0,0 & 0,0 & 0,0 \\
\hline Phragmitetea & 0,0 & 0,0 & 0,2 & 0,1 & 0,1 & 0,3 & 0,0 & 0,0 & 0,0 & 0,0 & 0,0 & 0,0 \\
\hline Magnocaricetalia & 0,0 & 0,0 & 0,0 & 0,0 & 0,0 & 0,0 & 0,0 & 0,0 & 0,0 & 0,0 & 0,0 & 0,0 \\
\hline Magnocaricion & 0,1 & 0,2 & 0,1 & 0,0 & 0,0 & 0,0 & 0,0 & 0,0 & 0,0 & 0,0 & 0,0 & 0,0 \\
\hline Caricenion gracilis & 0,0 & 0,0 & 0,1 & 0,0 & 0,0 & 0,0 & 0,0 & 0,0 & 0,0 & 0,0 & 0,0 & 0,0 \\
\hline Magnocaricion s.l. & 0,1 & 0,2 & 0,2 & 0,0 & 0,0 & 0,0 & 0,0 & 0,0 & 0,0 & 0,0 & 0,0 & 0,0 \\
\hline Magnocaricetalia s.l. & 0,1 & 0,2 & 0,2 & 0,0 & 0,0 & 0,0 & 0,0 & 0,0 & 0,0 & 0,0 & 0,0 & 0,0 \\
\hline Phragmitetea s.l. & 0,1 & 0,2 & 0,4 & 0,1 & 0,1 & 0,3 & 0,0 & 0,0 & 0,0 & 0,0 & 0,0 & 0,0 \\
\hline Cypero-Phragmitea s.l. & 0,1 & 0,2 & 0,4 & 0,1 & 0,1 & 0,3 & 0,0 & 0,0 & 0,0 & 0,0 & 0,0 & 0,0 \\
\hline Oxycocco-Caricea nigrae & 0,0 & 0,0 & 0,0 & 0,0 & 0,0 & 0,0 & 0,0 & 0,0 & 0,0 & 0,0 & 0,0 & 0,0 \\
\hline Scheuchzerio-Caricetea nigrae & 0,0 & 0,0 & 0,0 & 0,0 & 0,0 & 0,0 & 0,0 & 0,0 & 0,0 & 0,0 & 0,0 & 0,0 \\
\hline Scheuchzerio-Caricetalia nigrae & 0,0 & 0,0 & 0,0 & 0,0 & 0,0 & 0,0 & 0,0 & 0,0 & 0,0 & 0,0 & 0,0 & 0,0 \\
\hline Caricion canescenti-nigrae & 0,0 & 0,0 & 0,1 & 0,0 & 0,0 & 0,0 & 0,0 & 0,0 & 0,0 & 0,0 & 0,0 & 0,0 \\
\hline Scheuchzerio-Caricetalia nigrae s.l. & 0,0 & 0,0 & 0,1 & 0,0 & 0,0 & 0,0 & 0,0 & 0,0 & 0,0 & 0,0 & 0,0 & 0,0 \\
\hline Scheuchzerio-Caricetea nigrae s.l. & 0,0 & 0,0 & 0,1 & 0,0 & 0,0 & 0,0 & 0,0 & 0,0 & 0,0 & 0,0 & 0,0 & 0,0 \\
\hline Oxycocco-Caricea nigrae s.l. & 0,0 & 0,0 & 0,1 & 0,0 & 0,0 & 0,0 & 0,0 & 0,0 & 0,0 & 0,0 & 0,0 & 0,0 \\
\hline Molinio-Arrhenatherea & 1,9 & 1,6 & 0,4 & 1,0 & 0,9 & 0,6 & 0,8 & 3,3 & 0,0 & 0,1 & 0,2 & 0,0 \\
\hline Molinio-Juncetea & 0,2 & 0,0 & 0,5 & 0,2 & 0,1 & 0,1 & 0,0 & 0,0 & 0,1 & 0,0 & 0,0 & 0,0 \\
\hline Molinietalia coeruleae & 1,1 & 1,2 & 0,0 & 0,1 & 0,1 & 0,0 & 0,8 & 3,1 & 0,0 & 0,0 & 0,0 & 0,0 \\
\hline Molinion coeruleae & 0,0 & 0,0 & 0,0 & 0,0 & 0,1 & 0,0 & 0,8 & 3,1 & 0,0 & 0,0 & 0,0 & 0,0 \\
\hline Deschampsion caespitosae & 0,1 & 0,2 & 0,1 & 0,1 & 0,0 & 0,0 & 0,0 & 0,0 & 0,0 & 0,0 & 0,0 & 0,0 \\
\hline Filipendulo-Cirsion oleracei & 0,0 & 0,2 & 0,0 & 0,0 & 0,0 & 0,0 & 0,0 & 0,0 & 0,0 & 0,0 & 0,0 & 0,0 \\
\hline Alopecurion pratensis & 0,1 & 0,2 & 0,0 & 0,0 & 0,0 & 0,0 & 0,0 & 0,0 & 0,0 & 0,0 & 0,0 & 0,0 \\
\hline Molinietalia coeruleae s.l. & 1,3 & 1,8 & 0,1 & 0,2 & 0,2 & 0,0 & 0,0 & 0,0 & 0,0 & 0,0 & 0,0 & 0,0 \\
\hline Molinio-Juncetea s.l. & 1,5 & 1,8 & 0,6 & 0,4 & 0,3 & 0,1 & 0,8 & 3,1 & 0,1 & 0,0 & 0,0 & 0,0 \\
\hline Arrhenatheretea & 0,0 & 0,0 & 0,0 & 0,0 & 0,0 & 0,0 & 0,0 & 0,0 & 0,0 & 0,0 & 0,0 & 0,0 \\
\hline Arrhenatheretalia & 0,8 & 0,3 & 0,3 & 0,3 & 0,8 & 0,3 & 0,1 & 0,0 & 0,0 & 0,1 & 0,1 & 0,0 \\
\hline Arrhenatherion elatioris & 0,1 & 0,0 & 0,0 & 0,0 & 0,1 & 0,1 & 0,0 & 0,0 & 0,0 & 0,0 & 0,0 & 0,0 \\
\hline Triseto-Polygonion bistortae & 0,0 & 0,1 & 0,0 & 0,0 & 0,0 & 0,0 & 0,0 & 0,0 & 0,0 & 0,0 & 0,0 & 0,0 \\
\hline Arrhenatheretalia s.l. & 0,9 & 0,4 & 0,3 & 0,3 & 0,9 & 0,4 & 0,1 & 0,0 & 0,0 & 0,1 & 0,1 & 0,0 \\
\hline Arrhenatheretea s.l. & 0,9 & 0,4 & 0,3 & 0,3 & 0,9 & 0,4 & 0,1 & 0,0 & 0,0 & 0,1 & 0,1 & 0,0 \\
\hline
\end{tabular}


KEVEY \& BőHM (2017) - Kitaibelia 22 (1): 147-178.

\begin{tabular}{|c|c|c|c|c|c|c|c|c|c|c|c|c|}
\hline & \multicolumn{6}{|c|}{ Csoportrészesedés } & \multicolumn{6}{|c|}{ Csoporttömeg } \\
\hline & Sz & Szk & D-T & Mf & $\mathbf{B a}$ & $\mathrm{Ny}$ & Sz & Szk & D-T & Mf & $\mathbf{B a}$ & $\mathrm{Ny}$ \\
\hline Nardo-Callunetea & 0,0 & 0,0 & 0,0 & 0,0 & 0,0 & 0,0 & 0,0 & 0,0 & 0,0 & 0,0 & 0,0 & 0,0 \\
\hline Nardetalia & 0,0 & 0,0 & 0,0 & 0,0 & 0,0 & 0,0 & 0,0 & 0,0 & 0,0 & 0,0 & 0,0 & 0,0 \\
\hline Nardo-Agrostion tenuis & 0,2 & 0,1 & 0,0 & 0,1 & 0,2 & 0,0 & 0,0 & 0,0 & 0,0 & 0,0 & 0,0 & 0,0 \\
\hline Nardetalia s.l. & 0,2 & 0,1 & 0,0 & 0,1 & 0,2 & 0,0 & 0,0 & 0,0 & 0,0 & 0,0 & 0,0 & 0,0 \\
\hline Nardo-Callunetea s.l. & 0,2 & 0,1 & 0,0 & 0,1 & 0,2 & 0,0 & 0,0 & 0,0 & 0,0 & 0,0 & 0,0 & 0,0 \\
\hline Calluno-Ulicetea & 0,0 & 0,0 & 0,0 & 0,0 & 0,0 & 0,0 & 0,0 & 0,0 & 0,0 & 0,0 & 0,0 & 0,0 \\
\hline Vaccinio-Genistetalia & 0,0 & 0,0 & 0,0 & 0,0 & 0,0 & 0,0 & 0,0 & 0,0 & 0,0 & 0,0 & 0,0 & 0,0 \\
\hline Calluno-Genistion & 0,0 & 0,0 & 0,1 & 0,0 & 0,0 & 0,0 & 0,0 & 0,0 & 0,2 & 0,0 & 0,0 & 0,0 \\
\hline Vaccinio-Genistetalia s.l. & 0,0 & 0,0 & 0,1 & 0,0 & 0,0 & 0,0 & 0,0 & 0,0 & 0,2 & 0,0 & 0,0 & 0,0 \\
\hline Calluno-Ulicetea s.l. & 0,0 & 0,0 & 0,1 & 0,0 & 0,0 & 0,0 & 0,0 & 0,0 & 0,2 & 0,0 & 0,0 & 0,0 \\
\hline Molinio-Arrhenatherea s.l. & 4,5 & 3,9 & 1,4 & 1,8 & 2,3 & 1,1 & 1,7 & 6,4 & 0,3 & 0,2 & 0,3 & 0,0 \\
\hline Puccinellio-Salicornea & 0,0 & 0,0 & 0,0 & 0,0 & 0,0 & 0,0 & 0,0 & 0,0 & 0,0 & 0,0 & 0,0 & 0,0 \\
\hline Festuco-Puccinellietea & 0,0 & 0,0 & 0,0 & 0,0 & 0,0 & 0,0 & 0,0 & 0,0 & 0,0 & 0,0 & 0,0 & 0,0 \\
\hline Festuco-Puccinellietalia & 0,1 & 0,0 & 0,0 & 0,0 & 0,0 & 0,0 & 0,0 & 0,0 & 0,0 & 0,0 & 0,0 & 0,0 \\
\hline Juncion gerardi & 0,0 & 0,0 & 0,0 & 0,0 & 0,1 & 0,0 & 0,0 & 0,0 & 0,0 & 0,0 & 0,0 & 0,0 \\
\hline Festuco-Puccinellietalia s.l. & 0,1 & 0,0 & 0,0 & 0,0 & 0,1 & 0,0 & 0,0 & 0,0 & 0,0 & 0,0 & 0,0 & 0,0 \\
\hline Festuco-Puccinellietea s.l. & 0,1 & 0,0 & 0,0 & 0,0 & 0,1 & 0,0 & 0,0 & 0,0 & 0,0 & 0,0 & 0,0 & 0,0 \\
\hline Puccinellio-Salicornea s.l. & 0,1 & 0,0 & 0,0 & 0,0 & 0,1 & 0,0 & 0,0 & 0,0 & 0,0 & 0,0 & 0,0 & 0,0 \\
\hline Festuco-Bromea & 0,4 & 0,2 & 0,1 & 0,0 & 0,1 & 0,0 & 0,0 & 0,0 & 0,0 & 0,0 & 0,0 & 0,0 \\
\hline Festucetea vaginatae & 0,0 & 0,0 & 0,0 & 0,0 & 0,0 & 0,0 & 0,0 & 0,0 & 0,0 & 0,0 & 0,0 & 0,0 \\
\hline Festucetalia vaginatae & 0,0 & 0,0 & 0,0 & 0,0 & 0,0 & 0,0 & 0,0 & 0,0 & 0,0 & 0,0 & 0,0 & 0,0 \\
\hline Festucion vaginatae & 0,1 & 0,1 & 0,1 & 0,0 & 0,0 & 0,0 & 0,0 & 0,0 & 0,0 & 0,0 & 0,0 & 0,0 \\
\hline Festucetalia vaginatae s.l. & 0,1 & 0,1 & 0,1 & 0,0 & 0,0 & 0,0 & 0,0 & 0,0 & 0,0 & 0,0 & 0,0 & 0,0 \\
\hline Festucetea vaginatae s.l. & 0,1 & 0,1 & 0,1 & 0,0 & 0,0 & 0,0 & 0,0 & 0,0 & 0,0 & 0,0 & 0,0 & 0,0 \\
\hline Festuco-Brometea & 2,9 & 1,2 & 1,8 & 0,6 & 0,5 & 0,0 & 0,3 & 0,2 & 0,2 & 0,1 & 0,1 & 0,0 \\
\hline Festucetalia valesiacae & 2,1 & 0,7 & 1,3 & 0,7 & 0,1 & 0,1 & 0,3 & 0,1 & 0,3 & 0,1 & 0,0 & 0,0 \\
\hline Seslerio-Festucion pallentis & 0,0 & 0,1 & 0,0 & 0,0 & 0,0 & 0,0 & 0,0 & 0,0 & 0,0 & 0,0 & 0,0 & 0,0 \\
\hline Festucion rupicolae & 0,8 & 0,4 & 0,6 & 0,7 & 0,2 & 0,0 & 0,1 & 0,0 & 0,1 & 0,1 & 0,0 & 0,0 \\
\hline Cynodonto-Festucenion & 0,0 & 0,0 & 0,0 & 0,0 & 0,0 & 0,0 & 0,0 & 0,0 & 0,0 & 0,0 & 0,0 & 0,0 \\
\hline Festucion rupicolae s.l. & 0,8 & 0,4 & 0,6 & 0,7 & 0,2 & 0,0 & 0,1 & 0,0 & 0,1 & 0,1 & 0,0 & 0,0 \\
\hline Festucetalia valesiacae s.l. & 2,9 & 1,2 & 1,9 & 1,4 & 0,3 & 0,1 & 0,4 & 0,1 & 0,4 & 0,2 & 0,0 & 0,0 \\
\hline Brometalia erecti & 0,0 & 0,0 & 0,0 & 0,0 & 0,0 & 0,0 & 0,0 & 0,0 & 0,0 & 0,0 & 0,0 & 0,0 \\
\hline Cirsio-Brachypodion & 0,2 & 0,0 & 0,0 & 0,0 & 0,0 & 0,0 & 0,0 & 0,0 & 0,0 & 0,0 & 0,0 & 0,0 \\
\hline Brometalia erecti s.l. & 0,2 & 0,0 & 0,0 & 0,0 & 0,0 & 0,0 & 0,0 & 0,0 & 0,0 & 0,0 & 0,0 & 0,0 \\
\hline Festuco-Brometea s.l. & 6,0 & 2,4 & 3,7 & 2,0 & 0,8 & 0,1 & 0,7 & 0,3 & 0,6 & 0,3 & 0,1 & 0,0 \\
\hline Festuco-Bromea s.l. & 6,5 & 2,7 & 3,9 & 2,0 & 0,9 & 0,1 & 0,7 & 0,3 & 0,6 & 0,3 & 0,1 & 0,0 \\
\hline Chenopodio-Scleranthea & 1,6 & 0,3 & 1,2 & 0,4 & 0,4 & 0,6 & 0,2 & 0,0 & 0,2 & 0,1 & 0,1 & 0,1 \\
\hline Secalietea & 1,3 & 1,1 & 2,3 & 1,0 & 1,1 & 1,0 & 0,1 & 0,1 & 0,4 & 0,1 & 0,2 & 0,8 \\
\hline Secalietalia & 0,0 & 0,0 & 0,0 & 0,0 & 0,0 & 0,0 & 0,0 & 0,0 & 0,0 & 0,0 & 0,0 & 0,0 \\
\hline Caucalidion platycarpos & 0,2 & 0,1 & 0,1 & 0,0 & 0,0 & 0,2 & 0,0 & 0,0 & 0,0 & 0,0 & 0,0 & 0,0 \\
\hline Secalietalia s.l. & 0,2 & 0,1 & 0,1 & 0,0 & 0,0 & 0,2 & 0,0 & 0,0 & 0,0 & 0,0 & 0,0 & 0,0 \\
\hline Secalietea s.l. & 1,5 & 1,2 & 2,4 & 1,0 & 1,1 & 1,2 & 0,1 & 0,1 & 0,4 & 0,1 & 0,2 & 0,8 \\
\hline
\end{tabular}


KEVEY \& BőHM (2017) - Kitaibelia 22 (1): 147-178.

\begin{tabular}{|c|c|c|c|c|c|c|c|c|c|c|c|c|}
\hline & \multicolumn{6}{|c|}{ Csoportrészesedés } & \multicolumn{6}{|c|}{ Csoporttömeg } \\
\hline & Sz & Szk & D-T & Mf & Ba & $\mathrm{Ny}$ & Sz & Szk & D-T & Mf & Ba & $\mathrm{Ny}$ \\
\hline Chenopodietea & 0,3 & 0,9 & 2,3 & 1,1 & 1,3 & 1,2 & 0,0 & 0,1 & 0,3 & 0,1 & 0,2 & 0,1 \\
\hline Onopordetalia & 0,0 & 0,0 & 0,0 & 0,0 & 0,0 & 0,0 & 0,0 & 0,0 & 0,0 & 0,0 & 0,0 & 0,0 \\
\hline Onopordion acanthii & 0,1 & 0,0 & 0,0 & 0,0 & 0,0 & 0,0 & 0,0 & 0,0 & 0,0 & 0,0 & 0,0 & 0,0 \\
\hline Onopordetalia s.l. & 0,1 & 0,0 & 0,0 & 0,0 & 0,0 & 0,0 & 0,0 & 0,0 & 0,0 & 0,0 & 0,0 & 0,0 \\
\hline Chenopodietea s.l. & 0,4 & 0,9 & 2,3 & 1,1 & 1,3 & 1,2 & 0,0 & 0,1 & 0,3 & 0,1 & 0,2 & 0,1 \\
\hline Artemisietea & 0,0 & 0,0 & 0,0 & 0,0 & 0,0 & 0,0 & 0,0 & 0,0 & 0,0 & 0,0 & 0,0 & 0,0 \\
\hline Artemisietalia & 0,0 & 0,0 & 0,0 & 0,0 & 0,0 & 0,0 & 0,0 & 0,0 & 0,0 & 0,0 & 0,0 & 0,0 \\
\hline Arction lappae & 0,5 & 0,8 & 2,0 & 1,3 & 1,9 & 1,8 & 0,1 & 0,1 & 0,5 & 0,3 & 0,3 & 5,5 \\
\hline Artemisietalia s.l. & 0,5 & 0,8 & 2,0 & 1,3 & 1,9 & 1,8 & 0,1 & 0,1 & 0,5 & 0,3 & 0,3 & 5,5 \\
\hline Artemisietea s.l. & 0,5 & 0,8 & 2,0 & 1,3 & 1,9 & 1,8 & 0,1 & 0,1 & 0,5 & 0,3 & 0,3 & 5,5 \\
\hline Galio-Urticetea & 0,0 & 0,0 & 0,0 & 0,0 & 0,0 & 0,0 & 0,0 & 0,0 & 0,0 & 0,0 & 0,0 & 0,0 \\
\hline Calystegietalia sepium & 0,0 & 0,0 & 0,0 & 0,0 & 0,0 & 0,0 & 0,0 & 0,0 & 0,0 & 0,0 & 0,0 & 0,0 \\
\hline Galio-Alliarion & 1,5 & 1,5 & 3,8 & 4,1 & 5,0 & 6,4 & 0,2 & 0,2 & 0,8 & 1,2 & 2,1 & 6,4 \\
\hline Calystegion sepium & 0,5 & 0,6 & 1,2 & 0,5 & 1,3 & 0,6 & 0,1 & 0,1 & 0,1 & 0,1 & 0,2 & 0,1 \\
\hline Calystegietalia sepium s.l. & 2,0 & 2,1 & 5,0 & 4,6 & 6,3 & 7,0 & 0,3 & 0,3 & 0,9 & 1,3 & 2,3 & 6,5 \\
\hline Galio-Urticetea s.l. & 2,0 & 2,1 & 5,0 & 4,6 & 6,3 & 7,0 & 0,3 & 0,3 & 0,9 & 1,3 & 2,3 & 6,5 \\
\hline Bidentetea & 0,0 & 0,0 & 0,0 & 0,0 & 0,0 & 0,0 & 0,0 & 0,0 & 0,0 & 0,0 & 0,0 & 0,0 \\
\hline Bidentetalia & 0,1 & 0,4 & 0,3 & 0,3 & 0,4 & 0,1 & 0,0 & 0,0 & 0,0 & 0,0 & 0,1 & 0,0 \\
\hline Bidentetea s.l. & 0,1 & 0,4 & 0,3 & 0,3 & 0,4 & 0,1 & 0,0 & 0,0 & 0,0 & 0,0 & 0,1 & 0,0 \\
\hline Plantaginetea & 0,0 & 0,0 & 0,0 & 0,0 & 0,0 & 0,0 & 0,0 & 0,0 & 0,0 & 0,0 & 0,0 & 0,0 \\
\hline Plantaginetalia majoris & 0,1 & 0,4 & 0,2 & 0,2 & 0,3 & 0,3 & 0,0 & 0,0 & 0,0 & 0,0 & 0,0 & 0,0 \\
\hline Plantaginetea s.l. & 0,1 & 0,4 & 0,2 & 0,2 & 0,3 & 0,3 & 0,0 & 0,0 & 0,0 & 0,0 & 0,0 & 0,0 \\
\hline Epilobietea angustifolii & 0,0 & 0,0 & 0,0 & 0,0 & 0,0 & 0,0 & 0,0 & 0,0 & 0,0 & 0,0 & 0,0 & 0,0 \\
\hline Epilobietalia & 2,2 & 2,7 & 4,3 & 5,4 & 6,7 & 8,9 & 0,2 & 0,3 & 0,9 & 1,1 & 2,8 & 7,7 \\
\hline Epilobion angustifolii & 0,0 & 0,1 & 0,1 & 0,0 & 0,0 & 0,4 & 0,0 & 0,0 & 0,0 & 0,0 & 0,0 & 0,2 \\
\hline Epilobietalia s.l. & 2,2 & 2,8 & 4,4 & 5,4 & 6,7 & 9,3 & 0,2 & 0,3 & 0,9 & 1,1 & 2,8 & 7,9 \\
\hline Epilobietea angustifolii s.l. & 2,2 & 2,8 & 4,4 & 5,4 & 6,7 & 9,3 & 0,2 & 0,3 & 0,9 & 1,1 & 2,8 & 7,9 \\
\hline Urtico-Sambucetea & 0,0 & 0,0 & 0,0 & 0,0 & 0,0 & 0,0 & 0,0 & 0,0 & 0,0 & 0,0 & 0,0 & 0,0 \\
\hline Sambucetalia & 0,0 & 0,0 & 0,0 & 0,0 & 0,0 & 0,0 & 0,0 & 0,0 & 0,0 & 0,0 & 0,0 & 0,0 \\
\hline Sambuco-Salicion capreae & 0,1 & 0,0 & 0,5 & 0,4 & 0,6 & 0,8 & 0,0 & 0,0 & 0,1 & 0,1 & 0,5 & 0,7 \\
\hline Sambucetalia s.l. & 0,1 & 0,0 & 0,5 & 0,4 & 0,6 & 0,8 & 0,0 & 0,0 & 0,1 & 0,1 & 0,5 & 0,7 \\
\hline Urtico-Sambucetea s.l. & 0,1 & 0,0 & 0,5 & 0,4 & 0,6 & 0,8 & 0,0 & 0,0 & 0,1 & 0,1 & 0,5 & 0,7 \\
\hline Chenopodio-Scleranthea s.l. & 8,5 & 8,9 & 18,3 & 14,7 & 19,0 & 22,3 & 0,9 & 0,9 & 3,3 & 3,1 & 6,5 & 21,6 \\
\hline Indifferens & 2,6 & 2,2 & 4,3 & 2,7 & 3,9 & 3,9 & 0,3 & 0,3 & 1,0 & 0,5 & 1,2 & 7,3 \\
\hline Adventiva & 9,5 & 4,6 & 6,6 & 3,9 & 1,3 & 4,6 & 3,3 & 1,3 & 4,8 & 0,9 & 0,4 & 3,0 \\
\hline
\end{tabular}

Sz: Melico nutantis-Quercetum roboris, Szentendrei-sziget (KeVEY \& BőHM ined.: 10 felv.)

Szk: Melico nutantis-Quercetum roboris, Szigetköz (Kevey 2008: 25 felv.)

D-T: Polygonato latifolii-Quercetum roboris, Duna-Tisza köze (Kevey \& Lendvai ined.: 10 felv.)

Mf: Polygonato latifolii-Quercetum roboris, Mezőföld (Kevey 2015: 25 felv.)

Ba: Polygonato latifolii-Quercetum roboris, Bakonyalja (Kevey 2013: 10 felv.)

Ny: Convallario-Quercetum roboris, Nyírség (Horánszky 1998: 15 felv.) 
KEVEY \& BőHM (2017) - Kitaibelia 22 (1): 147-178.

5. táblázat. Szociális magatartási típusok aránya

Table 5. Proportion of Social Behaviour Types (SBT)

\begin{tabular}{|cc|cc|cc|}
\hline \multicolumn{2}{c|}{ SBT } & & \multicolumn{2}{|c|}{$\mathbf{1 9 4 3}$} & \multicolumn{2}{c|}{$\mathbf{2 0 1 2}$} \\
\hline $\mathrm{S}$ & 6 & 6,0 & 4,5 & 5,5 & 9,2 \\
$\mathrm{Su}$ & 10 & 0,0 & 0,0 & 0,0 & 0,0 \\
$\mathrm{Sr}$ & 8 & 0,0 & 0,0 & 0,0 & 0,0 \\
$\mathrm{C}$ & 5 & 13,6 & 40,8 & 9,5 & 31,8 \\
$\mathrm{Cu}$ & 9 & 0,0 & 0,0 & 0,0 & 0,0 \\
$\mathrm{Cr}$ & 7 & 0,0 & 0,0 & 0,0 & 0,0 \\
$\mathrm{G}$ & 4 & 60,8 & 40,0 & 53,8 & 53,4 \\
$\mathrm{Gu}$ & 8 & 0,0 & 0,0 & 0,0 & 0,0 \\
$\mathrm{Gr}$ & 6 & 0,0 & 0,0 & 0,0 & 0,0 \\
$\mathrm{NP}$ & 3 & 0,0 & 0,0 & 0,0 & 0,0 \\
$\mathrm{DT}$ & 2 & 15,6 & 14,2 & 17,3 & 1,8 \\
$\mathrm{~W}$ & 1 & 1,5 & 0,1 & 2,5 & 0,3 \\
$\mathrm{I}$ & -1 & 0,0 & 0,0 & 3,6 & 2,2 \\
$\mathrm{~A}$ & -1 & 0,0 & 0,0 & 0,9 & 0,1 \\
$\mathrm{RC}$ & -2 & 0,0 & 0,0 & 1,1 & 0,1 \\
$\mathrm{AC}$ & -3 & 2,5 & 0,5 & 5,9 & 1,1 \\
\hline
\end{tabular}

1943: ZsolT (1943: 10 felv.)

2012: KeveY \& BőHM (ined. 2012: 10 felv.) 